Aus der Poliklinik für Präventive Zahnmedizin, Parodontologie und Kariologie (Direktorin: Prof. Dr. med. dent. A. Wiegand) im Zentrum Zahn-, Mund- und Kieferheilkunde der Medizinischen Fakultät der Universität Göttingen

\title{
Die Erfolgsquote orthograder endodontischer Revisionsbehandlungen nach nicht erfolgreicher Wurzelspitzenresektion
} Eine retrospektive Auswertung von Röntgenaufnahmen

\author{
INAUGURAL-DISSERTATION \\ zur Erlangung des Doktorgrades für Zahnheilkunde \\ der Medizinischen Fakultät der \\ Georg-August-Universität zu Göttingen
}

vorgelegt von

Anne Ziegerahn

aus

Berlin 
Dekan

1. Berichterstatter

2. Berichterstatter

3. Berichterstatter
Prof. Dr. rer. nat. H. K. Kroemer

Prof. Dr. med. dent. M. Hülsmann

Prof. Dr. med. dent. R. Bürgers

Prof. Dr. med. dent. R. Bürgers KG Wiese 



\section{Inhaltsverzeichnis}

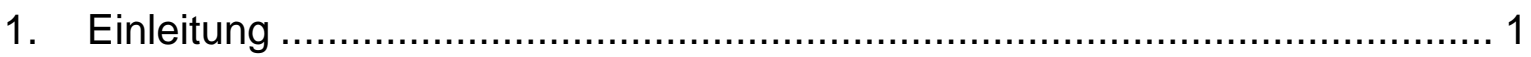

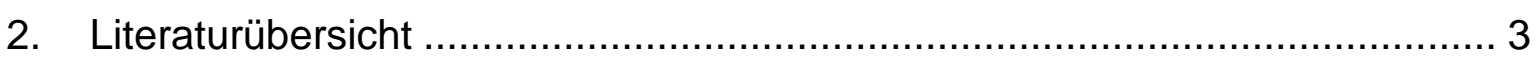

2.1 Die Wurzelspitzenresektion (WSR) ……….................................... 3

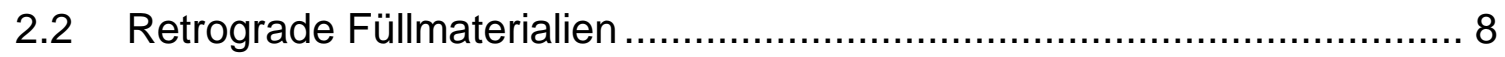

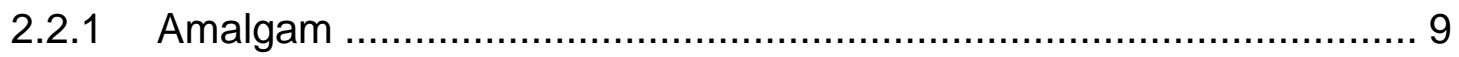

2.2.2 Zinkoxid-Eugenol-Zement........................................................ 10

2.2.3 Komposit (Retroplast) …….................................................. 10

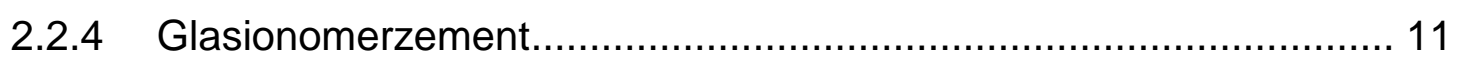

2.2.5 Mineral Trioxide Aggregate (MTA) ............................................. 11

2.3 Die orthograd-endodontische Revision nach Wurzelspitzen-resektion ... 14

2.3.1 Entfernung der retrograden Füllung .......................................... 16

2.3.2 Belassen der retrograden Füllung.................................................. 19

2.3.3 Mögliche Komplikationen bei der Behandlung .............................. 20

2.3.3.1 Die Bestimmung der Arbeitslänge ........................................... 20

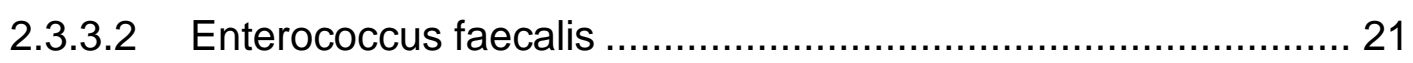

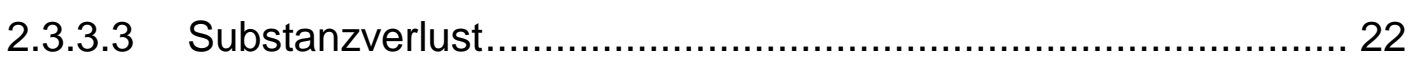

2.4 Behandlungsalternativen zur orthograden Revision ............................. 22

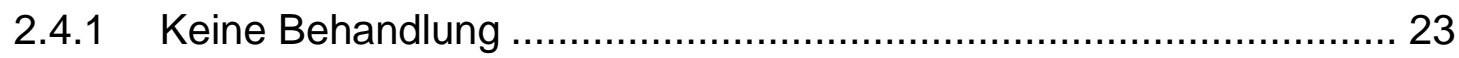

2.4.2 Beobachten .................................................................... 23

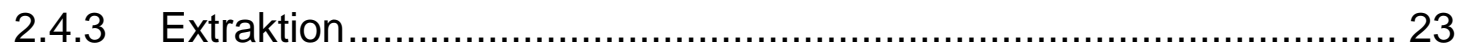

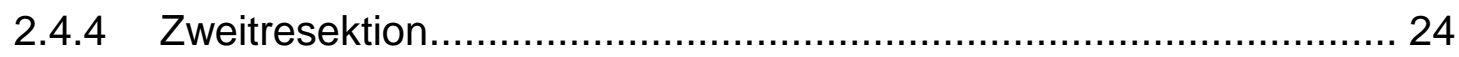

2.5 Erfolgskriterien endodontischer und apikalchirurgischer Behandlungen . 26

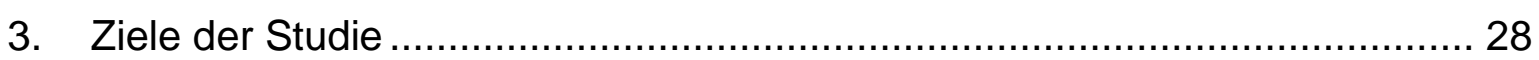

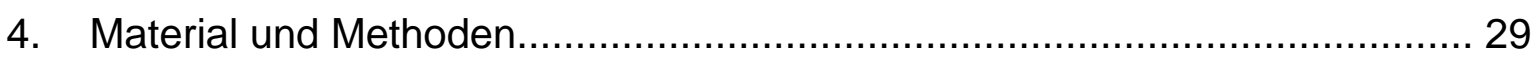

4.1 Zahnärztliche Untersuchung ………………................................... 29

4.2 Kriterien zur Aufnahme in die Studie und Ablauf der Behandlung........... 31

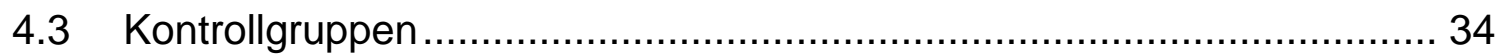

4.4 Ablauf der Primär- und Revisionsbehandlung ……………................ 34

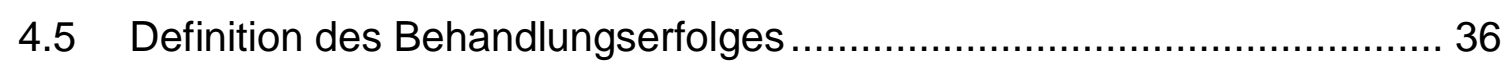

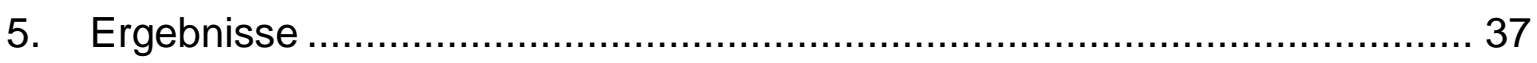

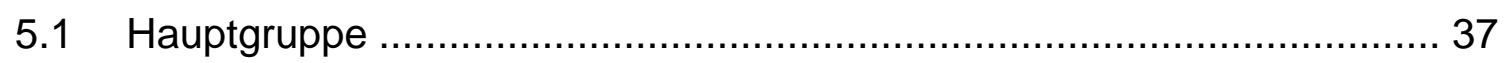

5.1.1 Allgemeine Merkmale des Kollektivs .......................................... 37 
5.1.2 Häufigkeit der Behandlung in den einzelnen Zahngruppen der Hauptgruppe

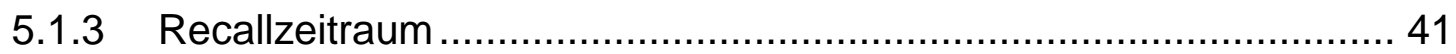

5.1.4 Präoperativer Befund des Periapex (Parodontitis apicalis) ............... 41

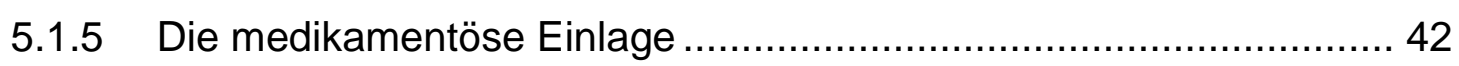

5.1.6 Erfolg in Abhängigkeit von einer medikamentösen Einlage und vom präoperativen Befund des Periapex (Parodontitis apicalis) ......................... 43

5.1.7 Die retrograde Füllung .............................................................. 44

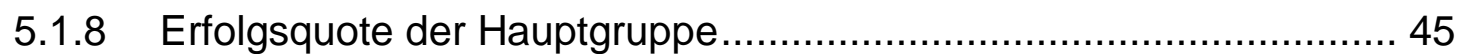

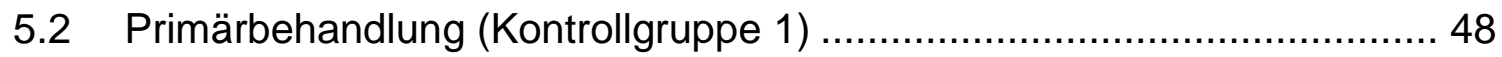

5.2.1 Allgemeine Merkmale des Kollektivs ......................................... 48

5.2.2 Häufigkeit der Behandlung in den einzelnen Zahngruppen der

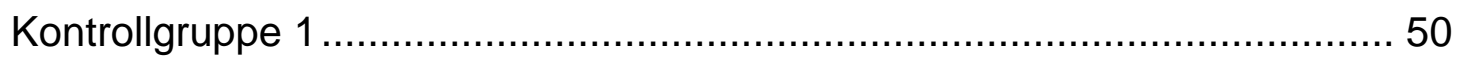

5.2.3 Recallzeitraum der Kontrollgruppe 1 (Primärbehandlung) ............... 52

5.2.4 Präoperativer Befund des Periapex (Parodontitis apicalis) .............. 52

5.2.5 Die medikamentöse Einlage ................................................... 53

5.2.6 Erfolgsabhängigkeit der Behandlung mit medikamentöser Einlage vom präoperativen Befund des Periapex (Parodontitis apicalis) ................... 54

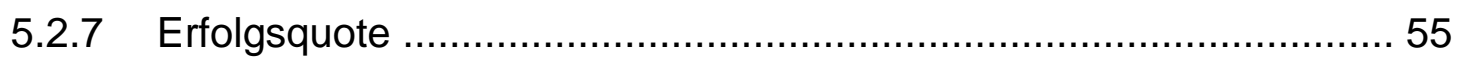

5.3 Revisionsbehandlung (Kontrollgruppe 2) ......................................... 57

5.3.1 Allgemeine Merkmale des Kollektivs .......................................... 57

5.3.2 Häufigkeit der Behandlung in den einzelnen Zahngruppen .............. 60

5.3.3 Recallzeitraum der Kontrollgruppe 2 (Revisionsbehandlung) ........... 61

5.3.4 Präoperativer Befund des Periapex (Parodontitis apicalis) ............... 62

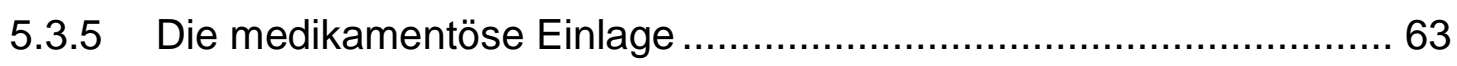

5.3.6 Erfolgsabhängigkeit der Behandlung mit medikamentöser Einlage vom präoperativen Befund des Periapex (Parodontitis apicalis) ................... 64

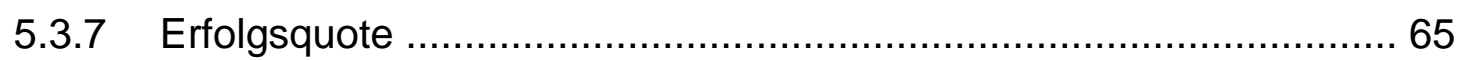

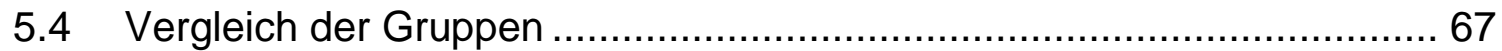

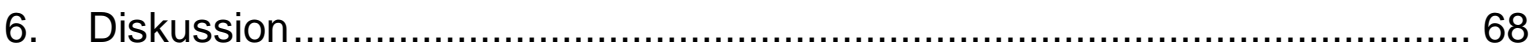

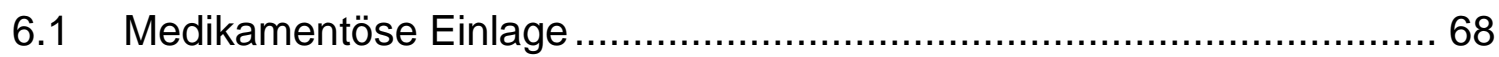

6.2 Fallzahl im Vergleich zu anderen Studien ......................................... 69

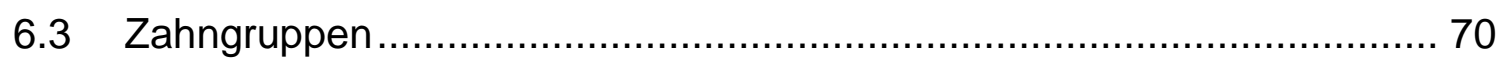

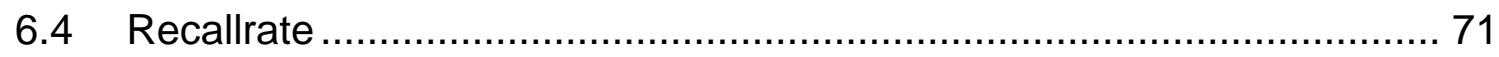




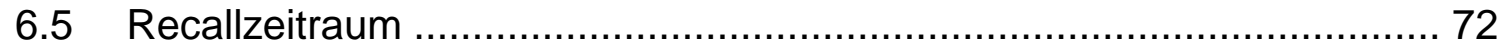

6.6 Die periapikale Ausgangssituation .................................................... 73

6.7 Vergleich der Erfolgsquoten mit Literaturangaben ............................... 74

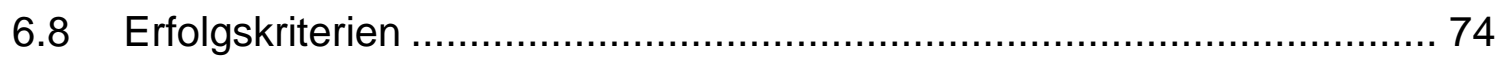

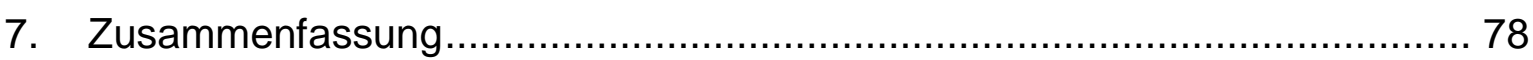

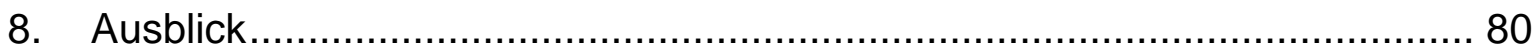

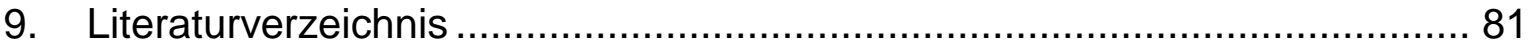

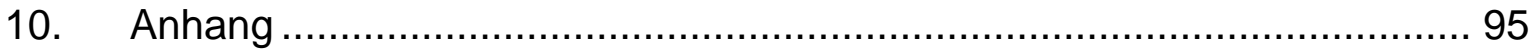

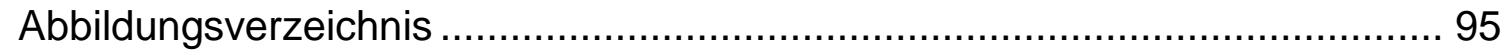

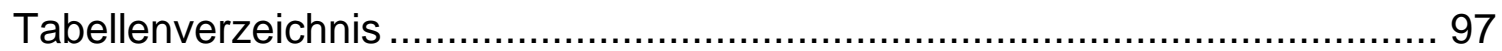

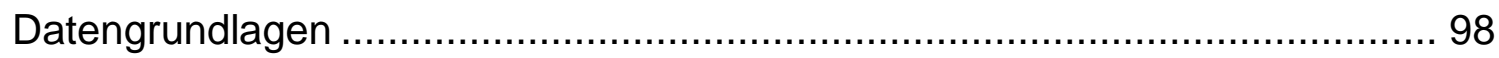

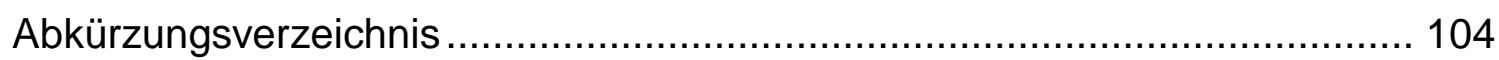




\section{Einleitung}

Bei irreversibler Entzündung der Pulpa oder Vorliegen einer Pulpanekrose ist eine endodontische Behandlung zwingend erforderlich, um die Ausbreitung oder Entstehung einer Parodontitis apicalis, einer bakteriell bedingten Entzündung des periradikulären Gewebes infolge einer Pulpainfektion, zu verhindern.

Der betroffene Zahn wird in diesem Fall von orthograd eröffnet und nach ausreichender Präparation und Desinfektion des oder der Wurzelkanäle wieder obturiert. Wird nach den Prinzipien der Asepsis und Antisepsis behandelt und werden moderne Techniken und Materialien angewandt, können mittlerweile sehr gute Erfolgsquoten von bis zu 90\% ( $\mathrm{Ng}$ et al. 2010) erzielt werden und der Zahn kann langfristig erhalten bleiben.

Eine endodontische Behandlung wird als erfolgreich eingestuft, wenn die klinischen Symptome, welche von der apikalen Entzündung verursacht wurden, abklingen und keine weiteren auftreten. Röntgenologisch zeigt sich nach einer erfolgreichen Wurzelkanalbehandlung ein durchgängiger Parodontalspalt im apikalen Bereich des Zahnes (European Society of Endodontology 1994).

Sollte es dennoch zu einem Misserfolg der endodontische Behandlung kommen, stehen mehrere Therapieoptionen zur Auswahl, um den betroffenen Zahn zu erhalten. Es kann eine orthograde, nicht-chirurgische endodontische Revision vorgenommen werden, bei der nach Entfernung der alten Füllung von orthograd eine erneute Wurzelkanalbehandlung durchgeführt wird. Oftmals wird aber bereits zu diesem Zeitpunkt eine chirurgische Wurzelspitzenresektion vorgezogen. Hierbei wird über einen chirurgisch geschaffenen Zugang der von koronal schlecht zugängliche apikale Anteil der Wurzel abgetrennt. Eine zusätzliche Präparation und Desinfektion des apikalen Wurzelkanalabschnittes erfolgt. Eine retrograde Füllung wird abschließend eingebracht und verschließt die resezierte Wurzel.

Sollten auch diese Maßnahmen nicht zu einer Ausheilung der periapikalen Entzündung, der Parodontitis apicalis, führen, so galt der Zahn bislang meist als austherapiert und wurde extrahiert. Einer Extraktion folgen unweigerlich weitere prothetische oder implantologische Schritte, die langwierig und kostenintensiv sind. Folglich sollten der Erhalt eines Zahnes angestrebt und alle zur Verfügung stehenden Möglichkeiten ausgeschöpft werden. 
Die Gründe für das Scheitern einer Wurzelkanalbehandlung bzw. Wurzelspitzenresektion sind unterschiedlich, allen gemein ist aber der Verbleib von Bakterien oder eine Reinfektion des Wurzelkanalsystems.

Bei der Resektion der Wurzelspitze wird trotz der allgemeinen Empfehlung und der deutlich höheren Erfolgsquoten (Friedman 1998) häufig auf die vorherige oder parallele Erneuerung der bestehenden Wurzelfüllung verzichtet und lediglich der apikale Bereich von retrograd desinfiziert und gefüllt. Bakterien, die wegen der insuffizienten Primärdesinfektion im gesamten Wurzelkanalsystem verblieben sind, können deshalb nur durch eine orthograde Revisionsbehandlung beseitigt werden.

Aufgrund der fehlenden apikalen Konstriktion nach einer Wurzelspitzenresektion (WSR) und der oftmals bestehenden prothetischen Versorgung wird ein rein orthogrades Vorgehen jedoch sehr erschwert. Nach einer langen Therapiehistorie und wegen fehlenden Instrumentariums wird in diesen Fällen oftmals die Entscheidung zur Extraktion getroffen.

In der vorliegenden Untersuchung soll durch eine retrospektive Auswertung präund postoperativer Röntgenaufnahmen geklärt werden, ob eine orthogradendodontische Revisionsbehandlung an bereits wurzelspitzenresezierten Zähnen mit persistierender Parodontitis apicalis oder an wurzelspitzenresezierten Zähnen, an denen aufgrund von röntgenologisch insuffizienter Behandlungsqualität das Auftreten einer Parodontitis apicalis zu erwarten ist, eine ausreichende Erfolgsquote aufweist, um dieses Verfahren zur klinischen Anwendung empfehlen zu können. 


\section{Literaturübersicht}

In der internationalen Literatur liegen viele Studien zur Prognose von primären Wurzelkanalbehandlungen, Revisionsbehandlungen und auch Wurzelspitzenresektionen vor. Evidenzbasierte Literatur und Studien über die orthograde Revision bei nicht erfolgreichen Wurzelspitzenresektionen finden sich jedoch kaum. Es liegen überwiegend Fallbeispiele und Erfahrungsberichte vor (Herrmann 2007, Tulus 2007 und 2008). In lediglich einer Case-control-Studie von 2005 wurde der Erfolg orthograder Revisionen an bereits resezierten Zähnen untersucht (Caliskan 2005).

\subsection{Die Wurzelspitzenresektion (WSR)}

Eine Wurzelspitzenresektion bezeichnet das operative Vorgehen, bei dem über einen oralen Zugang durch eine Osteotomie die Wurzelspitze eines periapikal beherdeten Zahnes freigelegt und entfernt wird. Dabei kann definitionsgemäß eine orthograde Wurzelfüllung mit oder ohne retrograden Verschluss eingebracht werden.

Nach den Leitlinien der European Society of Endodontology (ESE) ist das Ziel einer Wurzelspitzenresektion „die Entfernung des Wurzelteils, der nicht desinfiziert und / oder mit einem Wurzelkanalfüllmaterial obturiert werden konnte und dessen Inhalt möglicherweise eine Entzündung verursachte oder unterhielt. Die Wurzelspitzenresektion soll zudem den Zugang ermöglichen, der erforderlich ist, um die notwendigen Präparationen für eine retrograde Füllung vornehmen zu können. Die Wurzelspitze sollte ohne oder mit einer nur geringen Abschrägung reseziert werden" (European Society of Endodontology 2006).

Die anschließende Präparation der retrograden Kavität erfolgt unter Berücksichtigung der Kontur des Wurzelkanalsystems und der Kanalachse. Es folgt eine Desinfektion des apikalen Abschnittes des Endodontes. Abschließend wird ein bakteriendichter apikaler Verschluss des Wurzelkanalsystems eingebracht. 
Im Jahr 2007 erstellte die Zahnärztliche Zentralstelle Qualitätssicherung (ZZQ) des Instituts der Deutschen Zahnärzte (IDZ) Leitlinien zur Wurzelspitzenresektion, in denen folgende Indikationen zur WSR angegeben werden:

- „Bei persistierender apikaler Parodontitis mit klinischer Symptomatik oder zunehmender radiologischer Osteolyse nach einer vollständigen oder unvollständigen Wurzelkanalfüllung oder Revisionsbehandlung, falls diese nicht oder nur unter unverhältnismäßigen Risiken entfernt oder verbessert werden kann (z.B. bei aufwändiger prothetischer Versorgung und insbesondere der Versorgung mit Wurzelstiften).

- Nach Wurzelkanalfüllung mit überpresstem Wurzelfüllmaterial und klinischer Symptomatik oder Beteiligung von Nachbarstrukturen wie der Kieferhöhle oder des Mandibularkanals.

- Bei konservativ nicht durchführbarer Wurzelkanalbehandlung bzw. bei erheblichen morphologischen Varianten der Wurzeln, die eine vollständige Wurzelkanalfüllung nicht zulassen.

- Bei Zähnen mit obliteriertem, nicht mehr instrumentierbarem Wurzelkanal bei klinischer und/oder radiologischer Symptomatik." (ZZQ 2007, S. 301309).

Als Kontraindikationen für die endodontische Chirurgie im Allgemeinen nennt die ESE folgende Kriterien:

- lokale anatomische Faktoren, wie zum Beispiel eine unzugängliche Wurzelspitze

- Zähne ohne ausreichenden parodontalen Halt

- nicht kooperative Patienten

- ein Patient mit stark beeinträchtigtem allgemeinem Gesundheitszustand (European Society of Endodontology 2006, S. 921-930).

Es besteht die Möglichkeit, die orthograd-endodontische Behandlung vor dem chirurgischen Eingriff durchzuführen oder zeitgleich. Eventuelle Fehler bei der Wurzelkanalfüllung wie das Überpressen von Füllmaterial in das periapikale Gewebe können dann im Zuge der WSR zusätzlich korrigiert werden. 
Wird durch ein rein chirurgisches Vorgehen eine mittlere Erfolgsquote von 58,9\% erzielt, so wird diese durch die vorhergehende Revision der Wurzelkanalbehandlung auf 79,6\% gesteigert (Friedman 1998).

Für den Erfolg und somit für den Zahnerhalt ist weiterhin die Vorgehensweise von Bedeutung. Durch die Anwendung eines dentalen OP-Mikroskops wird eine verbesserte Übersicht über das OP-Gebiet geschaffen, mikrochirurgische Techniken ermöglichen ein gezielteres und sauberes Arbeiten und Materialien wie MTA erreichen im Vergleich zu veralteten Materialien wie Amalgam einen dichten Verschluss des Wurzelkanalsystems.

Rubinstein und Kim (1999) erzielten durch mikrochirurgisches Vorgehen bei der Wurzelspitzenresektion eine Erfolgsquote von 96,8\%. Im Vergleich zum konservativen Vorgehen waren Umfang und Häufigkeit der postoperativen Komplikationen signifikant reduziert. Laut Rubinstein und Kim fällt bei der mikrochirurgischen Osteotomie der Durchmesser der Resektionshöhle mit 4-5 mm bedeutend kleiner aus als bei der makrochirurgischen Osteotomie und die Wundheilung ist schneller abgeschlossen. Auch kann durch Verwendung kleinerer periapikaler Küretten, kleinerer Scaler und die unter Vergrößerung mögliche schonendere Behandlung der Wunde das chirurgische Trauma verringert werden. Einziehungen, Isthmen und akzessorische Wurzelkanäle können durch das Operationsmikroskop identifiziert und behandelt werden. Die Anwendung von Ultraschall ermöglicht eine retrograde Präparation axial innerhalb des Wurzelkanalsystems. Dies ist mit einem Miniaturkopf-Handstück oft nicht möglich und führt häufig zur Perforation der Wurzel. Außerdem bewirkt die ultraschallgestützte Präparation die Entfernung des Smear Layers von den Kanalwänden. Dies resultiert in einer besseren Adaptation des Füllungsmaterials. Durch die Ultraschallpräparation entfällt zudem die Notwendigkeit einer starken Anschrägung der Wurzelspitze. Daraus folgt eine geringere Exposition von Dentintubuli und somit verringert sich das Risiko des Auftretens einer apikalen Undichtigkeit. Des Weiteren besteht die Möglichkeit, die Sauberkeit der apikalen Präparation mit Mikrospiegeln zu kontrollieren. Mit Hilfe von Mikroexplorern kann anschließend unter hoher Vergrößerung die retrograde Füllung kondensiert werden (Rubinstein und Kim 1999).

Eine systematische Übersicht zeigt eine Erfolgsquote von 79,6\% bzw. nach 6 Jahren von nur noch $62,9 \%$ bei traditioneller Vorgehensweise (Torabinejad et al. 
2009). Laut Tsesis liegt die Erfolgsquote bei Anwendung traditioneller Techniken allerdings nur bei $44,2 \%$. Werden moderne mikrochirurgische Techniken wie das dentale Operationsmikroskop und neue Materialien wie MTA verwendet, so kann eine Quote von 91,6\% erzielt werden (Tsesis et al. 2009).

Setzer et al. beschreiben in einer aktuellen Metaanalyse ähnliche Unterschiede der Erfolgsquoten. Bei der Anwendung traditioneller chirurgischer Techniken konnte eine Erfolgsquote von 59\% erreicht werden, jedoch von 94\% bei Anwendung moderner mikrochirurgischer Techniken (Setzer et al. 2010).

Untersuchungen zeigten, dass eine apikale Parodontitis häufiger bei wurzelkanalgefüllten Zähnen auftritt als bei nicht gefüllten Zähnen (Kirkevang und Wenzel 2003, Caplan 2004). In der Studie von Kirkevang und Wenzel wurden insgesamt 613 Personen untersucht. 318 Patienten wiesen an einem oder mehreren Zähnen eine Wurzelkanalfüllung auf, 295 von ihnen hatten keine endodontische Behandlung erfahren. $72,6 \%$ der Patienten mit Wurzelkanalfüllungen wiesen eine apikale Parodontitis auf, während dies bei den Patienten mit nicht wurzelkanalgefüllten Zähnen nur 9,5\% waren (Kirkevang und Wenzel 2003). Diese Befunde werden durch weitere Studien gestützt (Heppeler und Hülsmann 2006). Folglich besteht häufig weiterer Behandlungsbedarf an Zähnen mit bereits erfolgter Wurzelkanalbehandlung wegen einer persistierenden oder wieder auftretenden Entzündung. Des Weiteren sollten endodontisch behandelte Zähne öfter röntgenologisch überprüft werden, um eine apikale Entzündung frühzeitig zu erkennen. Die alleinige Wurzelspitzenresektion ist in Fällen einer persistierenden Parodontitis apicalis neben der orthograden Revision oft die Therapie der Wahl.

Friedman konnte nach Auswertung von sieben vergleichbaren Studien eine Erfolgsquote von Wurzelspitzenresektionen von 37-91\% feststellen (Friedman 2005). Die Angaben variieren stark und sind zum einen abhängig von der Vorgehensweise des behandelnden Zahnarztes, zum anderen auch von den Auswahlkriterien der jeweiligen Studie.

Lokalisation des Zahnes, Anzahl der Wurzeln, Anzahl der untersuchten Zähne, Primär- oder Sekundärbehandlung, intraoperatives Vorgehen, verwendete Materialien, Recalldauer und nicht zuletzt die Auswertung der Röntgenbilder beeinflussen das Ergebnis einer Studie stark (Friedman 2005) und führen zu nicht vergleichbaren Werten unterschiedlicher Untersuchungen (Friedman 1998). 
Die Ursachen für den Misserfolg einer WSR sind unterschiedlicher Natur. Allen gemein sind auch hier der Verbleib von Bakterien oder die Reinfektion des Wurzelkanalsystems und die dadurch persistierende beziehungsweise sich ausbildende Parodontitis apicalis.

Saunders benennt Aspekte, die speziell für den Misserfolg von Resektionen an bereits endodontisch behandelten Zähnen von Bedeutung sind und die bei der Weiterbehandlung beachtet werden müssen (Saunders 2005):

1. Eine unzureichende Desinfektion des Wurzelkanalsystems führt zu einem Verbleib von Bakterien und verhindert die Heilung einer Parodontitis apicalis. Resektionen werden häufig als Alternative zur orthograden Wurzelkanalbehandlung durchgeführt, wenn z.B. der Wurzelkanal aufgrund einer Sklerosierung nicht aufzufinden ist oder eine aufwändige koronale Versorgung vorliegt.

2. Zu einer Rekontamination des Wurzelkanalsystems mit Bakterien kann es durch eine koronale Undichtigkeit (coronal leakage) kommen. Bakterien haben über eine insuffiziente koronale Versorgung oder Dentincracks Zugang zum Wurzelkanalsystem und verhindern über diese Reinfektion die Ausheilung der Entzündung oder führen zu deren Neuauftreten.

3. Anatomische Anomalien wie Seitenkanäle oder ein Isthmus zwischen zwei Kanälen erschweren die vollständige Desinfektion und es verbleiben Bakterien im Kanalsystem, wenn diese Bereiche im Zuge der Resektion nicht entfernt werden können.

4. latrogene Schäden des Zahnes, die zustandekommen durch einen falschen Resektionswinkel, die unvollständige Entfernung der Wurzelspitze oder die Perforation der Wurzelspitze durch ein Abweichen von der Längsachse des Zahnes, können das Ergebnis einer Resektion negativ beeinflussen. Oftmals liegt eine unzureichende retrograde Präparationstiefe vor, sodass für den Füllwerkstoff keine ausreichende Widerstands- und Retentionsform erzielt werden kann und deshalb kein dichter retrograder Verschluss vorhanden ist.

5. Das parodontale Weichgewebe steht in enger Beziehung zum periradikulären Gewebe. Eine marginale Parodontitis zur Zeit einer Wurzelspitzenresektion kann eine apikale Entzündung postoperativ 
bedingen (Rud et al. 1972). Daher ist es wichtig, vor einer geplanten Resektion den parodontalen Status zu erheben und ggf. zu therapieren.

6. Endodontisch behandelte Zähne, speziell solche mit einer Stift- oder Brückenkonstruktion, sind anfälliger für vertikale Wurzelfrakturen. Es ist schwierig, eine Wurzelfraktur mit konventionellen Untersuchungsmethoden zu diagnostizieren und in den meisten Fällen gibt auch das Röntgenbild keinen eindeutigen Hinweis darauf. Deshalb werden Längsfrakturen oft erst bei einem chirurgischen Eingriff sicher festgestellt (Fuss et al. 2001). Einen Hinweis kann allerdings eine stark erhöhte Sondierungstiefe an dieser Stelle darstellen, da diese Frakturen oftmals mit einem marginalen Knochenabbau assoziiert sind.

Die genaue Ursache für das Scheitern der Primärbehandlung sollte vor einer geplanten Resektion evaluiert werden, um ein Scheitern der weiterführenden Therapie möglichst zu vermeiden.

Deutlich wird weiterhin, dass eine Wurzelspitzenresektion somit keine Behandlungsalternative zur orthograden endodontischen Behandlung darstellt, sondern nur eine zusätzliche weiterführende Maßnahme bei komplizierten Verhältnissen oder Scheitern der orthograden Primär- oder Sekundärbehandlung und folgerichtig nur dann zu einem dauerhaften Erhalt des Zahnes führen kann, wenn die im Kanalsystem verbliebenen Bakterien durch eine orthograde Revisionsbehandlung weitestgehend eliminiert werden und eine retrograde Füllung ein Austreten eventuell verbleibender Bakterien verhindert.

\subsection{Retrograde Füllmaterialien}

Das Ziel einer retrograden Wurzelfüllung nach Resektion ist die Ausblockung der retrograden Kavität und die Versiegelung aller Verbindungen zwischen Wurzelkanal und periradikulärem Gewebe durch einen möglichst dichten Verschluss des Wurzelkanalsystems. Dadurch soll bei einem rein chirurgischen Vorgehen eine erneute Entzündung des periapikalen Gewebes durch im restlichen Wurzelkanalsystem verbliebene Mikroorganismen verhindert werden. Nach einer Übersicht von von Arx (von Arx et al. 2001) wurde in der Geschichte der periapikalen Chirurgie fast jedes für die restaurative Zahnheilkunde entwickelte 
Füllungsmaterial zur retrograden Wurzelfüllung angewandt. Die folgenden Materialien kommen oder kamen am häufigsten zum Einsatz und werden in der Literatur am häufigsten diskutiert:

- Amalgam

- Zinkoxid-Eugenol-Zement

- Komposit (Retroplast)

- Glasionomerzement

- Mineral Trioxid Aggregat (MTA).

Materialien, die als retrograde Füllung Anwendung finden, sollten folgende Kriterien erfüllen:

- Biokompatibilität

- Dimensionsstabilität

- Tauglichkeit zur Versiegelung

- Unempfindlichkeit gegenüber Gewebeflüssigkeiten

- Unlöslichkeit

- keine Förderung bakteriellen Wachstums

- Röntgenopazität

(European Society of Endodontology 2006).

\subsubsection{Amalgam}

Amalgam war lange Zeit der Werkstoff der Wahl in der zahnärztlichen Füllungstherapie und fand ebenfalls Anwendung zur retrograden Füllung. Es erfüllt viele Anforderungen, die an einen zahnärztlichen Werkstoff gestellt werden. So ist es kostengünstig, leicht zu erwerben, einfach zu verarbeiten und röntgenopak. Ursprünglich ging man auch von einem zufriedenstellenden Ergebnis nach seiner Verwendung als retrogrades Füllmaterial aus. Jedoch haben mittlerweile mehrere Studien die Nachteile von Amalgam verdeutlicht. In einer von Theodosopoulou und Niedermann 2005 veröffentlichten In-vitro-Studie konnte gezeigt werden, dass Amalgam keinen ausreichend dichten Verschluss gewährleistet (Theodosopoulou 
und Niedermann 2005). Durch Korrosion und merkuroskopische Expansion des Materials kommt es zu Dimensionsänderungen und Undichtigkeiten der Füllung. Amalgam kann nicht adhäsiv befestigt werden. Da eine entsprechende Präparation einer Widerstands- und Retentionsform sich apikal sehr schwierig gestaltet, ist es möglich, dass sich die retrograde Amalgamfüllung löst und ein dichter Verschluss der Resektionsstelle nicht mehr besteht.

Durch Absonderung metallischer Bestandteile der Amalgamfüllung kann es zu einer Amalgamtätowierung kommen, die bläulich oder gräulich im Weichgewebe durchscheint und besonders im Frontzahnbereich unästhetisch wirkt. Daher ist bei der Entfernung der retrograden Amalgamfüllung darauf zu achten, dass keine Partikel in das periapikale Gewebe extrudiert werden.

\subsubsection{Zinkoxid-Eugenol-Zement}

Zinkoxid-Eugenol-Zement wird aus zwei Komponenten hergestellt, dem Zinkoxidhaltigen Pulver und der Eugenol-haltigen Flüssigkeit. Um die Eigenschaften des Zements zu verbessern, entwickelte man SuperEBA. Die anfängliche Zytotoxizität des EBAs durch das Eugenol verringert sich nach dem Abbinden kontinuierlich (Bruce et al. 1993). Die Vorteile von EBA sind die geringe Abbindezeit und die gute Gewebeverträglichkeit.

\subsubsection{Komposit (Retroplast)}

Retroplast ist ein chemisch aushärtender Zweikomponenten-Kunststoff, der speziell für den retrograden Verschluss von resezierten Wurzelkanälen entwickelt wurde und adhäsiv befestigt wird. Die Geweberegeneration nach Anwendung von Retroplast wurde histologisch untersucht. In einigen Fällen wurde eine Entzündung des periapikalen Gewebes festgestellt, während diese in anderen Fällen ausblieb und die Bildung von Zement und Sharpeyschen Fasern beobachtet werden konnte (Rud et al. 1991a, Rud et al. 1991b). Da Retroplast über einen adhäsiven Verbund in der retrograden Kavität befestigt wird, ist eine sehr gute Trockenlegung des Arbeitsfeldes Voraussetzung für einen suffizienten Verschluss des Wurzelkanalsystems. In Fällen einer Wurzelspitzenresektion mit ungenügender Blutstillung während des Einbringens der retrograden Füllung 
konnte eine schlechtere bzw. unvollständige Heilung der apikalen Region nachgewiesen werden (Rud et al. 1991a).

\subsubsection{Glasionomerzement}

Glasionomerzement (GIZ) ist ein Polyalkenoatzement, der aus einem PulverFlüssigkeits-Gemisch besteht und durch eine Säuren-Basen-Reaktion aushärtet. GIZ kann über ionische und kovalente Bindungen eine chemische Verbindung mit der Zahnhartsubstanz eingehen.

Die Gewebeverträglichkeit von GIZ wurde in mehreren Studien mit der von anderen zur retrograden Füllung angewandten Materialien verglichen. Eine anfängliche Entzündungsreaktion des umliegenden Gewebes konnte nach Einbringen der retrograden Wurzelfüllung festgestellt werden. Diese war nach dem Beobachtungszeitraum der jeweiligen Studie abgeheilt (Lehtinen 1986, Callis und Santini 1987). Im Vergleich mit Amalgam, Guttapercha mit Sealer und EBA konnte für GIZ über einen längeren Beobachtungszeitraum eine bessere Gewebeverträglichkeit nachgewiesen werden (Zetterqvist et al. 1987, Callis und Santini 1987, Tassery et al. 1997). Andere Studien belegen allerdings keinen signifikanten Unterschied zwischen Amalgam und GIZ (Zetterqvist et al. 1991, Jesslén et al. 1995). Aus beiden Untersuchungen geht jedoch hervor, dass GIZ als eine Alternative zu Amalgam als retrogrades Füllungsmaterial empfohlen werden kann. Die Modifikation von GIZ erleichtert die Anwendung. Eine absolute Trockenlegung des Arbeitsfeldes ist jedoch Voraussetzung für den suffizienten retrograden Verschluss des Wurzelkanals. Auch wenn ein trockenes Arbeitsfeld geschaffen wird, ist Feuchtigkeit in der Umgebung jedoch unvermeidbar und beeinflusst den GIZ-Dentin-Verbund (Trope et al. 1996).

\subsubsection{Mineral Trioxide Aggregate (MTA)}

MTA ist ein hydrophiles Pulver, das durch Zugabe von Wasser zu einem Zement aushärtet, und das dank seiner vielen Einsatzmöglichkeiten auch im Bereich der Endodontie Verwendung findet. Dieses Material wurde 1993 von Torabinejad als Wurzelfüllmaterial genauer gesagt zum Verschluss lateraler Perforationen vorgestellt (Torabinejad 1993). Mittlerweile findet es auch Anwendung als apikales Verschlussmaterial bei Zähnen mit nicht abgeschlossenem Wurzelwachstum, als 
retrogrades Wurzelfüllmaterial bei Wurzelspitzenresektionen und als Überkappungsmaterial der vitalen Pulpa. Allen genannten Situationen gemein ist ein lokaler Defekt der Zahnhartsubstanz, der den langfristigen entzündungsfreien Erhalt des Zahnes beeinträchtigt.

Die Biokompatibilität und Gewebetoxizität von MTA wurde in mehreren Studien untersucht. Vor allem wegen seiner geringen Löslichkeit im wässrigen Milieu und des basischen pH-Wertes nach dem Abbinden von 12 bis 13, was in etwa dem $\mathrm{pH}$-Wert einer Kalziumhydroxidsuspension entspricht, kommt MTA Zement bei endodontischen Maßnahmen zur Anwendung. Ein Material, das zur Reparatur von Wurzelperforationen und zum orthograden oder retrograden Verschluss des Wurzelkanalsystem angewandt wird, sollte idealerweise die Regeneration des parodontalen Gewebes wie Parodontalligament, Knochen und Zement fördern. Laut den Ergebnissen mehrerer Studien ist es durch den Einsatz von MTA möglich, die Regeneration von Parodontalligamentfibroblasten und die Anlagerung zementoblastenähnlicher Zellen zu fördern und die Knochenneubildung zu induzieren (Schwartz et al. 1999). Durch die Freisetzung von Kalzium- und Hydroxylionen hat MTA eine bioaktive Wirkung. Beim Abbinden findet eine Umwandlung von Kalziumphosphat zu apatitähnlichen Kristallen statt und MTA stimuliert so die Dentinogenese und auch die Zementogenese (Camilleri 2007 und 2008).

Durch die Resektion der Wurzelspitze entsteht eine vergrößerte Kontaktfläche des Wurzelkanals zum periapikalen Gewebe und eine vollständige Trocknung des Wurzelkanals, wie es für die Re-Obturation nötigt wäre, ist nicht immer möglich. MTA hat den Vorteil, dass es auch in Gegenwart von Feuchtigkeit oder Blut eine ausgezeichnete Abdichtung an der Dentinwand erreicht (Soluti et al. 1993, Torabinejad et al. 1994). Außerdem kommt es durch den erweiterten Apex an der Resektionsstelle zum direkten Kontakt des MTA Zementes mit dem periapikalen Gewebe, weshalb eine sehr hohe zelluläre Verträglichkeit voraus zu setzen ist. Lediglich kurz nach dem Anmischen konnte ein geringer zytotoxischer Effekt auf humane Zellen festgestellt werden (Balto 2004). Es konnte jedoch für MTA im initialen sowie im ausgehärteten Zustand eine gegenüber den jeweiligen Vergleichsmaterialien gleichwertige oder sogar überlegene Biokompatibilität nachgewiesen werden (Torabinejad et al. 1995, Mitchell et al. 1999, Keiser et al. 2000). In einem Tierexperiment konnte belegt werden, dass Glasionomerzement 
und Amalgam im Kontakt mit periapikalem Gewebe unterschiedlich ausgeprägte Entzündungsreaktionen provozieren, während die MTA-exponierten Bereiche völlig entzündungsfrei verblieben (Torabinejad et al. 1997, Holland et al. 1999). Bei weitem Foramen apicale ist ein Überstopfen des MTA bei der orthograder Applikation nicht auszuschließen. Jedoch konnte anhand eines Einzelfalls gezeigt werden, dass trotz massiver apikaler Extrusion des MTA der Fistelgang und die Parodontitis apicalis an einem Zahn mit nicht abgeschlossenem Wurzelwachstum ausheilten (Tahan et al. 2010). In einer weiteren retrospektiven Untersuchung konnte ebenfalls kein Einfluss überextrudierten MTAs auf die Erfolgsrate festgestellt werden (Mente et al. 2009).

Eine weitere Anforderung, die an MTA als Wurzelfüllmaterial gestellt werden muss, ist ein ideales Abdichtungsvermögen. Durch eine In-vitro-Studie wurde das Abdichtungsvermögen von MTA bei der Reparatur von Wurzel- und Furkationsperforationen mit unterschiedlichen Flüssigkeits- und Bakterienpenetrationstests untersucht. Im Vergleich zu anderen Verschlussmaterialien wie Amalgam und Zinkoxid-Eugenol-Zement konnte MTA unter In-vitro-Bedingungen ein gleichwertiges oder überlegenes Abdichtungsverhalten nachgewiesen werden (Nakata et al. 1998, Torabinejad und Chivian 1999, Weldon et al. 2002). Diese Tatsache belegte Torabinejad bereits 1995 mit einer Untersuchung, in der bei der Verwendung von Amalgam und Zinkoxid-Eugenol-Zement zur apikalen Füllung ein Randspalt von $15 \mu \mathrm{m}$ gemessen werden konnte, während die MTA-Füllungen nahezu randspaltfrei waren (Torabinejad et al. 1995).

Das Einbringen von frisch angerührtem MTA-Zement in die Zahnwurzel und die Kondensation gestalten sich aufgrund der Konsistenz des Materials oftmals sehr schwierig und sollten deshalb nur unter kontrollierten Sichtbedingungen eines OPMikroskops durchgeführt werden (Daoudi und Saunders 2002).

Derzeit scheint kein ideales Material für die retrograde Wurzelfüllung zu existieren, da keines der genannten alle gestellten Anforderungen erfüllt. Um ein einziges Material zu favorisieren, sind die wissenschaftlichen Belege unzureichend. Jedoch können MTA, Zinkoxid-Eugenol-Zement, Diaket und Retroplast als akzeptabel eingestuft werden (Chong und Pitt Ford 2005). Die Wahl des Materials hängt nicht zuletzt auch von der vorliegenden klinischen Situation ab. Ist ein Trockenlegen des Arbeitsfeldes nicht möglich, so kann ein sehr feuchtigkeitssensitives Material trotz guter Biokompatibilität nicht verwendet werden. 


\subsection{Die orthograd-endodontische Revision nach Wurzelspitzen- resektion}

Nicht selten werden Zähne mit persistierender oder neu auftretender Parodontitis apicalis nach fehlgeschlagener orthograde-endodontischer Therapie und Wurzelspitzenresektion als austherapiert eingestuft und extrahiert. Der Misserfolg wird von vielen Zahnärzten der scheinbar geringen Erfolgsquote endodontischer Maßnahmen zugeschrieben. Die Misserfolge sind jedoch in den meisten Fällen iatrogen bedingt und beruhen auf unzureichender Präparation, Desinfektion und Obturation des Wurzelkanalsystems.

Die erneute orthograde Revision nach WSR kann in solchen Fällen zum langfristigen Erhalt des Zahnes führen, wenn die vorhergehenden Behandlungsfehler behoben werden können. 1975 wurde diese Therapieform erstmalig von Stewart beschrieben (Stewart 1975). In der Fachliteratur kann bislang noch keine Empfehlung für dieses Therapieverfahren gefunden werden, obwohl es von Endodontiespezialisten nicht selten angewandt wird. Es liegen fast ausschließlich Fallberichte über die erfolgreiche orthograde Revision nach nicht erfolgreicher WSR (West und Lieb 1985, Moiseiwitsch und Trope 1998, Büttel 2008, Appel 2011, Pannkuk 2011) vor, was eher zu einer deutlichen Überbewertung der Erfolgsaussichten dieser Therapieoption führt, da Misserfolge in der Regel in der Literatur nicht dargestellt werden.

Es liegt lediglich eine klinische Studie zur Erfolgsquote orthograder Revisionen nach nicht erfolgreicher WSR vor (Caliskan 2005). In dieser Studie wurden Zähne mit persistierender Parodontitis apicalis behandelt, 75 nach orthogradendodontischer und 11 nach endodontisch-chirurgischer Behandlung. An allen Zähnen wurde eine rein orthograde zweizeitige Revision der alten Wurzelkanalbehandlung mit Kalziumhydroxid als medikamentöser Einlage durchgeführt. Diese Vorgehensweise ähnelt der der vorliegenden Studie. Zur Erweichung des Wurzelfüllmaterials wurde ein Lösungsmittel verwandt, die Desinfektion erfolgte mit 5,25\% NaOCl, die Re-Obturation mit Guttapercha. Die Anwendung eines dentalen OP-Mikroskops wurde allerdings nicht beschrieben. Der Recallzeitraum betrug $2-8$ Jahre. Als Erfolg wurden nur Fälle gewertet, in denen es während dieses Zeitraumes röntgenologisch zu einer vollständigen Ausheilung der periapikalen Läsion kam und klinische Symptomfreiheit beobachtet 
werden konnte. Kam es nur zu einer Reduktion der Läsionsgröße, so wurde dies als unvollständige Heilung bezeichnet, alle anderen Fälle wurden als Misserfolge gewertet. Von den 11 Zähnen, die chirurgisch behandelt waren und von orthograd revidiert wurden, konnten 5 (46\%) als Erfolge, 2 (18,\%) als unvollständige Heilung und $4(36, \%)$ als Misserfolge gewertet werden. In der Kontrollgruppe, in der 75 nicht resezierte Zähne von orthograd revidiert wurden, konnten 48 (64\%) erfolgreich therapiert werden, 10 (13\%) zeigten eine unvollständige Heilung und 17 (23\%) mussten als Misserfolge gewertet werden. Des Weiteren wurde in der Studie zwischen Zähnen unterschieden, deren präoperative Läsion $>5 \mathrm{~mm}$ und $<5$ mm Ausdehnung aufwiesen. Wurden nur die Zähne zum Vergleich herangezogen, deren präoperative Läsion eine Ausdehnung von mehr als $5 \mathrm{~mm}$ aufwies, so ergaben sich Erfolgsquoten von 58,8\% für die Kontrollgruppe (Revision nach Wurzelkanalbehandlung) und 45,5\% für die Revision nach WSR.

Mit $\mathrm{n}=11$ ist die Fallzahl dieser Studie sehr gering und die Ergebnisse sind daher nicht ausreichend aussagekräftig. Außerdem bieten neuere Materialien und Methoden der orthograden Revision heute mehr Möglichkeiten. Somit zeigt diese Studie mit 45,5\% erfolgreich therapierten Zähnen eine limitierte Erfolgsrate für die orthograde Revision nach nicht erfolgreicher WSR auf, welche älteren Erfolgsraten für die chirurgische Revision (35\% bis 60\%) ähnelt. Allerdings zeigen die Untersuchungen dieser Studie, die erstmals über die Darstellung eines Einzelfalls hinausgehen, dass die orthograde Revision von resezierten Zähnen mit persistierender Parodontitis apicalis durchaus eine erfolgreiche Therapieoption darstellen kann.

Von therapeutischen Misserfolgen wird in der Literatur dagegen nur in einzelnen Falldarstellungen berichtet (Hülsmann et al. zur Publikation eingereicht).

Im Falle eines Misserfolges wird die Ausgangssituation generell nicht verschlechtert, sodass diese Therapieform die Möglichkeit weiterer Behandlungsmaßnamen wie einer erneuten Resektion noch offen lässt.

Die Diagnostik entspricht der einer Revisionsbehandlung. Bei der Auswertung des Röntgenbildes muss auf die Qualität, Homogenität und Länge der Wurzelfüllung, eine eventuell vorhandene retrograde Füllung oder eine Stiftkonstruktion und deren Material geachtet werden.

Eine parodontale Erkrankung oder eine Wurzellängsfraktur sollten durch sorgfältige und umfassende klinische Untersuchungen weitestgehend ausge- 
schlossen werden, da in diesen Fällen eine endodontische Behandlung nicht zur Heilung beitragen kann.

Bei der orthograden Revision nach nicht erfolgreicher Wurzelspitzenresektion können zwei Ausgangsituationen unterschieden werden:

- Orthograde Revision eines resezierten Zahnes ohne retrograden Verschluss

- Orthograde Revision eines resezierten Zahnes mit retrogradem Verschluss.

Ist keine retrograde Füllung vorhanden, so kann bei der Therapie wie bei Zähnen mit offenen Apices verfahren werden. Es besteht jedoch die Gefahr, das Wurzelfüllmaterial über den erweiterten Apex zu extrudieren.

Ist eine retrograde Füllung vorhanden, so kommen drei Therapiemöglichkeiten in Frage:

- Orthograde Revision des resezierten Zahnes und Entfernung der retrograden Füllung von orthograd

- Orthograde Revision des resezierten Zahnes und Belassen der retrograden Füllung

- Orthograde Revision des resezierten Zahnes und Entfernen der retrograden Füllung mittels chirurgischer Nachresektion.

\subsubsection{Entfernung der retrograden Füllung}

Zahlreiche Studien beschäftigen sich mit den Vor- und Nachteilen der unterschiedlichen retrograden Füllungsmaterialien. Lediglich in einer Studie wird die Entfernbarkeit des retrograden Verschlusses untersucht. Allerdings wird nur Entfernung von retrograd, das heißt auf chirurgischem Wege, beschrieben, nicht aber von orthograd (Pirani et al. 2009). Sicherlich ist es so möglich, unter optimaler Sicht das gesamte retrograde Füllmaterial zu entfernen. Dieses Vorgehen ist aber nur bei einem vorher desinfizierten Wurzelkanalsystem sinnvoll. Da das Entfernen einer retrograden Füllung nicht nur Vor-, sondern auch Nachteile aufweist, muss vor Behandlungsbeginn entschieden werden, ob dies sinnvoll, notwendig und machbar ist. In jedem Fall müssen Risiken und Vorteile 
erneut abgewogen werden, um ein optimales Therapieergebnis erzielen zu können.

Folgende Argumente sprechen nach Hülsmann et al. (2011) für die Entfernung der retrograden Füllung:

- Das kontaminierte Füllmaterial wird entfernt und mit der neuen Wurzelfüllung durch nichtkontaminiertes ersetzt.

- Nach Entfernung der retrograden Füllung kann der Wurzelkanal vollständig präpariert und desinfiziert werden, auch in dem sonst unzugänglichen apikalen Wurzelkanalbereich.

- Ursache für den Misserfolg einer Wurzelspitzenresektion ist zum einen eine im Wurzelkanal persistierende bakterielle Infektion, vor allem aber auch ein ungenügend dichter apikaler Verschluss. Durch die Entfernung der retrograden Füllung wird auch diese Ursache behoben.

- Schließlich ist es eher möglich, eine dichtere und randständigere Wurzelkanalfüllung einzubringen.

Wird eine orthograde Entfernung des retrograden Verschlusses angestrebt, so sollten nach Krupp (2011) bei der klinischen Behandlungsplanung einige kritische Fragen gestellt werden:

- Welches Material wurde verwendet? Ist dies radiologisch erkennbar oder anderweitig zu eruieren?

- Wurde der apikale Verschluss über den ursprünglichen Kanaldurchmesser hinaus retrograd präpariert und falls ja, wie weit?

- Wie groß ist ein möglicher Substanzverlust durch einen Entfernungsversuch?

- In welcher Qualität wurde die vorhergehende Behandlung durchgeführt?

Die Risiken, die die Entfernung des retrograden Verschlusses mit sich bringt, müssen gleichermaßen beachtet werden: 
- Es besteht die Gefahr der Extrusion des retrograden Füllmaterials in das periapikale Gewebe. In diesem Fall kann es nur durch einen erneuten apikalchirurgischen Eingriff entfernt werden. Werden lediglich kleinere Mengen Füllmaterial überpresst, so können diese möglicherweise phagozytiert und vom Körper abgebaut werden. Allerdings muss davon ausgegangen werden, dass das extrudierte Material bakteriell infiziert ist und zu einer entzündlichen Reaktion oder Fremdkörperreaktion führen kann (Nair et al. 1990, Siqueira 2001).

- Da durch die Resektion die natürliche Konstriktion des Wurzelkanals entfernt wurde, besteht beim Entfernen des apikalen Verschlusses ein erhebliches Risiko, bei der Desinfektion Spüllösungen in das periapikale Gewebe zu extrudieren. Dies wiederum kann zu schwerwiegenden Problemen wie der Schädigung des periapikalen Gewebes führen (Hülsmann et al. 2007).

- Durch die Verwendung von Ultraschall zur Entfernung der retrograden Füllung können sich Risse, Sprünge und Frakturen des Wurzeldentins entwickeln und bereits bestehende Risse verstärkt werden.

- Beim Einbringen der neuen Wurzelkanalfüllung ist es möglich, dass Füllmaterial in das periapikale Geweben extrudiert wird.

Des Weiteren muss bedacht werden, dass einige Werkstoffe, die zum retrograden Verschluss verwendet werden, die orthograde Entfernung erheblich erschweren oder sogar unmöglich machen. Die Entfernung einer retrograden Füllung aus Retroplast, ein chemisch härtendes Zweikomponenten-Komposit, das auf der gesamten Resektionsfläche adhäsiv befestigt wird, ist meist nicht möglich (von Arx 2005).

Wenn also bereits röntgenologisch zu erkennen ist, dass der retrograde Verschluss einen deutlich größeren Durchmesser aufweist als der eigentliche Kanaldurchmesser oder das Material in deutlich unter sich gehenden Bereichen liegt, so ist zur Entfernung des Verschlusses der chirurgischen Nachresektion der Vorzug zu geben. Mit den heutigen modernen Techniken und Hilfsmitteln wie dem OP-Mikroskop ist die Entfernung kleiner, nicht über den Kanaldurchmesser hinausgehender und nicht adhäsiv befestigter retrograd eingebrachter Füllungen jedoch möglich. 
In Einzelfallbeispielen wurde die Entfernung der retrograden Füllung von orthograd mittels Ultraschall und speziellen mikrochirurgischen Ansätzen beschrieben. Herrmann (2007) gelang so die vollständige Entfernung. Appel stellte einen Fall vor, bei dem mit Hilfe von Ultraschall die vollständige Entfernung einer retrograden Amalgamfüllung gelang (Appel und Hülsmann 2007). Stöckl (2008) stellte einen Fall vor, in dem dies nicht vollständig gelang. Krupp veröffentlichte eine detaillierte Anleitung mit einzelnen Fallbeispielen und Beschreibung der Technik und der Materialien zur orthograden Entfernung der retrograden Wurzelfüllung (Krupp 2011).

Andererseits stellten andere Autoren Fälle vor, bei denen das retrograde Füllungsmaterial intentionell von orthograd über den Apex hinaus in das periapikale Gewebe gedrückt wurde und es dennoch zur Ausheilung der periapikalen Läsion kam (Fava 2001). In den Fällen von Soares et al. wanderte das in die periapikale Läsion dislozierte Amalgam entlang des Fistelganges in die Mundhöhle und es kam zu einer Ausheilung der Läsion (Soares et al. 2009). Allerdings muss bedacht werden, dass der Gewebekontakt mit Amalgam Entzündungen hervorrufen kann und auch die apikale Regeneration negativ beeinflusst (Chong et al. 1997, Chong und Pitt Ford 2005). Diese Technik wurde nur in Einzelfällen angewandt, sodass keine evidenzbasiert Daten vorliegen. Die Erfolgswahrscheinlichkeit muss demnach als fraglich angesehen werden.

Eine wichtige Bedingung für den orthograden Entfernungsversuch der retrograden Füllung ist die direkte Sicht unter dem OP-Mikroskop auf das Füllungsmaterial. Zur Entfernung stehen verschiedene Geräte zur Verfügung. Ziel ist die Zerkleinerung des Füllmaterials und das gezielte Absaugen mit entsprechenden Mikrosaugern. Bei nicht vollständiger Entfernung des retrograden Verschlussmaterials wird eine mikrochirurgische Wurzelspitzenresektion empfohlen (Bargholz et al. 2006, Stöckl 2008).

\subsubsection{Belassen der retrograden Füllung}

Das Belassen der retrograden Wurzelfüllung sollte kritisch diskutiert werden. Da der retrograde Verschluss ebenso wie die alte Wurzelfüllung ein potenzielles Bakterienreservoir darstellt, sollte diese im Zuge der Revision entfernt oder eine korrektive Nachresektion durchgeführt werden (Bargholz et al. 2006). In einem von 
Soares et al. beschriebenen Fall kam es nach im Zuge der orthograden Revision erfolgten Extrusion des retrograden Verschlusses zu keiner Heilung der periapikalen Läsion. Erst nachdem das Amalgam aus dem periapikalen Gewebe entfernt wurde, erfolgte die Ausheilung der Läsion (Soares et al. 2009). Ursache für das Persistieren der Läsion kann ein Biofilm auf der Oberfläche des Verschlussmaterials sein (Sunde et al. 2002).

Einzelne Fallberichte zeigen jedoch auch eine Heilung bei Belassen der retrograden Füllung, sodass bei heutigem Kenntnisstand keine eindeutige Empfehlung zur Entfernung ausgesprochen werden kann (Kleier 1984, Chalfin et al. 1993, Moiseiwitsch und Trope 1998, Bargholz et al. 2007).

\subsubsection{Mögliche Komplikationen bei der Behandlung}

\subsubsection{Die Bestimmung der Arbeitslänge}

Die Bestimmung der Arbeitslänge gestaltet sich an Zähnen mit resezierter Wurzelspitze aufgrund der fehlenden apikalen Konstriktion oftmals schwierig. Um eine Überinstrumentierung während der Aufbereitung und ein Überpressen des Wurzelfüllmaterials in den periapikalen Raum zu verhindern, ist es notwendig, die exakte Arbeitslänge zu ermitteln. Im Zuge der Wurzelspitzenresektion kommt es häufig zu einem Anschrägen der Wurzelspitze, sodass die genaue Arbeitslänge mit Hilfe der Röntgenmessaufnahme nicht eindeutig zu bestimmen ist.

Weiger beschrieb 1992 ein Verfahren, mit dessen Hilfe eine annähernd genaue Bestimmung des apikalen Mündungspunktes möglich ist. Anhand eines Röntgenbildes wurde ein weit koronal und ein weit apikal gelegener Punkt des auf dem Röntgenbild annähernd bestimmbaren Resektionsquerschnittes festgelegt und die Strecke zwischen beiden Punkten gemessen. Der gesuchte Punkt, das heißt die Mündung des Wurzelkanals liegt in der Mitte dieser Strecke, vorausgesetzt die Amputationsflächen ist plan und der Wurzelkanal verläuft mittig. Dadurch ist eine ausreichend genaue Bestimmung der Arbeitslänge möglich. Kann eine eindeutige Ausmessung des Röntgenbildes nicht erfolgen, besteht die Möglichkeit eine auf die geschätzte Arbeitslänge gekürzte Papierspitze in den Kanal einzubringen. Solange an der Papierspitze kein Blut zu erkennen ist, befindet sich diese im Wurzelkanal (Weiger 1992). Drebenstedt et al. berichteten 
ebenfalls von einem Fall, in dem keine reproduzierbare elektrometrische Längenbestimmung möglich war. Eine Röntgenmessaufnahme wurde angefertigt und durch den Papierspitzentest kontrolliert (Drebenstedt et al. 2011).

Allerdings gibt es ebenfalls Falldarstellungen, in denen Probleme bei der Bestimmung der Arbeitslänge nicht erwähnt werden und die Arbeitslänge elektrometrisch ermittelt und/oder röntgenologisch verifiziert wurde (Caliskan 2005, Stöckl 2008).

Tulus beschrieb in einer Falldarstellung ein weiteres Vorgehen zur genaueren Bestimmung der endodontischen Arbeitslänge. Durch ein vorsichtiges Austasten der Wurzelkanalwände mit einem an der Spitze abgeknickten Instrument konnte an der vestibulären und oralen Resektionsgrenze eine Höhendifferenz von 1,5 mm ausgemacht werden, was einem Resektionswinkel von $40^{\circ}-45^{\circ}$ entspricht (Tulus 2007).

\subsubsection{Enterococcus faecalis}

Die in den letzten Jahren mit Hilfe von modernen Nachweisverfahren durchgeführten In-vivo- und In-vitro-Studien verdeutlichen, dass das Keimspektrum im infizierten Wurzelkanalsystem weitaus differenzierter, komplexer und vielfältiger ist als bisher angenommen und dass dem Bakterium Enterococcus faecalis bei der Pathogenese endodontischer Misserfolge eine Schlüsselrolle zukommt.

E. faecalis kann aufgrund seiner guten Adhärenzeigenschaften die Biofilmbildung unterstützen und bietet anderen Mikroorganismen umfassenden Schutz, sodass deren Resistenz gegenüber Phagozytose, Antikörpern und antimikrobiell wirksamen Pharmaka wie Kalziumhydroxid und anderen herkömmlichen endodontischen Desinfektionsmaßnahmen verstärkt wird (Stuart et al. 2006; Svensäter und Bergenholtz 2004).

Chlorhexidingluconat sowohl in flüssiger Form als desinfizierende Spülung als auch in gelartiger Form als medikamentöse Einlage inhibiert das Wachstum von $E$. faecalis in Konzentrationen von $0,05 \%$ bis $2 \%$ auch über mehrere Tage hinweg. Es erreicht als 2\%ige Flüssigkeit die gleiche Effektivität wie 5,25\%iges Natriumhypochlorit (Gomes et al. 2001) und kann bei Revisionsbehandlungen effektiv gegen $E$. faecalis eingesetzt werden.

Siren et al. untersuchten in einer Studie den Zusammenhang zwischen dem Auftreten von E. faecalis in der Mundflora und im Wurzelkanalsystem. In Fällen, in 
denen die Wurzelkanäle einige Zeit zur Mundhöhle exponiert waren, zeigte sich eine erhöhte Prävalenz von E. faecalis (Siren et al. 1997).

Weitere Studien befassten sich mit der Keimbesiedlung des Endodonts. In mehreren Studien konnte E. faecalis als Vertreter der fakultativen Anaerobier in 30 bis $64 \%$ der Fälle mit endodontischem Misserfolg nachgewiesen werden (Molander et al. 1998; Sundqvist et al. 1998; Hancock et al. 2001; Pinheiro et al. 2003). Er ist somit der häufigste in diesen Fällen nachgewiesene Mikroorganismus (Portenier et al. 2003). Ursache für die differierenden Ergebnisse der einzelnen Studien sind unter anderem die angewandten Nachweistechniken, mit denen der Keimnachweis unterschiedlich gut gelingt (Stuart et al. 2006; Sedgley et al. 2006). Aufgrund der hohen Widerstandsfähigkeit gegenüber herkömmlichen Desinfektionsmaßnahmen stellt E. faecalis einen Problemkeim in der Endodontie vor allem bei Revisionsbehandlungen dar. Mit Hilfe entsprechend wirksamer Medikamente und desinfizierender Spüllösungen ist eine erfolgreiche Eliminierung von E. faecalis aus dem Wurzelkanalsystem jedoch möglich.

\subsubsection{Substanzverlust}

Durch den Versuch, den retrograden Verschluss von orthograd zu entfernen, kommt es zu weiterem Substanzverlust im Bereich der Wurzelspitze. Dies kann die apikale Kanalwand zusätzlich schwächen. Bereits bei der retrograden Präparation wurde möglicherweise die Wurzelkanalanatomie verändert, sodass die Situation vor der Revision schlecht einschätzbar ist (Herrmann 2007).

Ein erneutes mechanisches Aufbereiten des Wurzelkanals ist jedoch nötig, da die Bakterien als Biofilm am Wurzelkanaldentin haften und bis zu $300 \mu \mathrm{m}$ und tiefer in die Dentintubuli einwandern und von Spülösungen nicht ausreichend erreicht werden.

\subsection{Behandlungsalternativen zur orthograden Revision}

Werden die Ursachen für die Persistenz einer Parodontitis apicalis nach Wurzelspitzenresektion betrachtet, dann erscheint die orthograde Revision als Therapie besonders geeignet.

Dennoch ist nicht in jedem Falle eines wurzelspitzenresezierten Zahnes mit persistierender oder neu auftretender Parodontitis apicalis die orthograde 
nichtchirurgische Revision die Erfolg versprechende Option. Deshalb ist eine ausführliche Diagnostik vor Therapiebeginn unabdingbar. Ein präoperatives Röntgenbild ist sowohl zur Bewertung der Qualität einer Wurzelspitzenresektion als auch zur Prognose und Risikoabschätzung eines Versuchs der orthograden Revision erforderlich.

\subsubsection{Keine Behandlung}

Ist auf dem Röntgenbild eine Aufhellung im Sinne einer Parodontitis apicalis zu erkennen, dann ist der Patient mit oder ohne klinische Symptomatik über das Vorhandensein eines chronischen Entzündungsherdes und die Möglichkeit der Exazerbation aufzuklären. Behandlungsmöglichkeiten sowie Vor- und Nachteile sind zu erläutern.

\subsubsection{Beobachten}

Besteht lediglich eine geringe apikale Aufhellung, dann ist es möglich, den Zahn vorerst nur zu beobachten, solange der Patient symptomlos und ohne Schmerzen verbleibt. Regelmäßige Röntgenkontrollaufnahmen sind erforderlich. Allerdings liegen keine Studien zur Prognose von symptomlosen Zähnen nach nicht erfolgreicher Wurzelspitzenresektion mit persistierender Parodontitis apicalis vor (Saunders 2005).

\subsubsection{Extraktion}

Eine Extraktion sollte nur in folgenden Fällen in Erwägung gezogen werden

- wenn der Zahn tief zerstört und die Krone nicht mehr zu restaurieren ist,

- wenn bereits mehrere Zähne fehlen und eine herausnehmbare Prothese getragen wird

- oder wenn weitere chirurgische Maßnahmen zu einem ungünstigen KronenWurzel-Verhältnis führen würden, speziell bei parodontal vorgeschädigten Zähnen

(Saunders 2005). 
Die Extraktion des betroffenen Zahnes stellt die einfachste und kostengünstigste Therapie der Parodontitis apicalis dar. Dafür spricht, dass mit großer Sicherheit die bakterielle Infektion vollständig beseitigt wird und ein Rezidiv ausgeschlossen werden kann. Andererseits ist es eine endgültige Maßnahme, der nur prothetische oder implantologische Schritte folgen können mit entsprechend hohen Kosten für den Patienten. Bei einer prothetischen Versorgung mit einer Brücke müssten die Nachbarzähne zusätzlich präpariert werden und verlieren gesunde Zahnhartsubstanz.

Des Weiteren ist bei dieser Entscheidung die Wertigkeit des Zahnes für vorhandene oder eventuell folgende prothetische Versorgungen zu berücksichtigen. Demnach soll ein Zahn, der eine Schaltlücke begrenzt, möglichst erhalten bleiben, um eine prothetisch ungünstige Freiendsituation zu vermeiden.

\subsubsection{Zweitresektion}

Trotz deutlich geringerer Erfolgsquoten wird bei persistierender Parodontitis apicalis nach WSR häufig eine Zweitresektion ohne orthograde Revision vorgenommen.

Zu diesem Thema steht wenig evidenzbasierte Literatur zur Verfügung. Mead et al. durchsuchten 2005 die Literatur seit 1970 zum Thema WSR. Es fanden sich lediglich 79 Studien, von denen jedoch nicht mehr als zwei die Evidenzklasse zwei erreichten. Außerdem wurde in diesen Studien lediglich das chirurgische und das nicht-chirurgische Vorgehen verglichen. Des Weiteren ist der Großteil der über wiederholte periradikuläre Chirurgie vorhandenen Literatur fast 20 Jahre alt, sodass Techniken und Materialien nicht mehr dem aktuellen Stand entsprechen und keine vergleichbaren Ergebnisse vorliegen (Persson 1973). In einer von Peterson und Gutmann durchgeführten Metaanalyse über die Erfolgsquoten wiederholter apikalchirurgischer Eingriffe waren von insgesamt acht ausgewerteten Studien sechs vor den 80er Jahren durchgeführt worden und differieren hinsichtlich der angewandten Techniken und Materialien ebenfalls sehr vom heutigen Stand. Die Auswertung der Analyse ergab insgesamt eine Erfolgsquote für Zweitresektionen von lediglich 35,7\% (Peterson und Gutmann 2001).

Gagliani et al. verglichen ebenfalls 2005 in einer Studie die Ergebnisse von Erstund Zweitresektionen an endodontisch behandelten Zähnen mit persistierender 
Parodontitis apicalis. Nach einem 5-Jahres-Recall konnte bei $86 \%$ der primärresezierten Zähne ein Erfolg erzielt werden, 7\% befanden sich in Heilung, nur 6\% wurden als Misserfolg gewertet. Die Zweitresektion führte jedoch nur in 59\% der Fälle zum Erfolg, 17\% befanden sich in Heilung, 23\% mussten als Misserfolg gewertet werden. Folglich hat laut Gagliani et al. eine Zweitresektion zwar eine geringere Erfolgsquote als eine Erstresektion, ist aber einer Extraktion vorzuziehen (Gagliani et al. 2005). Durch die routinemäßige Anwendung moderner Operationstechniken wie dem dentalen Operationsmikroskop, Ultraschall und MTA konnten noch bessere Ergebnisse für Zweitresektionen erzielt werden. An 42 Zähnen wurde eine Zweitresektion vorgenommen und bei einer 2-JahresRecallrate von $77,8 \%$ konnte eine Erfolgsquote von $92,9 \%(n=39)$ erreicht werden (Song et al. 2011).

Im Gegensatz dazu kamen Schwartz-Arad et al. (2003) zu einem deutlich schlechteren Ergebnis, allerdings mit einer vergleichsweise geringen Fallzahl von 19 Zähnen. Nur 21\% der Behandlungen konnten als Erfolg gewertet werden, während $31,6 \%$ sich in Heilung befanden und $47,4 \%$ als Misserfolg eingestuft wurden.

Die Aussagen zur Zweitresektion in der Literatur sind nicht einheitlich. Daher kann eine darauf basierende abschließende Empfehlung nicht ausgesprochen werden.

Die Indikationen zur erneuten Wurzelspitzenresektion sind die gleichen wie schon bei der primären Resektion.

Vor einem erneuten chirurgischen Eingriff zur Therapie einer Parodontitis apicalis sollte eine genaue Diagnostik erfolgen, um die Ursachen des Misserfolges der vorherigen Wurzelspitzenresektion zu evaluieren (Saunders 2005). Es muss berücksichtigt werden, dass die Probleme, die zum Misserfolg der primären WSR geführt haben, möglicherweise durch eine Zweitresektion ebenfalls nicht behoben werden können. Eventuell lassen sich diese eher orthograd-endodontisch und nicht-chirurgisch lösen.

Vorteile der WSR liegen im direkten Zugang zur apikalen Läsion und der Entfernung von ca. $3 \mathrm{~mm}$ des Apex. Die Wurzelspitze besitzt eine komplexe Anatomie mit einem apikalen Delta des Wurzelkanalsystems. Hinzu kommen Seitenkanäle und Ramifikationen. Von orthograd ist dieser Wurzelabschnitt nur schwer vollständig aufzubereiten und zu desinfizieren, weshalb vor allem hier Bakterien verbleiben und eine Entzündung aufrechterhalten können. Durch die 
Resektion der Wurzelspitze können diese Strukturen im apikalen Bereich beseitigt werden. Die Kontraindikationen eines allein chirurgischen Vorgehens sind die gleichen wie bei der primären Resektion.

Zusätzlich verliert der betroffene Zahn erneut an Wurzelsubstanz und somit an Länge, was eine Einbeziehung in eine prothetische Versorgung ausschließen kann, da durch ein ungünstiges Kronen-Wurzel-Verhältnis nicht ausreichend Stabilität vorhanden ist, speziell auch bei einer parodontalen Erkrankung.

\subsection{Erfolgskriterien endodontischer und apikalchirurgischer Behandlungen}

Friedman erstellte 2002 eine Übersicht zur Klassifikation des Therapieerfolges einer endodontischen Behandlung:

1. Als Erfolg oder ausgeheilt werden Zähne gewertet, bei denen keine klinischen Anzeichen oder Symptome (Abwesenheit von Schmerz, Schwellung und anderen Symptomen, Fehlen eines Fistelgangs, Beibehaltung der Funktion) oder eine röntgenologische Aufhellung als Zeichen einer Parodontitis apicalis vorliegen.

2. Als "in Heilung“ ist ein endodontisch behandelter Zahn zu bezeichnen, der klinisch symptomfrei ist und röntgenologisch eine Reduzierung der apikalen Läsion in einem Beobachtungszeitraum von maximal 4 Jahren erkennen lässt. Das Auftreten oder die Persistenz einer röntgenologischen Aufhellung im apikalen Bereich mit oder ohne klinische Anzeichen und Symptome wie Schmerz, Schwellung und Hypersensibilität des Zahnes und des Weichgewebes sind Zeichen einer vorherrschenden Entzündung.

3. Überleben (survival): Der endodontisch therapierte Zahn ist nach einem Beobachtungszeitraum von 4 Jahren noch in situ und in Funktion, jedoch besteht röntgenologisch eine apikale Aufhellung, das heißt eine Entzündung.

4. Als Misserfolg wird ein endodontisch behandelter Zahn gewertet, an dem es zu einer Persistenz oder Neuentwicklung einer Parodontitis apicalis kommt auch wenn sonst keine klinischen Anzeichen oder Beschwerden vorliegen (Friedman 2002). 
Da durch die klinische Diagnostik chronische Veränderungen nicht erfasst werden können, ist ein Röntgenbild für die endgültige Erfolgsbeurteilung einer endodontischen Therapie zwingend erforderlich. Ohne röntgenologische Kontrolle kann ein endodontisch behandelter Zahn bestenfalls als „Überleben“ (survival) bezeichnet werden (Hülsmann und Schäfer 2007).

Nach den Richtlinien der European Society of Endodontology ist für die endgültige Beurteilung einer endodontischen Maßnahme ein Beobachtungszeitraum von vier Jahren erforderlich (ESE 2006). Nach Hülsmann und Schäfer ist dies der maximal zulässige Beobachtungszeitraum bis zur Auflösung/Nichtauflösung einer apikalen Läsion (Hülsmann und Schäfer 2007). 


\section{Ziele der Studie}

Es soll durch eine retrospektive Auswertung prä- und postoperativer Röntgenaufnahmen geklärt werden, ob eine orthograd-endodontische Revisionsbehandlung an wurzelspitzenresezierten Zähnen mit persistierender Parodontitis apicalis oder an Zähnen, an denen aufgrund röntgenologisch insuffizienter Behandlungsqualität das Auftreten einer Parodontitis apicalis zu erwarten ist, eine ausreichende Erfolgsquote aufweist, um dieses Verfahren zur klinischen Anwendung empfehlen zu können. 


\section{Material und Methoden}

Die vorliegende Studie wurde von der Ethikkommission der Universitätsmedizin Göttingen unter der Nummer 5/7/11 genehmigt.

Alle Patienten wurden in der zahnärztlichen Praxis von Dr. Gabriel Tulus (Viersen) endodontisch behandelt. Es handelt sich ausschließlich um Patienten, bei denen vom behandelnden Zahnarzt, Dr. Tulus, ein Misserfolg einer Wurzelspitzenresektion diagnostiziert wurde oder das Eintreten eines solchen Misserfolges aufgrund insuffizienter Behandlungsqualität wahrscheinlich erschien. Alle Patienten hatten sich mit der Auswertung ihrer anonymisierten Behandlungsunterlagen und Röntgenaufnahmen einverstanden erklärt.

Vor Beginn der Behandlung wurden eine Allgemeinanamnese und eine zahnärztliche Anamnese erhoben sowie eine zahnärztliche Untersuchung durchgeführt, um das Vorliegen von Erkrankungen auszuschließen, die einen Einfluss auf die endodontische Therapie haben könnten. Alle Angaben und Befunde wurden in der Karteikarte der Patienten dokumentiert.

\subsection{Zahnärztliche Untersuchung}

Die zahnärztliche Untersuchung umfasste:

- Zahnärztliche Anamnese inkl. Zeitpunkt der WSR

- Füllungsstatus

- Parodontalstatus (Sondierungstiefen, Lockerung, Furkationsstatus)

- Restaurationen wurde auf Randschluss, Sekundärkaries und funktionelle Störungen untersucht

- Inspektion und Palpation der Umschlagfalte (Narben, Fisteln, Rötungen, Schwellungen, Druckdolenzen)

- Perkussionstest

- Sensibilitätstest

- Bei Vorhandensein eines Fistelganges wurde dieser mit einer Guttaperchaspitze dargestellt 
- Zusätzlich wurde eine Röntgenaufnahme des fraglichen Zahnes angefertigt (Einzelzahnaufnahme), gegebenenfalls auch mehrere Aufnahmen mit unterschiedlichen Projektionen.

Als wurzelspitzenreseziert galten Zähne, wenn

- röntgenologisch retrograd in die Wurzel eingebrachtes Füllmaterial zu erkennen war, und/oder:

- wenn die Wurzel röntgenologisch deutlich kürzer war als die Wurzeln der Nachbarzähne, eine unphysiologische Außenkontur der Wurzelspitze (Ecken, scharfe Winkel) aufwies und der Zahn röntgenologisch Hinweise auf eine Wurzelkanalbehandlung zeigte (endodontische Zugangskavität, Füllmaterial im Wurzelkanal), und/oder:

- in der Umschlagfalte ein Narbenzug auf vorgenommene apikalchirurgische Eingriffe hinwies, und/oder

- vorliegende Röntgenaufnahmen oder Angaben des überweisenden Zahnarztes oder des Patienten in Kombination mit oben genannten Hinweisen eine zurückliegende WSR bestätigten.

Die Entscheidung für eine orthograde Revision beziehungsweise dagegen basierte auf klinischer und röntgenologischer Diagnostik. In den meisten Fällen war ersichtlich, dass eine insuffiziente Wurzelkanalbehandlung vorlag. Auch wenn die Wurzelkanalbehandlung röntgenologisch suffizient erschien, konnte der Behandler auf Grund seiner langjährigen klinischen Erfahrung davon ausgehen, dass entweder unbehandelte Wurzelkanäle vorlagen oder insuffizient aufbereitete und desinfizierte Wurzelkanalsysteme vorhanden waren.

Eine Zweitresektion anstatt einer orthograden Revision wurde äußerst selten durchgeführt und nur in Situationen, in denen entweder eine große prothetische Arbeit gefährdet sein könnte oder Stifte vorhanden sind, die nicht entfernbar sind. 


\subsection{Kriterien zur Aufnahme in die Studie und Ablauf der Behandlung}

Klinisches Vorgehen

In allen Fällen handelt es sich um Zähne, die endodontisch behandelt und deren Wurzelspitzen reseziert worden waren. Die orthograde Revision wurde von Dr. Tulus in dessen Praxis in Viersen durchgeführt. Alle Behandlungen erfolgten vor der Planung und Vorbereitung der vorliegenden Auswertung. Es wurden alle Zähne in die Studie aufgenommen, an denen im Zeitraum von 2003 bis 2011 von Dr. Tulus eine orthograde Revisionsbehandlung an bereits wurzelspitzenresezierten Zähnen vorgenommen worden war.

Bei allen Patienten folgte eine Aufklärung über die endodontische Therapie und alternative Behandlungsmöglichkeiten.

Alle Patienten wurden nach dem gleichen Ablaufschema behandelt.

Es wurde eine umfangreiche zahnärztliche Untersuchung des betroffenen Zahnes vorgenommen. Alle Behandlungen wurden unter Lokalanästhesie mit Ultracain DS (Sanofi-Aventis GmbH, Frankfurt am Main) durchgeführt. Um eine absolute Trockenlegung zu gewährleisten, wurde ein Kofferdam angebracht. Karies wurde vollständig exkaviert und eine Aufbaufüllung aus Kunststoff (Enamel Plus, Loser, Leverkusen) mit dem Adhäsivsystem Syntac Classic (Ivoclar Vivadent, Schaan, Liechtenstein) eingebracht. Nach der Trepanation erfolgte die Darstellung der Wurzelkanaleingänge. Um einen möglichst geraden und direkten Zugang mit Instrumenten zum Wurzelkanalsystem zu erlangen, wurden alle Überhänge oder Dentikel im koronalen Anteil mit Ultraschall (Vario, NSK Tochigi, Japan) entfernt. Die primäre und sekundäre Zugangskavität wurde so präpariert, dass über ein dentales OP-Mikroskop (Pro Ergo, Carl Zeiss, Jena) eine direkte Sicht auf das Wurzelende oder die retrograde Füllung geschaffen wurde. Musste im Vorfeld ein Wurzelstift entfernt werden, so wurde dafür ebenfalls das Ultraschallgerät eingesetzt. Das Wurzelfüllmaterial wurde vollständig entfernt und nach möglicherweise nicht entdeckten Wurzelkanälen gesucht. Um das alte Wurzelfüllmaterial zu entfernen, wurde kein Lösungsmittel verwendet. Die Entfernung erfolgte maschinell mit rotierenden Instrumenten (Flexmaster, VDW, München). 
War eine retrograde Füllung vorhanden, wurde stets der Versuch unternommen, diese mittels Ultraschall zu entfernen. Der Entfernungsversuch wurde abgebrochen, wenn die Gefahr bestand, das retrograde Füllungsmaterial in den periapikalen Raum zu extrudieren.

Es erfolgten eine elektrische Längenmessung (Raypex 4, VDW, München) und eine Röntgen-Messaufnahme (Trophy-Sensor 6100 Kodak, Stuttgart).

Zur Desinfektion und zum Herausspülen der Dentinspäne erfolgte ein häufiges und intensives Spülen mit unterschiedlichen Produkten nach einem festen Spülprotokoll: Natriumhypochlorit 3,25\% (hergestellt in der Apotheke), in der Regel 10-15 ml pro Kanal, Kochsalzlösung, CHX 2\% (hergestellt in der Apotheke), etwa $5 \mathrm{ml}$ pro Kanal, EDTA 17\% (hergestellt in der Apotheke), jeweils $2 \mathrm{ml}$ pro Kanal, Alkohol 90\%, jeweils $2 \mathrm{ml}$ pro Kanal. Im Rahmen der Aufbereitung wurde eine passiv ultraschallaktivierte Spülung (PUI - passive ultrasonic irrigation) für jeweils 3×20 Sekunden durchgeführt (Vario, NSK, Tochigi, Japan).

Aufbereitet wurde bis zu der durch die elektrische Längenmessung bestimmten und röntgenologisch kontrollierten Arbeitslänge. Dabei wurden unterschiedliche Instrumente verwendet je nach Situation und Handlichkeit: Nickel-Titan-Instrumente (Mtwo und Flexmaster, VDW, München) und Gates-Glidden-Bohrer (VDW, München) zur maschinellen Aufbereitung, Stahlinstrumente, vor allem K-Feilen, für die Erschließung der Wurzelkanäle, Handinstrumente, ProFile- und ProTaper NiTi-Instrumente sowie Micro-Debrider zur Entfernung von Guttapercharesten (Dentsply DeTrey, Konstanz) und Micro Opener (VDW, München).

Ein Operationsmikroskop (Pro Ergo, Carl Zeiss, Jena) mit einer 6- bis 33-fachen Vergrößerung wurde routinemäßig zur klinischen Untersuchung, Trepanation und Lokalisation der Kanaleingänge, Aufbereitung und Wurzelkanalfüllung eingesetzt.

Als medikamentöse Einlage wurde in den meisten Fällen ein Kalziumhydroxidpräparat (UltraCal, Ultradent, Köln) verwendet. Diese wurde mit dünnen Kanülen (Durchmesser ISO 30) eingebracht. Die Entscheidung für oder gegen eine medikamentöse Einlage wurde nach dem subjektiven Eindruck des behandelnden Zahnarztes getroffen. Patienten, bei denen aufgrund einer großen apikalen Aufhellung, Pusentleerung oder Schmerzen mit einer stärkeren Infektion des Wurzelkanalsystems zu rechnen war, wurden mit einer Kalziumhydroxideinlage versorgt. Dabei ist die Liegedauer auch von der Verfügbarkeit des Patienten abhängig und variierte deshalb teilweise stark. 
Für einen speicheldichten, provisorischen Verschluss wurde Cavit (3M Espe, Neuss) in die koronale Kavität eingebracht. War eine längere Liegedauer der medikamentösen Einlage und des provisorischen Verschlusses abzusehen, dann wurde abschließend eine Schicht Kunststoff (Enamel Plus, Loser, Leverkusen) adhäsiv befestigt.

Falls eine medikamentöse Einlage eingebracht worden war, wurde diese beim nächsten Termin durch intensives Spülen mit Natriumhypochlorit, teilweise auch ultraschallaktiviert, vollständig entfernt. In einigen Fällen wurde zur Kontrolle zusätzlich eine Masterpointaufnahme angefertigt.

Als apikaler Verschluss wurde ein ca. $4 \mathrm{~mm}$ starker Plug aus Mineral Trioxid Aggregate (MTA, Dentsply, Konstanz) mit Hilfe einer MTA-Gun (American Dental Systems, Vaterstetten) appliziert. Der Verschluss wurde unter Sichtkontrolle mit einem OPM mit 6- bis 33-facher Vergrößerung eingebracht und überprüft. Oftmals wurde eine Röntgenkontrollaufnahme angefertigt.

Die Re-Obturation der Wurzelkanäle erfolgte durch thermoplastisches Füllen mit warm vertikal kondensierter Guttapercha (BeeFill, VDW, München). Um eine Reinfektion zu verhindern, folgte koronal ein bakteriendichter adhäsiver Verschluss mit Komposit (Enamel Plus, Loser, Leverkusen). Eine abschließende Kontrollaufnahme des behandelten Zahnes wurde angefertigt.

Die anonymisierten prä- und posttherapeutischen Röntgenbilder wurden von zwei Zahnärzten ausgewertet, die in die Diagnosestellung und Behandlung nicht involviert waren. Es handelt sich überwiegend um digitale Röntgenbilder. Alle konventionellen Röntgenbilder wurden digitalisiert und am PC ausgewertet.

Bei den beiden externen Auswertern handelte es sich um eine Zahnmedizinstudentin im 10. Semester (A.Z.) sowie um einen Endodontie-Spezialisten mit langjähriger klinischer Erfahrung (M.H.).

Überprüft und dokumentiert wurden die folgenden Befunde:

- Zahn

- Präoperatives Vorliegen einer Parodontitis apicalis

- Versorgung mit einer retrograden Füllung: ja/nein

- Falls ja: Material, soweit identifizierbar (Amalgam/Zement)

- Intraoperative Entfernung der retrograden Füllung: ja/nein

- Medikamentöse Einlage: ja/nein 
- Falls ja: welche?

- Technik und Materialien zur Wurzelkanalfüllung

- Dauer der Kontrollzeit

- Ausheilung der Läsion bzw. Neuentwicklung einer Läsion: ja/nein

\subsection{Kontrollgruppen}

Eine optimale Kontrollgruppe hätte aus Zähnen bestanden, bei denen nach Misserfolg einer Wurzelspitzenresektion ein erneuter apikalchirurgischer Eingriff durchgeführt wurde. Idealerweise wären die Patienten dann randomisiert einer der beiden Gruppen zugeteilt worden.

Da für eine solche Kontrollgruppe nicht ausreichend Fälle zur Verfügung standen, dienten vom Praxisinhaber durchgeführte endodontische Primär- und Revisionsbehandlungen als Kontrollgruppen. Dieses Vorgehen erlaubt zumindest eine grobe Einordnung der letztlich ermittelten Erfolgsquote in Relation zu anderen endodontischen Behandlungen desselben Zahnarztes.

Als Kontrollen dienten jeweils die laut Kartei zuletzt vor der orthograden Revision nach WSR durchgeführten Primärbehandlungen und rein orthograden endodontischen Revisionen.

\subsection{Ablauf der Primär- und Revisionsbehandlung}

Alle Patienten wurden über alternative Therapieoptionen aufgeklärt und ausführlich zahnärztlich untersucht. Zur lokalen Schmerzausschaltung wurde gegebenenfalls Ultracain DS verabreicht (Sanofi-Aventis, Frankfurt am Main) und, um eine absolute Trockenlegung zu gewährleisten, eine Kofferdamisolierung vorgenommen. Karies wurde vollständig exkaviert und eine Aufbaufüllung aus Kunststoff (Enamel Plus, Loser, Leverkusen) adhäsiv eingebracht (Syntac Classic, Ivoclar Vivadent, Schaan, Liechtenstein).

Nach der Trepanation erfolgte die Darstellung der Wurzelkanaleingänge. Um einen möglichst geraden und direkten Zugang mit Instrumenten zum Wurzelkanalsystem zu erlangen, wurden alle Überhänge oder Dentikel im koronalen Anteil mit Ultraschall (Vario, NSK, Tochigi, Japan) entfernt und eine entsprechend große Kavität präpariert. Im Falle einer Revision wurde das alte 
Füllmaterial mit Handinstrumenten und rotierenden Instrumenten entfernt. Ein Lösungsmittel wurde nicht verwendet.

Zur Desinfektion und zum Herausspülen der Dentinspäne erfolgte ein häufiges und intensives Spülen mit unterschiedlichen Produkten nach einem festen Spülprotokoll: Natriumhypochlorit 3,25\% (hergestellt in der Apotheke), in der Regel 10-15 ml pro Kanal, Kochsalzlösung, CHX 2\% (hergestellt in der Apotheke), etwa $5 \mathrm{ml}$ pro Kanal, EDTA 17\% (hergestellt in der Apotheke), jeweils $2 \mathrm{ml}$ pro Kanal, Alkohol 90\%, jeweils $2 \mathrm{ml}$ pro Kanal. Im Rahmen der Aufbereitung wurde eine passiv ultraschallaktivierte Spülung (PUI - passive ultrasonic irrigation) für jeweils $3 \times 20$ Sekunden durchgeführt. Aufbereitet wurde bis auf die durch die elektrische Längenmessung (Raypex 4, VDW, München) bestimmte und röntgenologisch kontrollierte Arbeitslänge. Dabei wurde mit Stahlinstrumenten, vor allem K-Feilen, für die Erschließung der Wurzelkanäle, ProFile Handinstrumenten und ProTaper NiTi-Instrumenten sowie Micro-Debridern zur Entfernung von Guttapercharesten (Dentsply DeTrey, Konstanz und MicroOpener (VDW, München) gearbeitet. Zur maschinellen Präparation des Wurzelkanalsystems wurden Gates-Glidden-Bohrer (VDW, München) und Ni-Ti-Instrumente (Mtwo und FlexMaster, VDW, München) angewendet. Musste die Behandlung aus verschiedenen Gründen zweizeitig durchgeführt werden, so wurde eine medikamentöse Einlage aus Kalziumhydroxid (UltraCal, Ultradent, Köln) eingebracht. Die Dauer der Einlage war wie auch schon bei der Hauptgruppe hauptsächlich abhängig von der Verfügbarkeit des Patienten. Für den provisorischen, speicheldichten Verschluss wurde Cavit (3M Espe, Neuss) verwendet. Wurde eine medikamentöse Einlage eingebracht, so musste diese beim nächsten Termin durch intensive Spülung mit Natriumhypochlorit, teilweise ultraschallaktiviert, vollständig entfernt werden. Die Wurzelkanalfüllung erfolgte durch thermoplastisches Füllen mit warm vertikal kondensierter Guttapercha (BeeFill, VDW, München). Koronal wurde der Zahn mit Komposit wieder adhäsiv aufgebaut und bakteriendicht verschlossen. Eine Röntgenkontrollaufnahme wurde angefertigt. 


\subsection{Definition des Behandlungserfolges}

Als Erfolge wurden alle Behandlungen gewertet, die die folgenden Kriterien erfüllten: Die Recallzeit musste mindestens 11 Monate betragen, Behandlungen mit kürzeren Recallzeiten oder ohne Recall wurden nicht als Erfolge gewertet.

Der Zahn musste zum Zeitpunkt des Recalls noch in situ sein. War der Zahn extrahiert, wurde die Behandlung auch dann als Misserfolg gewertet, wenn er nach mehr als 11 Monaten entfernt wurde, der Zeitpunkt der Extraktion wurde für die Bewertung nicht berücksichtigt.

Wies der Zahn vor der orthograden Revisionsbehandlung röntgenologisch eine Parodontitis apicalis auf, wurde die Behandlung nur dann als Erfolg gewertet, wenn eine vollständige Rückbildung stattgefunden hatte und klinische Beschwerdefreiheit bestand. Bei einer Verkleinerung der Läsion wurde dies als unvollständige Heilung separat dokumentiert, aber nicht als Erfolg bewertet. 


\section{Ergebnisse}

\subsection{Hauptgruppe}

\subsubsection{Allgemeine Merkmale des Kollektivs}

Im Zeitraum von 2003 bis 2013 wurden in der Zahnarztpraxis Dr. Tulus unter anderem insgesamt 75 Patienten beziehungsweise 86 Zähne nach nicht erfolgreicher Wurzelspitzenresektion orthograd endodontisch behandelt. Bis 2013 lagen Röntgenkontrollaufnahmen von insgesamt 48 Patienten mit 59 behandelten Zähnen des Gesamtkollektivs zur Nachuntersuchung vor. Dies entspricht einer Recallrate von 68,6\%. Im Folgenden wird von dieser Recallgruppe ausgegangen. Die Röntgenaufnahmen zur Nachuntersuchung wurden entweder vom jeweiligen Hauszahnarzt oder in der Praxis Dr. Tulus angefertigt.

Die statistische Auswertung der Daten erfolgte nach dem Pearson-ML-Chi²-Test (Test auf Unabhängigkeit). Eine statistische Signifikanz wird ab einem $\mathrm{p}$-Wert $\leq$ 0,05 erreicht. Das statistische Signifikanzniveau beträgt demnach 5 Prozent.

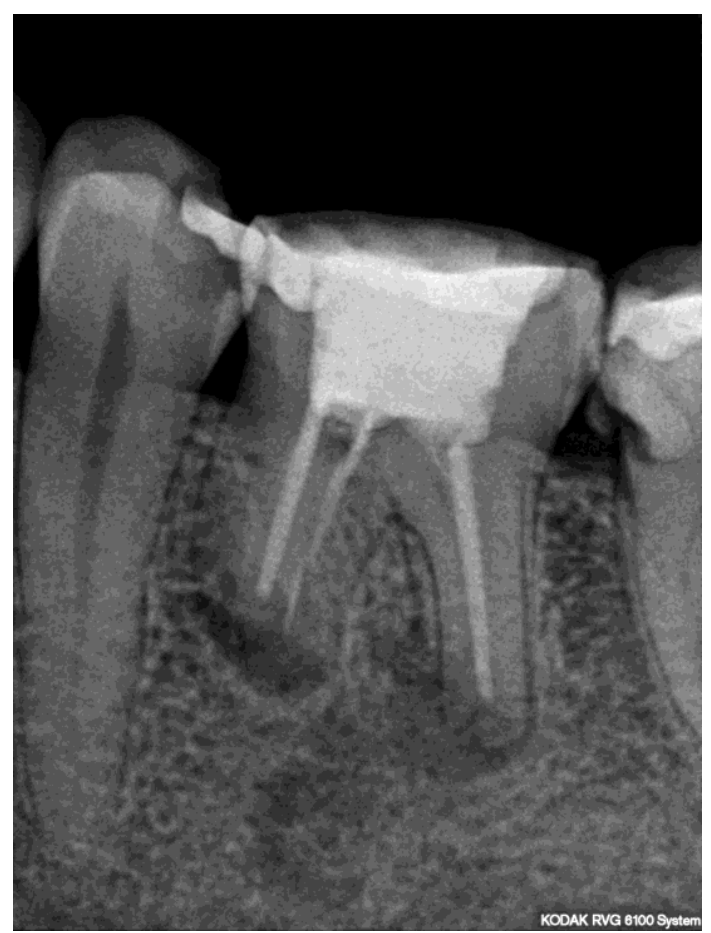

Abbildung 1: Zahn 36 initiale Aufnahme; 15.06.2010; mesiale Wurzel reseziert, deutliche apikale Aufhellung an beiden Wurzelspitzen erkennbar 


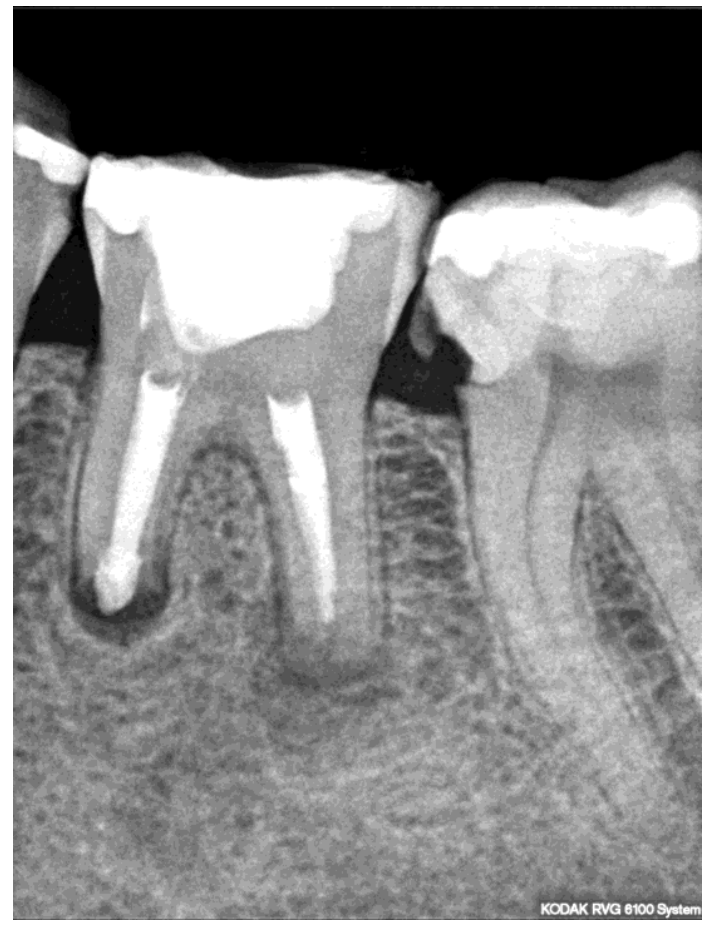

Abbildung 2: Zahn 36 Aufnahme der Wurzelfüllung; 02.07.2010

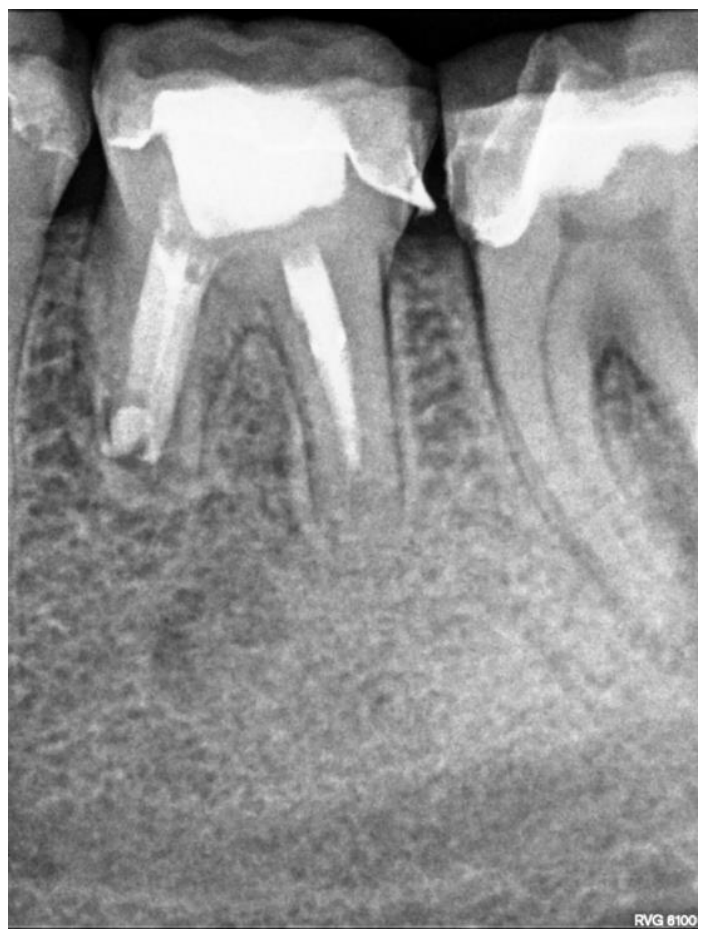

Abbildung 3: Zahn 36 Kontrollaufnahme der Wurzelfüllung; 08.12.2011; vollständige Ausheilung der apikalen Aufhellung 


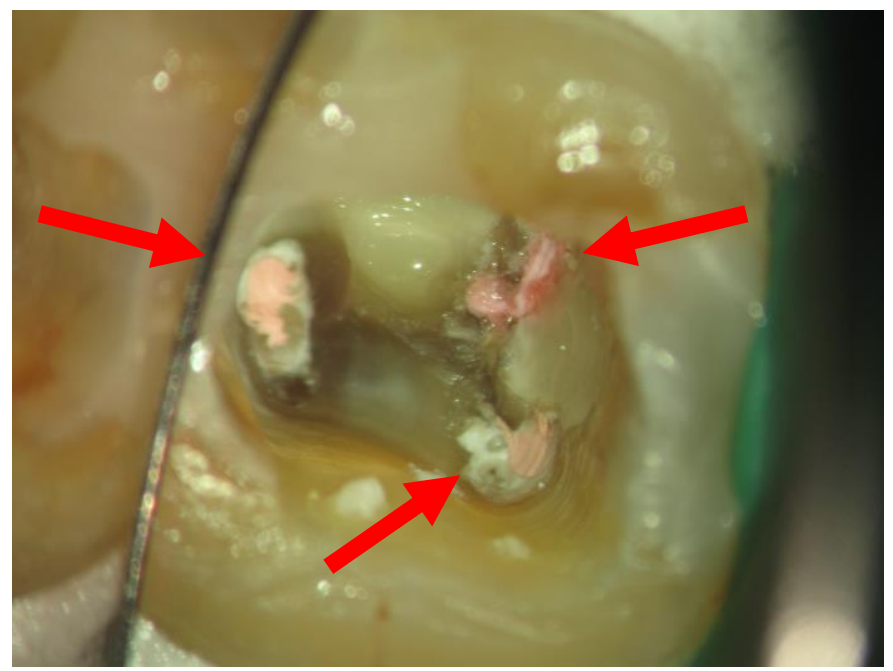

Abbildung 4: Zahn 36 intrakanaläre Aufnahme nach Wurzelfüllung; die Pfeile kennzeichnen die mit Guttapercha abgefüllten Kanaleingänge

\subsubsection{Häufigkeit der Behandlung in den einzelnen Zahngruppen der Hauptgruppe}

Um die Abhängigkeit des Behandlungserfolges von der jeweiligen Zahnposition zu ermitteln, wurden die Zähne in Gruppen eingeteilt. Gruppe 1 beinhaltet alle Frontzähne, Gruppe 2 alle Prämolaren und Gruppe 3 alle Molaren. Abbildung 5 zeigt die Verteilung der Behandlungen auf die Zahngruppen sowie jeweils die Anzahl der Fälle, die als Erfolg, Misserfolg oder als „in Heilung“ gewertet wurden. Die Verteilung auf Molaren $(n=18)$ und Prämolaren $(n=16)$ ist ausgeglichen. Es liegt ein leichtes Übergewicht bei den Frontzähnen vor $(n=25)$. Die Erfolgs- und Misserfolgsquote ist in den drei Gruppen ähnlich. 


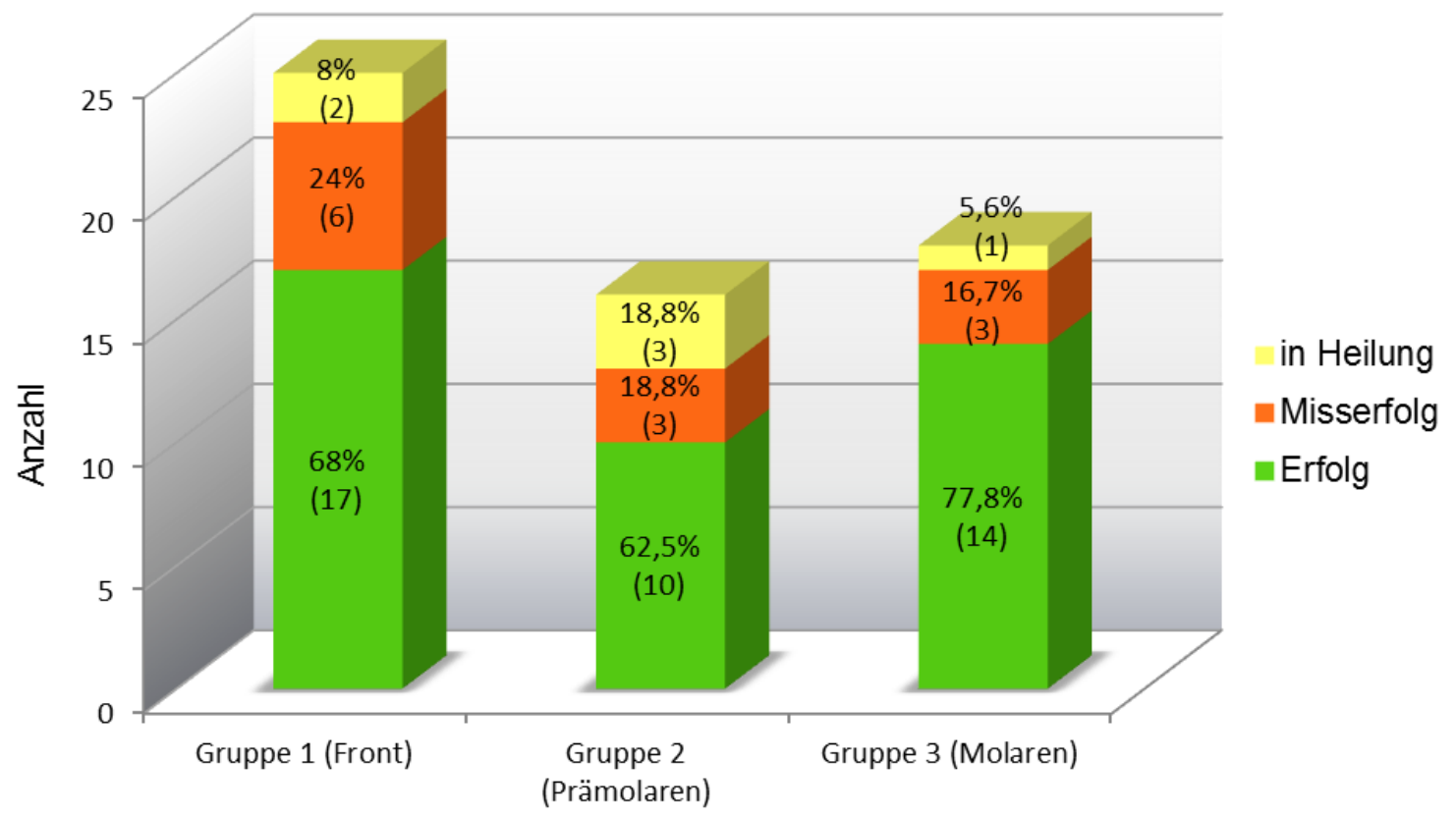

Abbildung 5: Erfolg in Abhängigkeit von der Zugehörigkeit zur Zahngruppe

Zusätzlich wird in Abbildung 6 die Verteilung der Behandlungen auf die einzelnen Zahngruppen im Oberkiefer und Unterkiefer dargestellt. Im Oberkiefer wurden 6 Molaren, 11 Prämolaren und 24 Frontzähne behandelt. Im Unterkiefer wurden hauptsächlich im posterioren Bereich liegende Zähne therapiert. Es wurden 12 Molaren, 5 Prämolaren und lediglich ein Frontzahn behandelt.

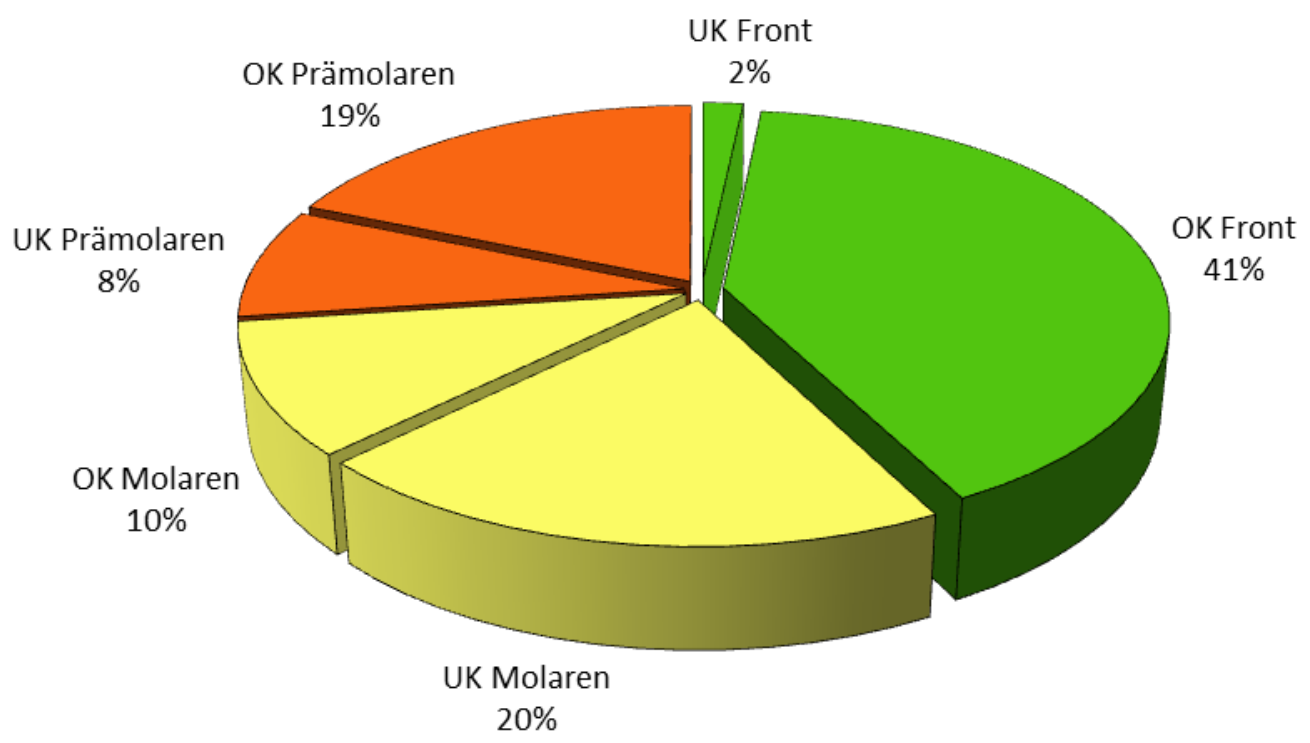

Abbildung 6: Anteile der behandelten Zähne in Ober- und Unterkiefer sowie Front, Prämolaren und Molaren 


\subsubsection{Recallzeitraum}

Der Recallzeitraum lag zwischen 3 und 60 Monaten. Der errechnete Medianwert beträgt 20 Monate. Ausreißer (60 Monate) und Extremwerte wurden bei der Errechnung nicht beachtet. 50\% der der Fälle hatten einen kürzeren und $50 \%$ der Fälle einen längeren Recallzeitraum als 20 Monate. Abbildung 7 zeigt in einem Boxplot den Recallzeitraum in Monaten.

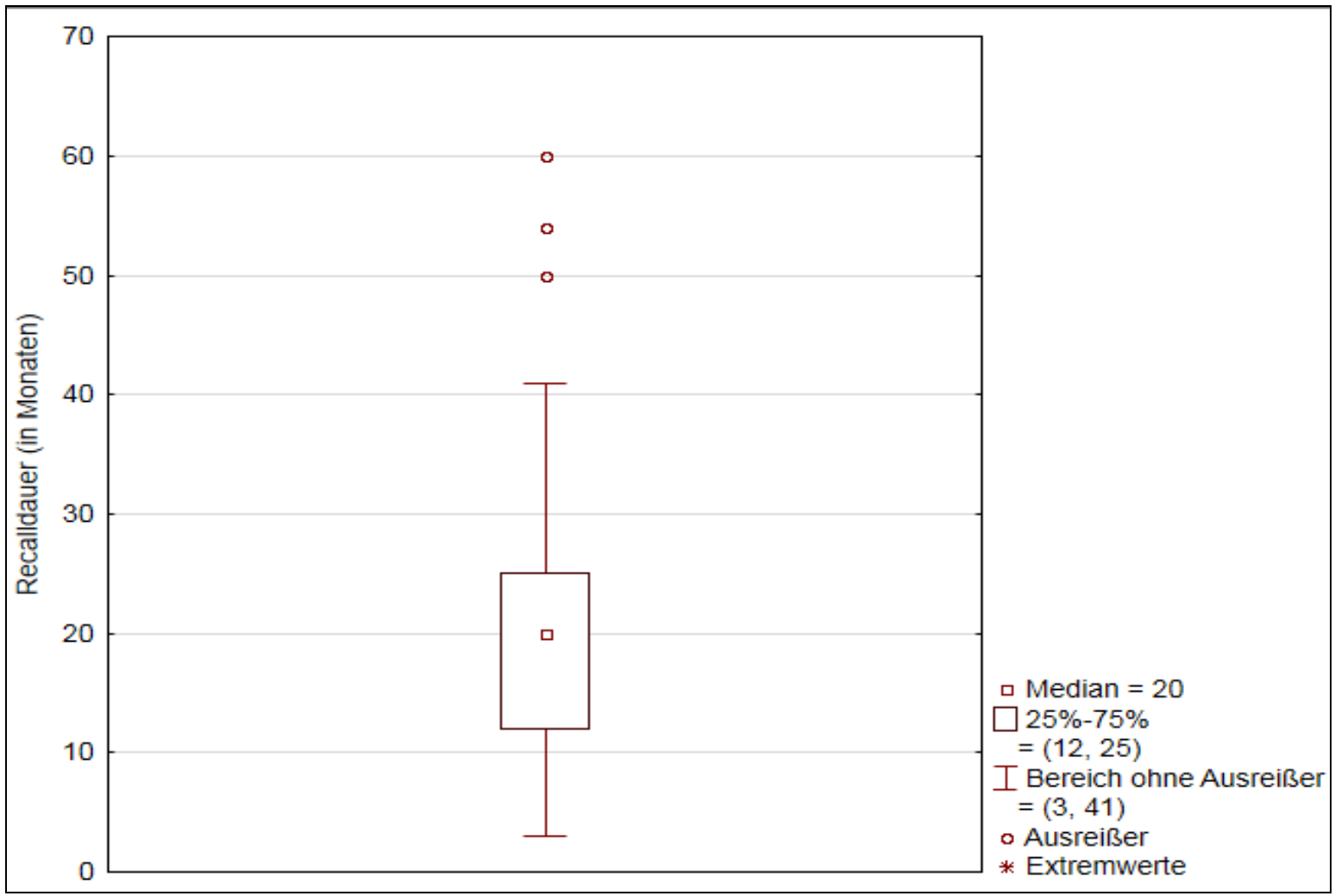

Abbildung 7: Recalldauer der Hauptgruppe in Monaten

\subsubsection{Präoperativer Befund des Periapex (Parodontitis apicalis)}

Bei der Beurteilung der Ausgangssituation der zu behandelnden Zähne konnte in 51 von 59 Fällen röntgenologisch eine Parodontitis apicalis festgestellt werden. In $64,7 \%$ der Fälle konnte eine vollständige Heilung erzielt werden, 11,8\% der Zähne befanden sich zum Zeitpunkt der Nachuntersuchung in Heilung und 23,5\% mussten als Misserfolg gewertet werden (Abbildung 8)

Alle Zähne, welche keine präoperative Parodontitis apicalis $(n=8)$ aufwiesen, konnten erfolgreich therapiert werden. 
Nach Auswertung der Daten mit dem Pearson-ML-Chi²-Test hat das Vorhandensein einer präoperativen Parodontitis apicalis an Zähnen nach nicht erfolgreicher Wurzelspitzenresektion keinen statistisch signifikanten Einfluss auf das Erfolgsergebnis $(p=0,13)$.

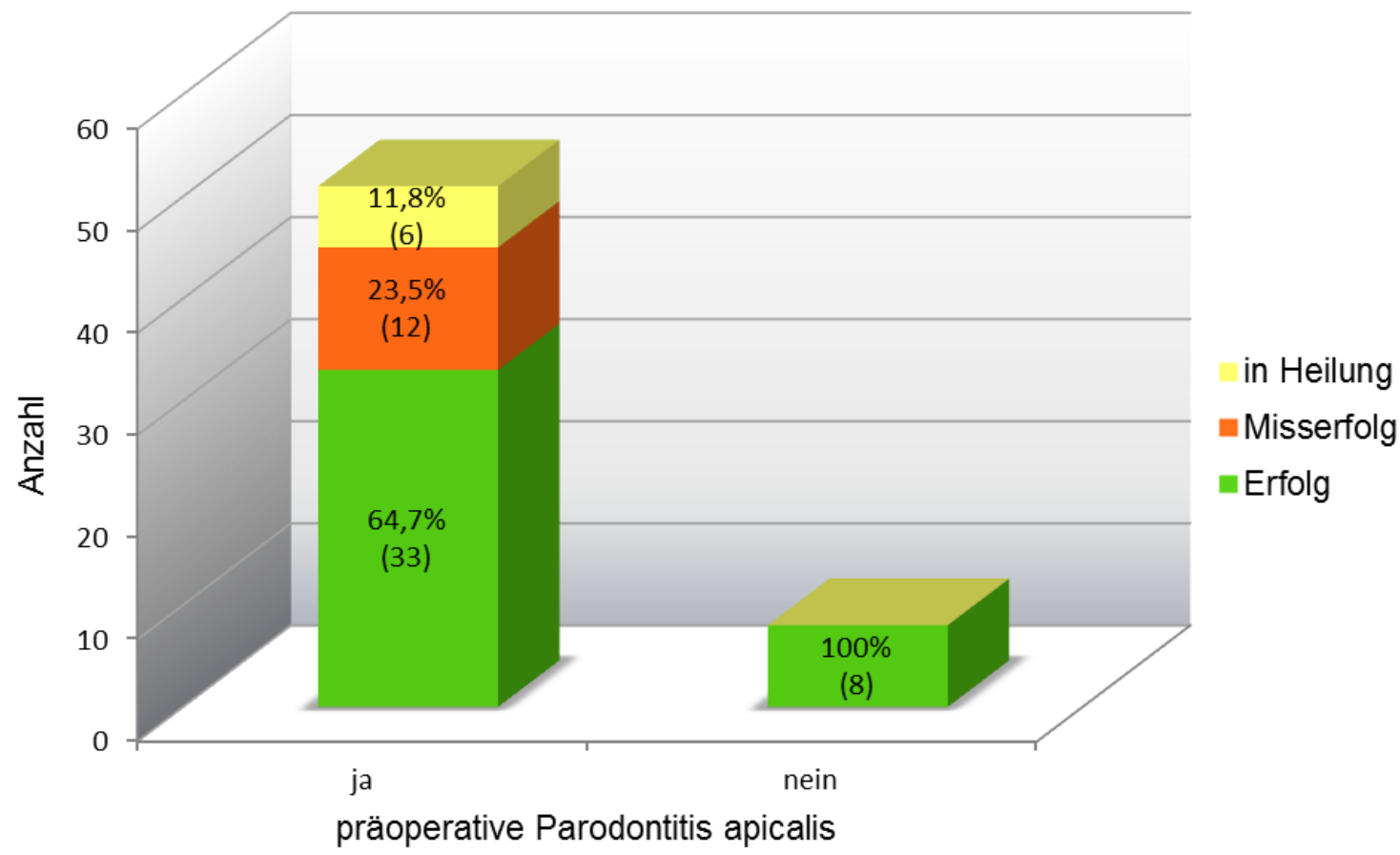

Abbildung 8: Erfolg in Abhängigkeit vom präoperativen Befund des Periapex (Parodontitis apicalis)

\subsubsection{Die medikamentöse Einlage}

In 36 von 59 Fällen wurde Kalziumhydroxid als medikamentöse Einlage zwischen den Terminen der Wurzelkanalaufbereitung und der Wurzelkanalfüllung eingebracht und der Zahn zweizeitig behandelt. Dieses Vorgehen führte in 61,1\% der Fälle ( $n=22)$ zum Erfolg. Bei 16 Zähnen wurde dieser Behandlungsschritt nicht unternommen und der Zahn einzeitig behandelt. In dieser Gruppe konnte eine Erfolgsquote von $87,5 \%(n=14)$ erzielt werden. In sieben Fällen kann keine Aussage zur medikamentösen Einlage getroffen werden (Abbildung 9)

Nach der statistischen Auswertung der Daten mittels Pearson-ML-Chi-Test wird ersichtlich, dass das Einbringen von Kalziumhydroxid als medikamentöse Einlage in Fällen nicht erfolgreich wurzelspitzenresezierter Zähne keinen signifikanten Einfluss auf das Erfolgsergebnis hat $(p=0,16)$. 


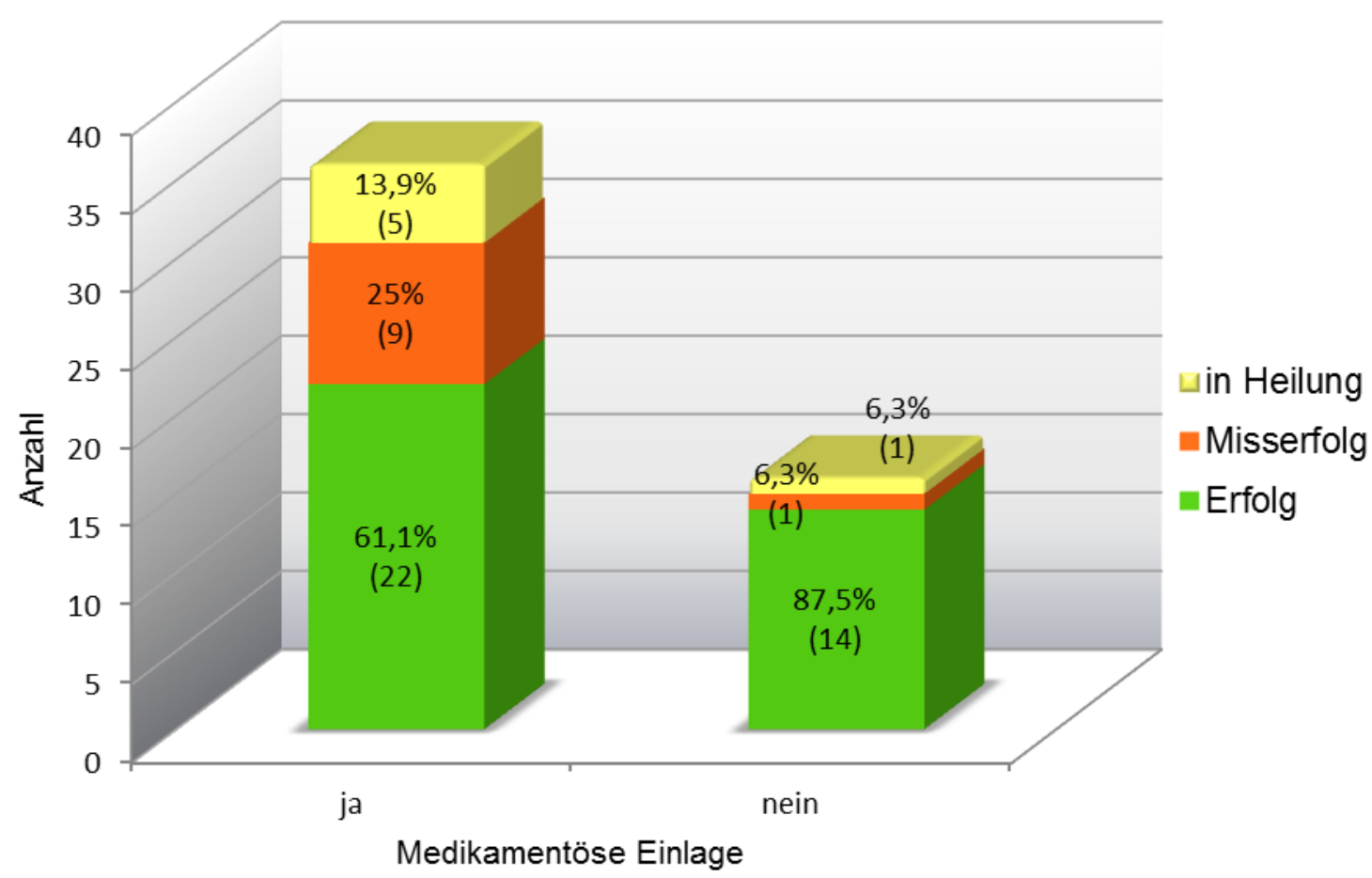

Abbildung 9: Erfolg in Abhängigkeit einer medikamentösen Einlage mit Kalziumhydroxid

\subsubsection{Erfolg in Abhängigkeit von einer medikamentösen Einlage und vom präoperativen Befund des Periapex (Parodontitis apicalis)}

Es wurde untersucht, ob der Behandlungserfolg mit oder ohne medikamentöse Einlage vom präoperativen Befund des Periapex abhängig ist. Da die jeweiligen Gruppen jedoch eine sehr unterschiedliche Fallzahl aufweisen (45 Fälle mit präoperativer Parodontitis apicalis und 7 Fälle ohne), ist ein direkter Vergleich nicht möglich. Tabelle 1 zeigt die Erfolgs- und Misserfolgsquoten der Fälle mit und ohne präoperativer Parodontitis apicalis und mit und ohne medikamentöser Einlage. 


\begin{tabular}{|c|c|c|c|c|c|c|}
\hline & $\begin{array}{c}\text { Parodontitis } \\
\text { apicalis }\end{array}$ & $\begin{array}{c}\text { medikamentöse } \\
\text { Einlage }\end{array}$ & Erfolg & Misserfolg & in Heilung & gesamt \\
\hline Anzahl & ja & ja & 19 & 9 & 5 & 33 \\
\hline Anzahl & ja & nein & 10 & 1 & 1 & 12 \\
\hline gesamt Gruppe 1 & & & & & & 45 \\
\hline Anzahl & nein & ja & 3 & - & - & 3 \\
\hline Anzahl & nein & nein & 4 & - & - & 4 \\
\hline gesamt Gruppe 2 & & & & & & 7 \\
\hline gesamt & & & 36 & 10 & 6 & 52 \\
\hline
\end{tabular}

Tabelle 1: Erfolg in Abhängigkeit von einer medikamentösen Einlage und vom präoperativen Befund des Periapex (Parodontitis apicalis)

\subsubsection{Die retrograde Füllung}

Anhand der präoperativen Röntgenaufnahmen wurden das Vorhandensein einer retrograden Wurzelfüllung und das verwendete Material registriert. Eine hohe Röntgenopazität des Füllmaterials im Resektionsbereich ließ auf Amalgam schließen, während ein weniger röntgendichter Verschluss auf Zement hinwies. Nur in 16 von 59 Fällen war allerdings eine retrograde Wurzelfüllung vorhanden, davon waren 5 Amalgam- und 11 Zementfüllungen.

Zusätzlich wurde untersucht, ob eine Entfernung der retrograden Füllung möglich war und ob der Behandlungserfolg davon abhing. Die Entfernung gelang jedoch in lediglich einem Fall. Es handelte sich um eine Zementfüllung. Die Behandlung führte in diesem Fall zum Erfolg. Eine präoperative Parodontitis apicalis bestand nicht.

Aufgrund der geringen Fallzahl erscheint die statistische Analyse zu dieser Fragestellung nicht sinnvoll. Abbildung 10 zeigt den Erfolg in Abhängigkeit vom retrograden Füllmaterial. 


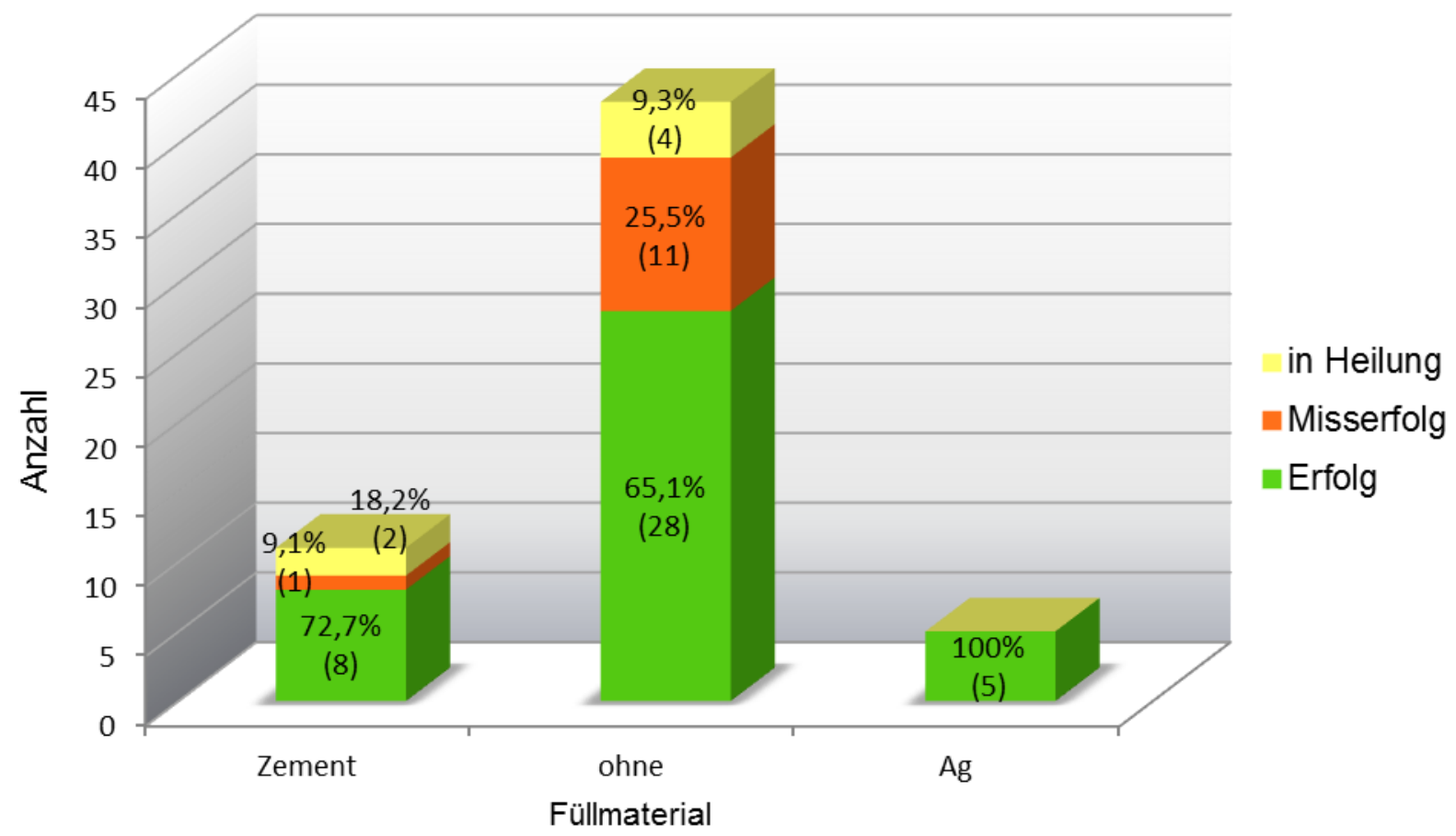

Abbildung 10: Erfolg in Abhängigkeit vom retrograden Füllmaterial

\subsubsection{Erfolgsquote der Hauptgruppe}

Als Erfolg wurden alle Behandlungen gewertet, in denen nach einer Recallzeit von 11 Monaten röntgenologisch keine Parodontitis apicalis vorlag und der Patient symptomlos und beschwerdefrei war. Von 59 untersuchten Zähnen konnte bei 41 Zähnen nach diesen Kriterien ein Erfolg verzeichnet werden. Die apikale Aufhellung war nicht mehr vorhanden und ein gleichmäßiger Parodontalspalt hatte sich gebildet. Dies entspricht einer Erfolgsquote von $69,5 \%$.

War nach der genannten Recallzeit röntgenologisch lediglich eine Verkleinerung der apikalen Aufhellung zu erkennen, so wurde dieser Fall als „in Heilung“ gewertet. In 10,2\% ( $n=6)$ der Fälle konnte eine Heilungstendenz erkannt werden. Die weiteren 12 Fälle $(20,3 \%)$ mussten aufgrund einer persistierenden Parodontitis apicalis als Misserfolg eingestuft werden.

Die Erfolgsquoten der einzelnen Zahngruppen unterscheiden sich nur gering. Von 25 Frontzähnen konnten $68 \%(n=17)$, von insgesamt 16 Prämolaren konnten $62,5 \%(n=10)$ erfolgreich behandelt werden. In der Molarengruppe konnten von insgesamt 18 Zähnen 14 (77,8\%) als Erfolg gewertet werden. 


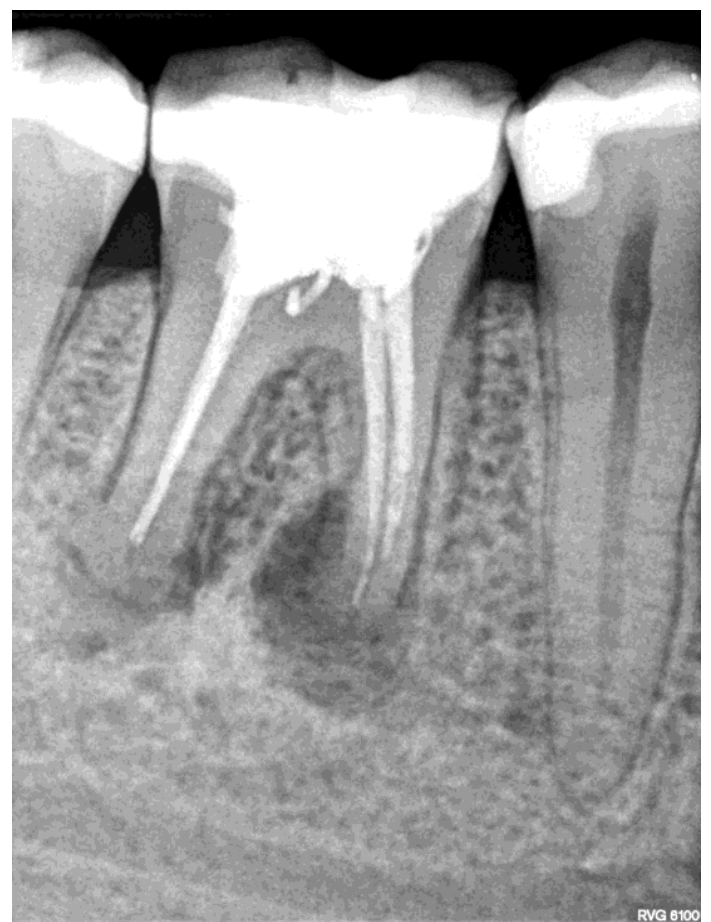

Abbildung 11: Zahn 46 initiale Aufnahme; 28.06.2010; insuffiziente Wurzelfüllung und apikale Aufhellung erkennbar

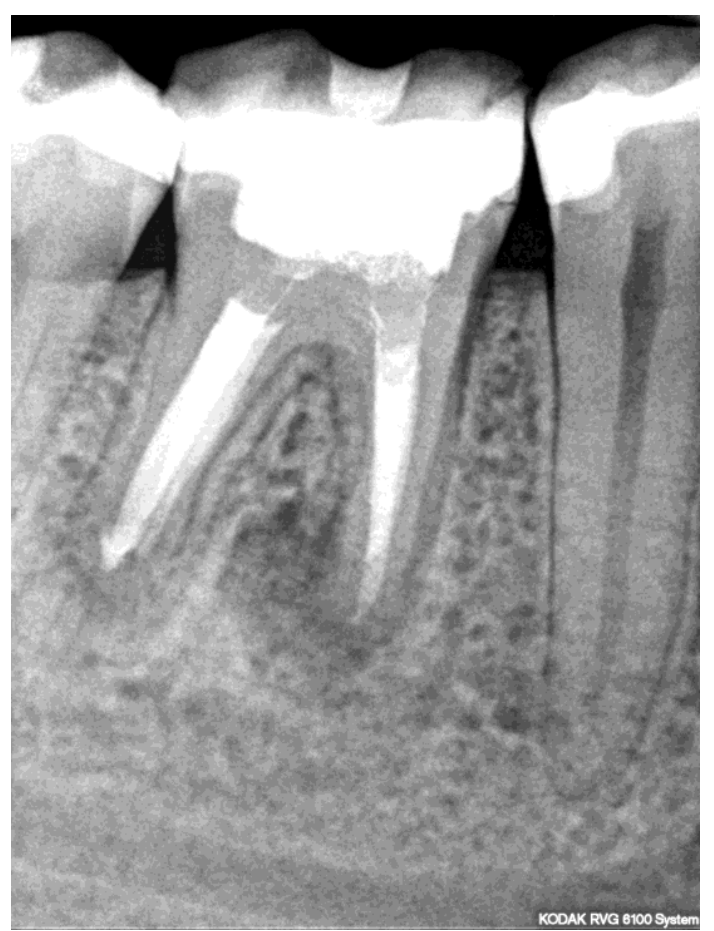

Abbildung 12: Zahn 46 Aufnahme der Wurzelfüllung; 22.12.2010 


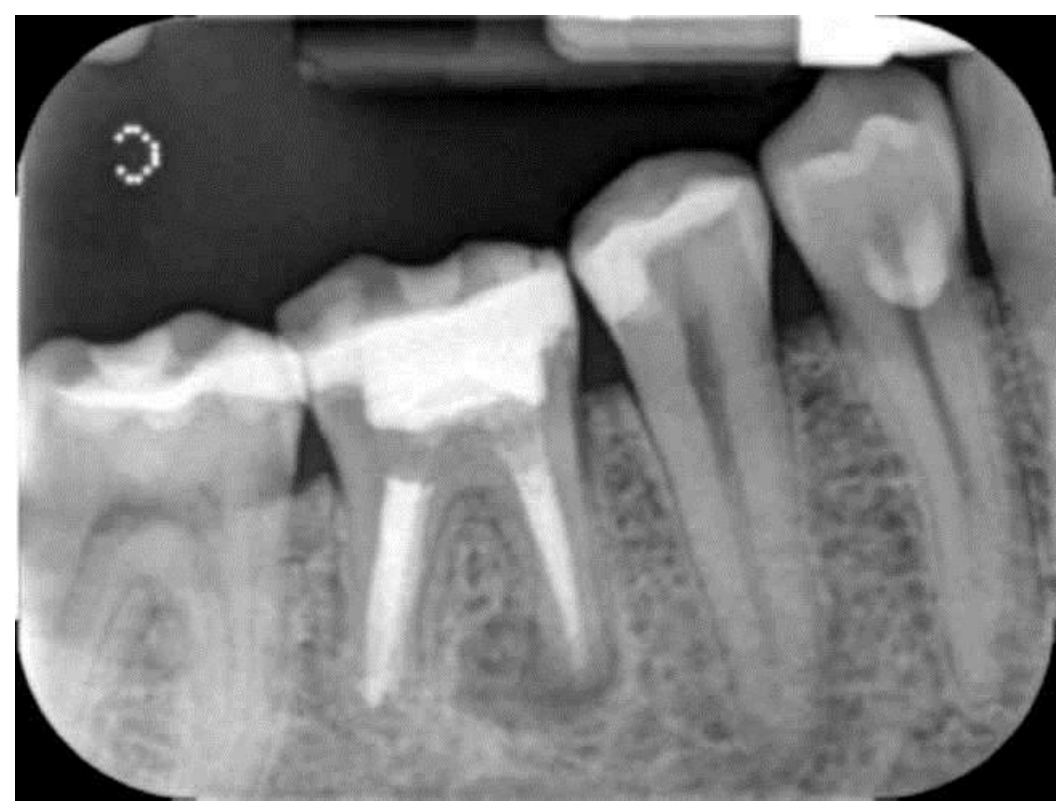

Abbildung 13: Zahn 46 Kontrollaufnahme der Wurzelfüllung; 18.12.2012; analoge Aufnahme des überweisenden Zahnarztes digitalisiert; an mesialer Wurzelspitze deutliche apikale Aufhellung erkennbar

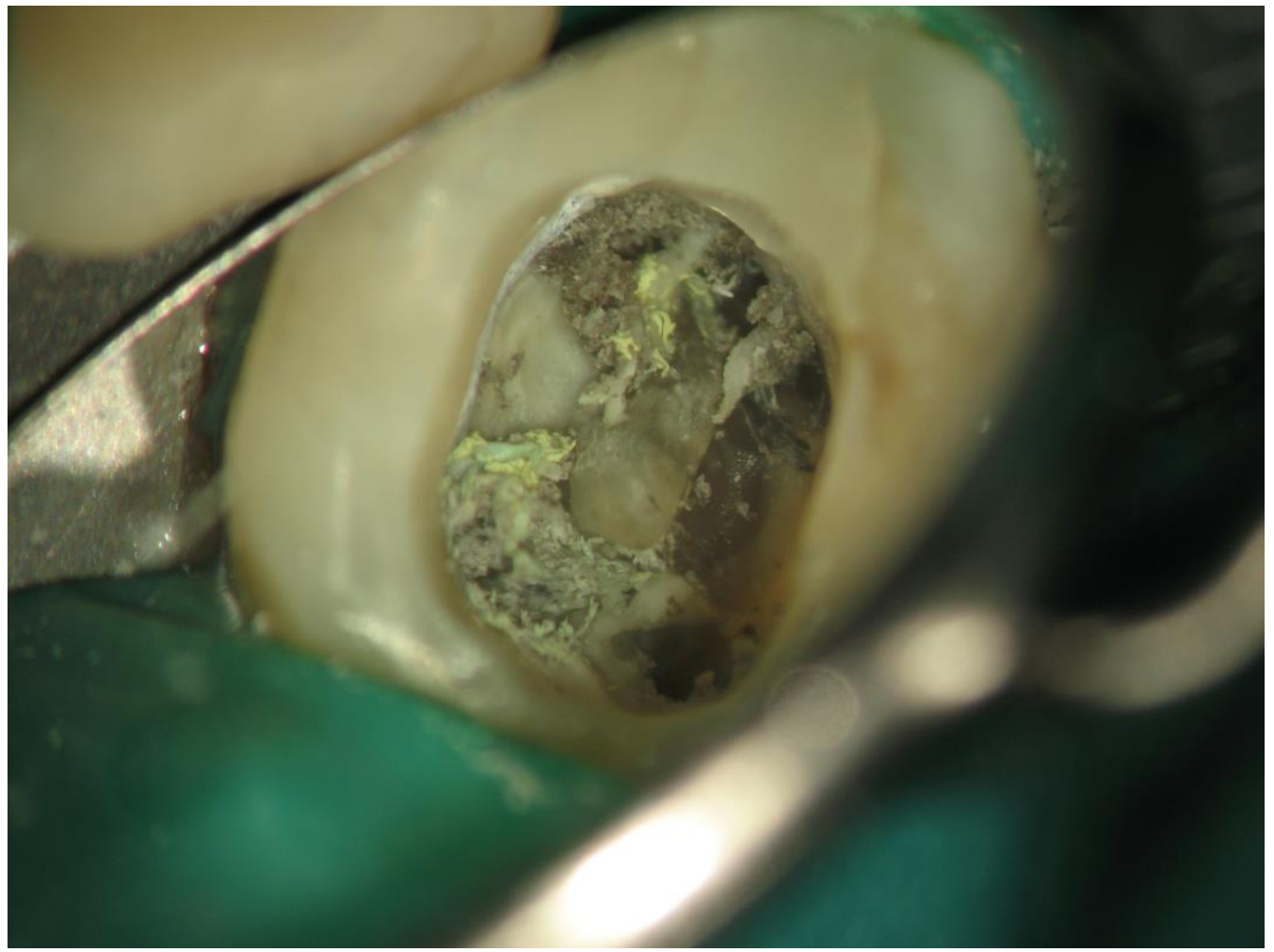

Abbildung 14: Zahn 46 intrakanaläre Aufnahme; altes Wurzelfüllmaterial (gelb) und infiziertes Gewebe erkennbar 


\subsection{Primärbehandlung (Kontrollgruppe 1)}

\subsubsection{Allgemeine Merkmale des Kollektivs}

Im Zeitraum von 2004 bis 2012 wurden in der Zahnarztpraxis Dr. Tulus insgesamt 61 Patienten beziehungsweise 91 Zähne primär endodontisch behandelt und für die vorliegende Arbeit nachuntersucht. Bis 2013 lagen röntgenologische Kontrollaufnahmen von insgesamt 66 behandelten Zähnen des Gesamtkollektivs zur Nachuntersuchung vor. Dies entspricht einer Recallrate von $72,5 \%$. Im Folgenden wird von dieser Recallgruppe ausgegangen. Die Röntgenaufnahmen zur Nachuntersuchung wurden entweder vom jeweiligen Hauszahnarzt oder in der Praxis Dr. Tulus angefertigt.

Die statistische Auswertung der Daten erfolgte nach dem Pearson-ML-Chi2-Test. Eine statistische Signifikanz wird ab einem $p$-Wert $\leq 0,05$ erreicht.

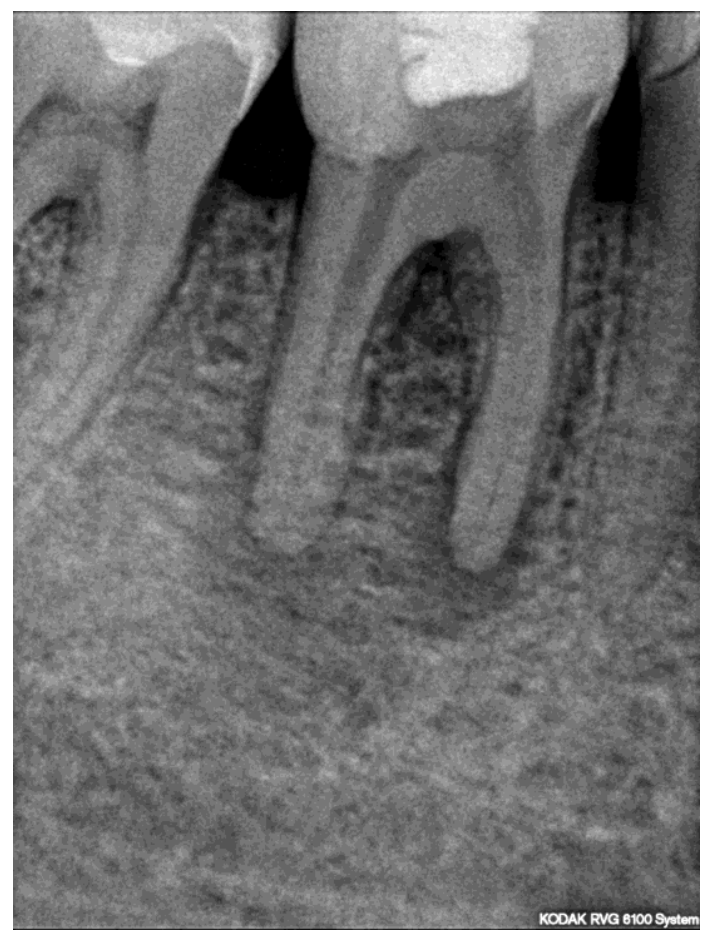

Abbildung 15: Zahn 46 initiale Aufnahme; 03.06.2009; apikale Aufhellung an beiden Wurzelspitzen erkennbar 


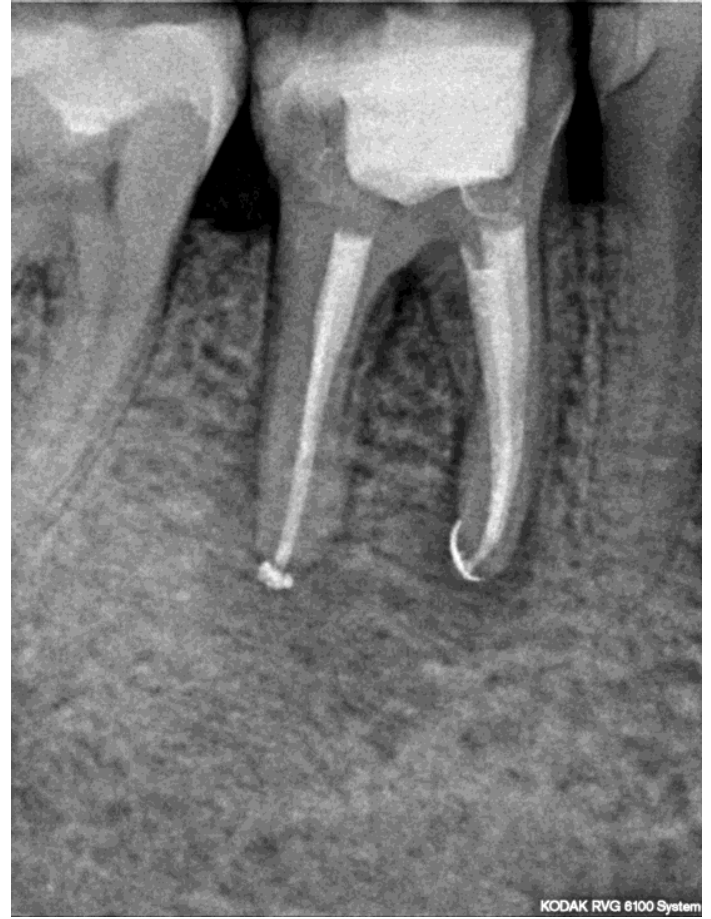

Abbildung 16: Zahn 46 Aufnahme der Wurzelfüllung; 06.09.2009; apikaler Puff an beiden Wurzelspitzen erkennbar

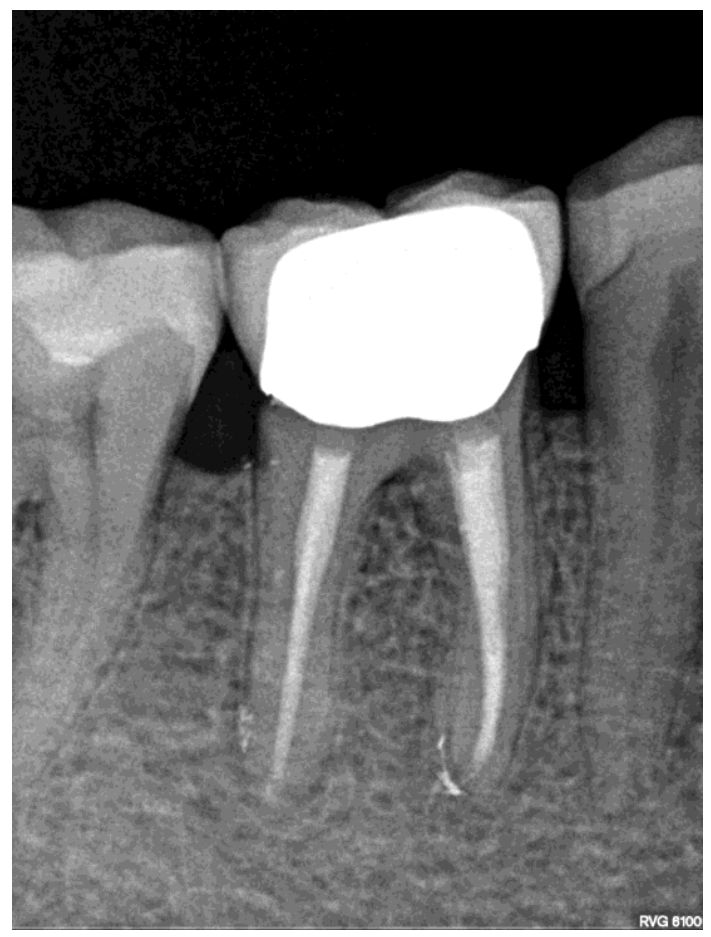

Abbildung 17: Zahn 46 Kontrollaufnahme der Wurzelfüllung; 20.04.2012; vollständige Ausheilung der apikalen Aufhellung 


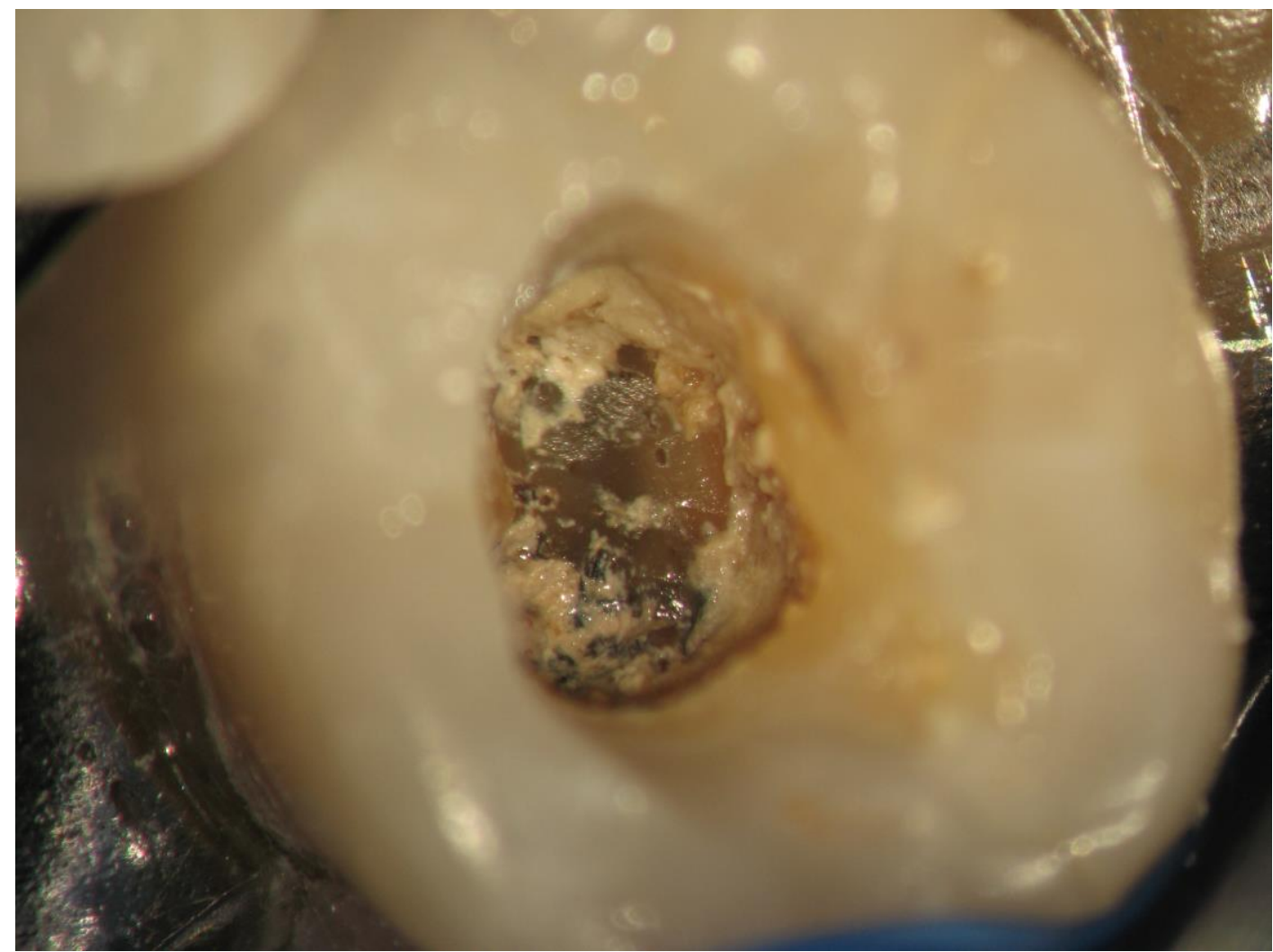

Abbildung 18: Zahn 46 intrakanaläre Aufnahme; primäre Zugangskavität; Zahnnerv devital; Kanaleingänge noch nicht dargestellt

\subsubsection{Häufigkeit der Behandlung in den einzelnen Zahngruppen der Kontrollgruppe 1}

In der Gruppe der Primärbehandlungen wurde ebenfalls die Verteilung der Behandlung auf die Zahngruppen untersucht.

Von insgesamt 66 Behandlungen wurden 7 an Frontzähnen, 18 an Prämolaren und 41 an Molaren vorgenommen. Es ist ein deutliches Übergewicht der Molaren zu erkennen. Die Erfolgsquote lag bei den Frontzähnen bei $100 \%$, bei den Prämolaren bei $61,1 \%$ und bei den Molaren bei $78,1 \%$.

Die unterschiedlichen Erfolgsquoten können jedoch aufgrund der verschiedenen Gruppenstärke nicht verglichen werden. Es wird allerdings deutlich, dass eine Primärbehandlung am häufigsten an Molaren durchgeführt wurde (Abbildung 19). 


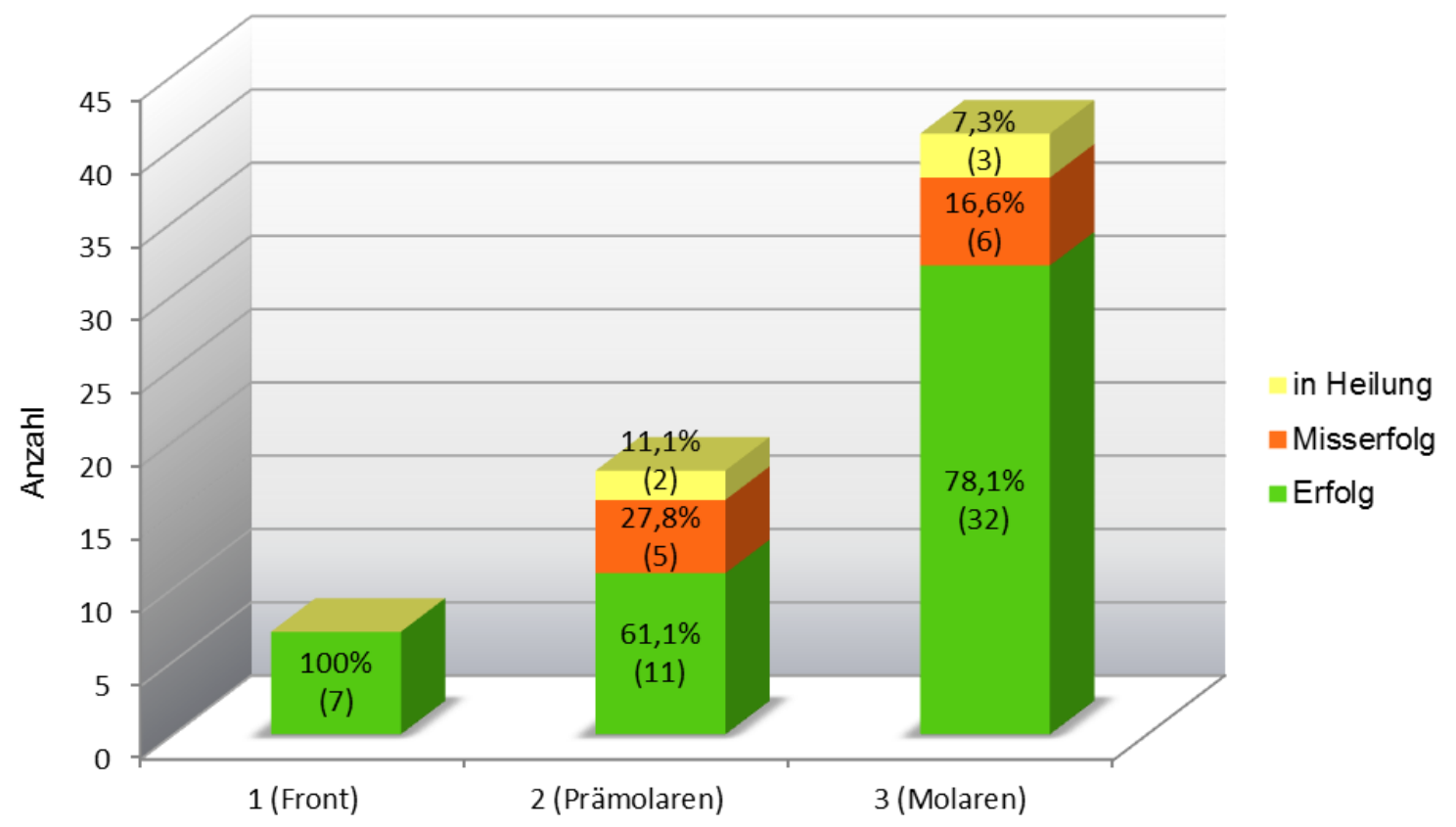

Abbildung 19: Erfolg in Abhängigkeit von der Zugehörigkeit zur Zahngruppe 


\subsubsection{Recallzeitraum der Kontrollgruppe 1 (Primärbehandlung)}

Der Recallzeitraum lag zwischen einem und 71 Monaten. Der errechnete Medianwert beträgt 28,5 Monate. Ausreißer und Extremwerte wurden bei der Errechnung nicht beachtet. 50\% der der Fälle hatten einen kürzeren und $50 \%$ der Fälle einen längeren Recallzeitraum als 28,5 Monate. Abbildung 20 zeigt in einem Boxplot den Recallzeitraum in Monaten.

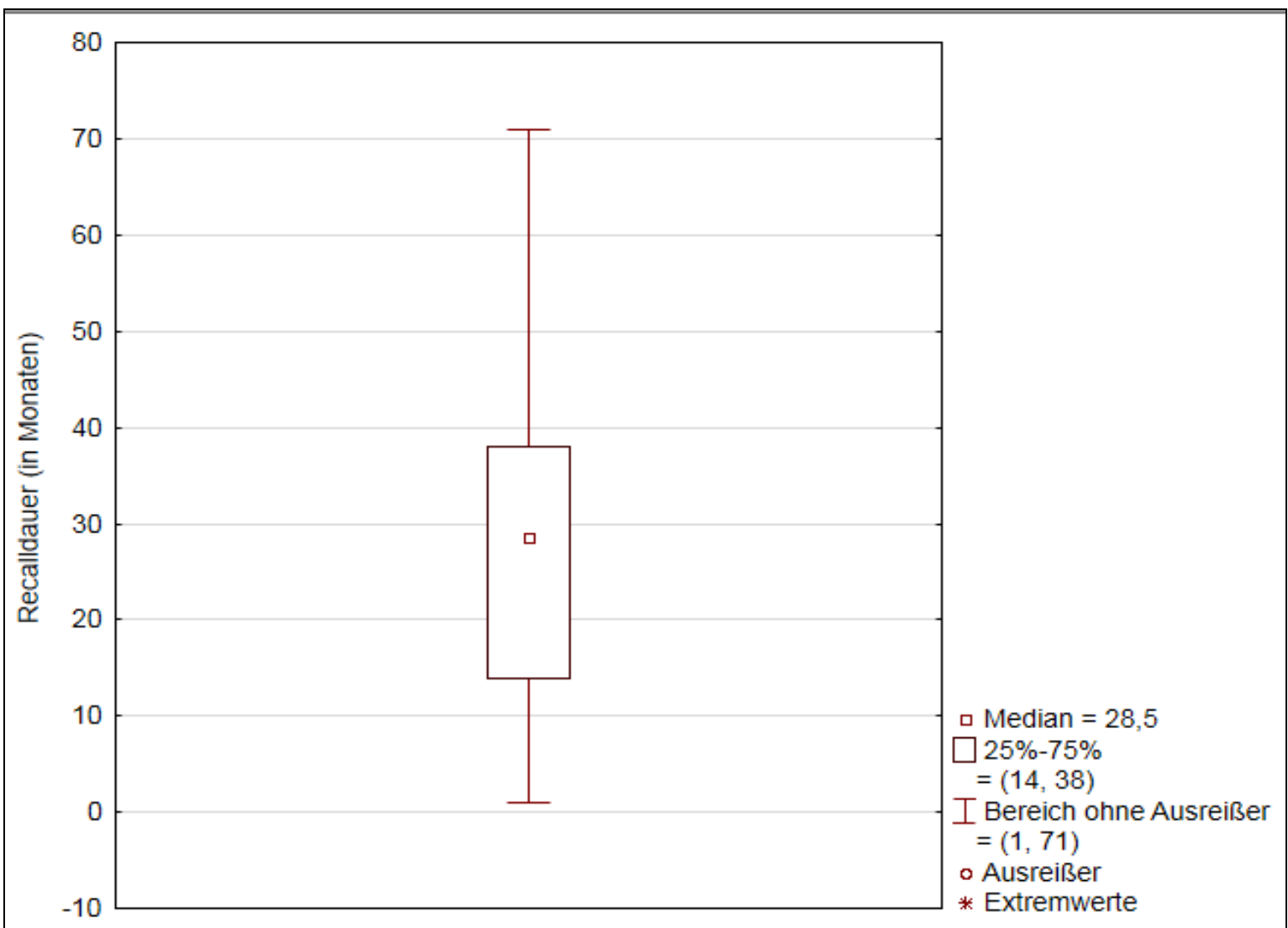

Abbildung 20: Recalldauer der Kontrollgruppe 1 in Monaten

\subsubsection{Präoperativer Befund des Periapex (Parodontitis apicalis)}

Anhand von Röntgenaufnahmen wurde untersucht, ob präoperativ eine Parodontitis apicalis diagnostiziert werden konnte. 32 von 66 Zähnen wiesen röntgenologisch eine apikale Aufhellung auf. Die durchgeführte Wurzelkanalbehandlung führte in 59,4\% der Fälle zum Erfolg $(n=19), 25 \%(n=8)$ konnten nicht erfolgreich therapiert werden und mussten als Misserfolg gewertet werden. 15,6\% 
$(\mathrm{n}=5)$ der Zähne zeigten zum Zeitpunkt der Nachuntersuchung eine Verkleinerung der apikalen Läsion und befanden sich in Heilung.

34 Zähne wiesen hingegen röntgenologisch keine apikale Läsion auf. Es konnte in 91,2\% der Fälle ein Erfolg erzielt werden. Lediglich 3 Fälle (9\%) mussten als Misserfolg gewertet werden (Abbildung 21).

Nach der statistischen Auswertung mit dem Pearson-ML-Chi²-Test konnte ein signifikanter Unterschied zwischen Zähnen mit und ohne präoperativer Parodontitis apicalis ermittelt werden. Der Erfolg einer Primärbehandlung hängt demnach von der periapikalen Ausgangssituation ab $(p<0,01)$. In Abbildung 9 wird der Erfolg in Abhängigkeit von der periapikalen Ausgangssituation.

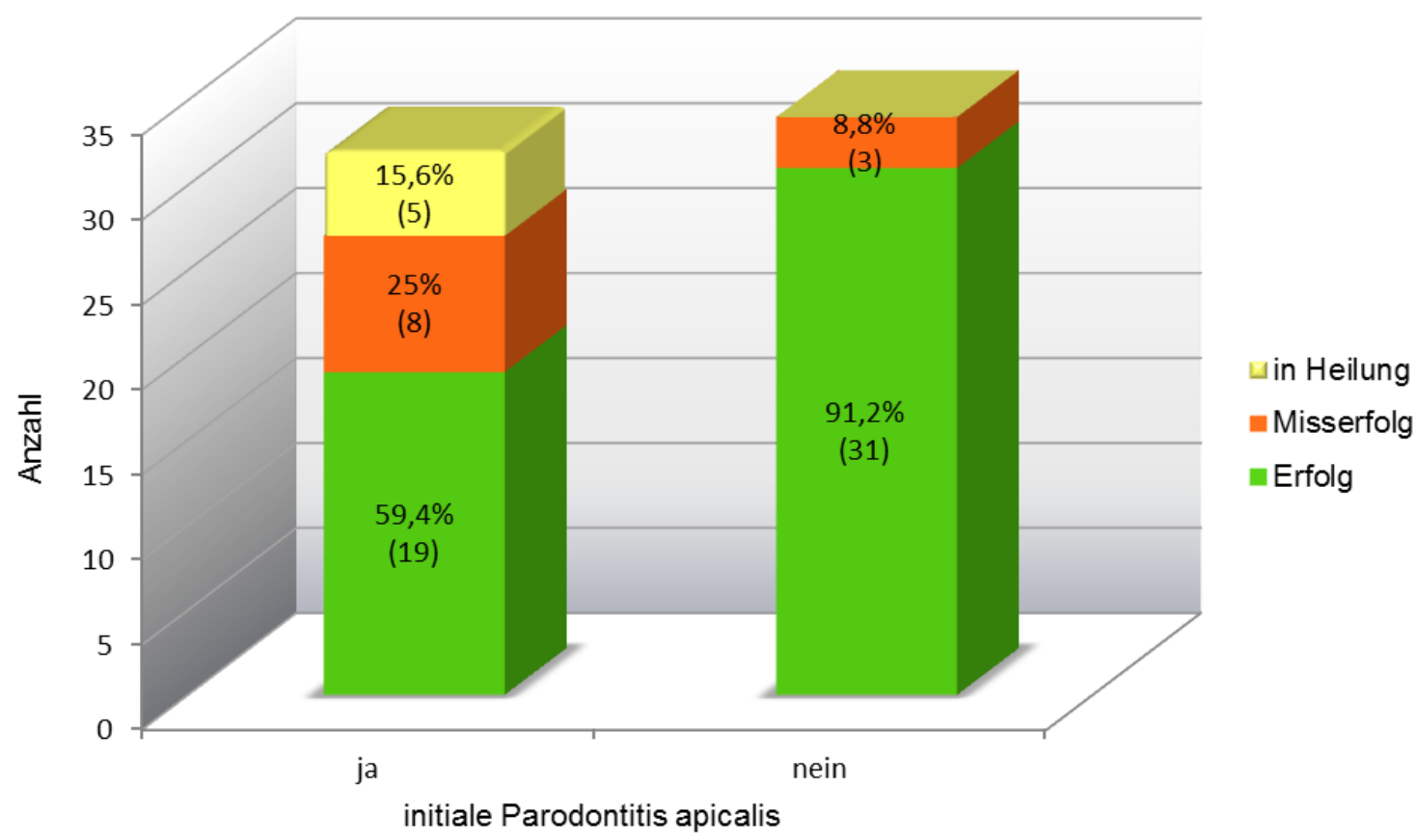

Abbildung 21: Erfolg in Abhängigkeit von der Ausgangssituation des Periapex (Parodontitis apicalis)

\subsubsection{Die medikamentöse Einlage}

In der Gruppe der primär endodontisch behandelten Zähne wurde ebenfalls untersucht, ob eine medikamentöse Einlage eingebracht wurde und ob diese einen Einfluss auf das Erfolgsergebnis hat. In 26 von 66 Fällen wurde eine Einlage mit Kalziumhydroxid eingebracht und der Zahn in mehreren Sitzungen therapiert. Dieses Vorgehen führte in 76,9\% der Fälle zum Erfolg. 11,5\% mussten als Misserfolg gewertet werden und $11,5 \%$ befanden sich in Heilung. 
In 40 von 66 Fällen wurde keine medikamentöse Einlage eingebracht und der Zahn in einer Therapiesitzung behandelt. Dies führte in $75 \%$ der Fälle $(n=30)$ zum Erfolg der Therapie. 5\% der Zähne $(n=2)$ befanden sich zum Zeitpunkt der Nachuntersuchung in Heilung und 20\% ( $n=8)$ mussten als Misserfolg gewertet werden (Abbildung 22).

Die Ergebnisse zeigen, dass eine medikamentöse Einlage mit Kalziumhydroxid keinen wesentlichen Einfluss auf den Therapieausgang hat. Sowohl die einzeitige als auch die zweizeitige Therapie führten zu einem ähnlichen Erfolgsergebnis. Die statistische Auswertung mittels Pearson-ML-Chi²-Test ergab $p=0,45$.

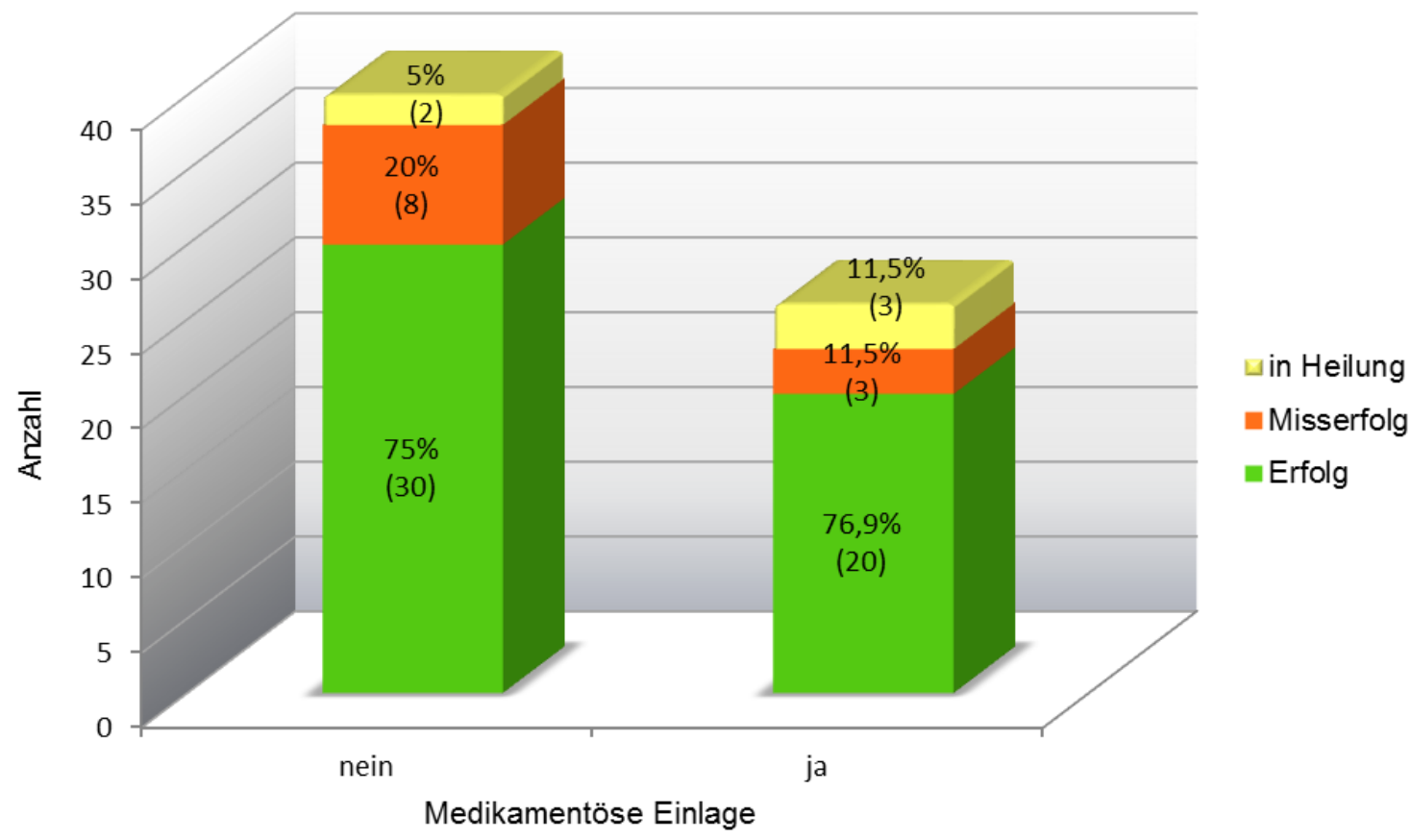

Abbildung 22: Erfolg in Abhängigkeit von der medikamentösen Einlage

\subsubsection{Erfolgsabhängigkeit der Behandlung mit medikamentöser} Einlage vom präoperativen Befund des Periapex (Parodontitis apicalis)

Es wurde untersucht, ob der Erfolg einer Behandlung mit oder ohne medikamentöser Einlage vom präoperativen Befund des Periapex abhängig ist. Von insgesamt 66 behandelten Zähnen konnten 50 als Erfolg eingestuft werden. $44 \%(n=22)$ der 50 Fälle wurden einzeitig therapiert. Es lag keine präoperative Parodontitis apicalis vor. In $22 \%(n=11)$ der Fälle, die erfolgreich therapiert werden 
konnten, lag präoperativ eine Parodontitis apicalis vor. Diese Zähne wurden zweizeitig mit einer medikamentösen Einlage behandelt. 11 von 66 Fällen wurden als Misserfolg gewertet. 45,5\% ( $n=5)$ der Fälle wiesen laut Röntgenbild eine Parodontitis apicalis auf und wurden einzeitig ohne Kalziumhydroxideinlage behandelt (Tabelle 2).

\begin{tabular}{|c|c|c|c|c|c|c|}
\hline & $\begin{array}{l}\text { Parodontitis } \\
\text { apicalis }\end{array}$ & $\begin{array}{l}\text { medikamentöse } \\
\text { Einlage }\end{array}$ & Erfolg & Misserfolg & $\begin{array}{c}\text { in } \\
\text { Heilung }\end{array}$ & gesamt \\
\hline Anzahl & ja & nein & 8 & 5 & 2 & 15 \\
\hline Anzahl & ja & ja & 11 & 3 & 3 & 17 \\
\hline gesamt Gruppe 1 & & & & & & 32 \\
\hline Anzahl & nein & nein & 22 & 3 & - & 25 \\
\hline Anzahl & nein & ja & 9 & - & - & 9 \\
\hline gesamt Gruppe 2 & & & & & & 34 \\
\hline gesamt & & & 50 & 11 & 5 & 66 \\
\hline
\end{tabular}

Tabelle 2: Erfolg in Abhängigkeit von einer medikamentösen Einlage und vom präoperativen Befund des Periapex (Parodontitis apicalis)

\subsubsection{Erfolgsquote}

In der Gruppe der endodontischen Erstbehandlung konnte eine Erfolgsquote von $75,8 \%(n=50)$ erzielt werden. Weitere $7,6 \%(n=5)$ der Fälle befanden sich zum Zeitpunkt der Nachuntersuchung in Heilung. Als nicht erfolgreich therapiert mussten $16,7 \%$ der Behandlungen ( $n=11$ ) eingestuft werden. 


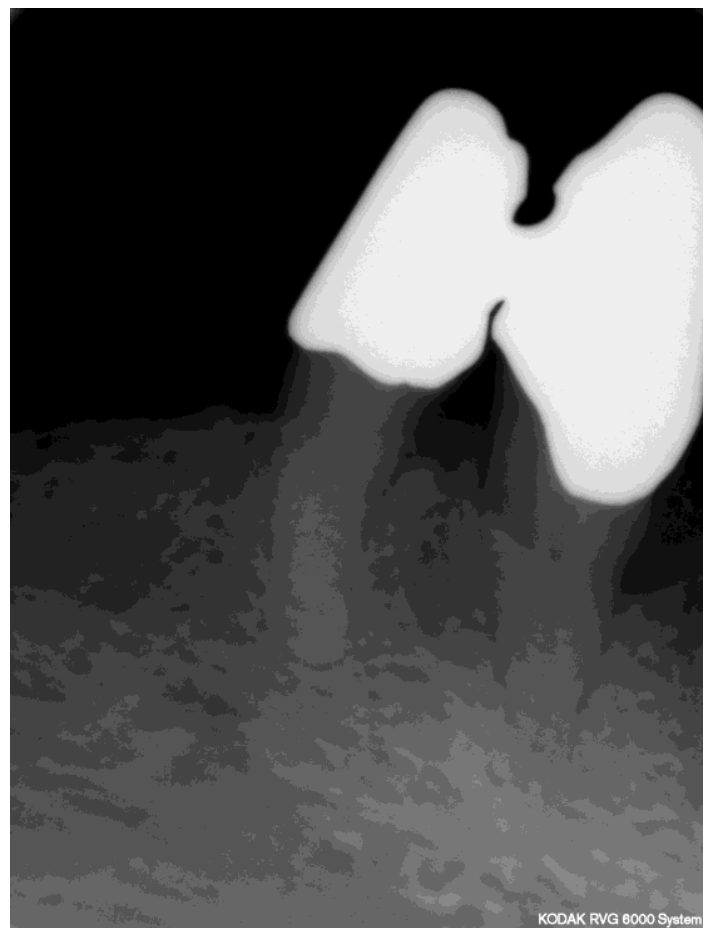

Abbildung 23: Zahn 44 initiale Aufnahme; 23.03.2009, keine apikale Aufhellung erkennbar

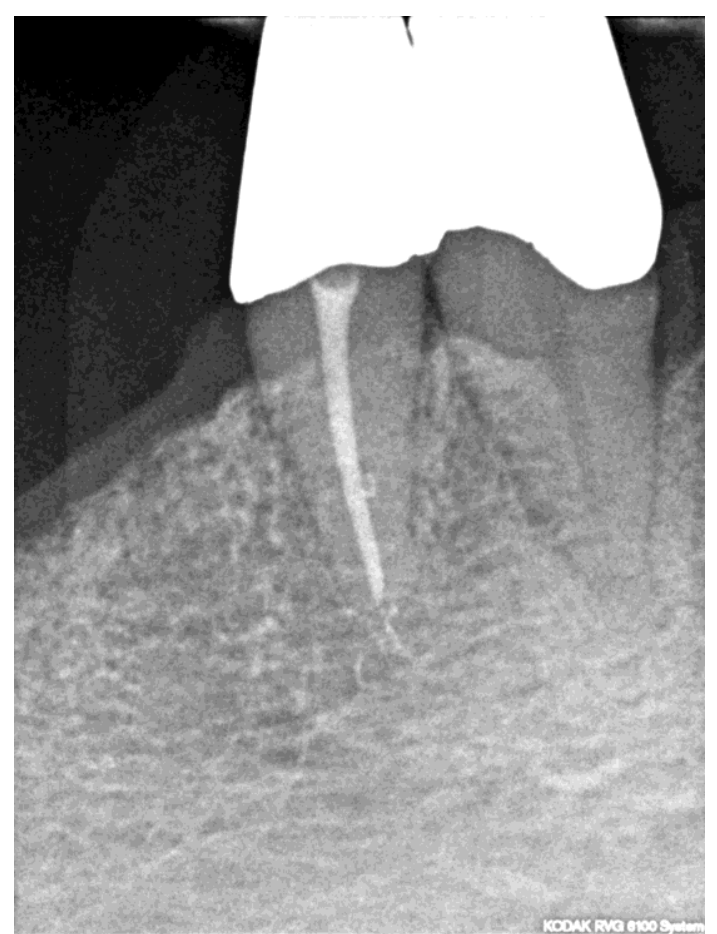

Abbildung 24: Zahn 44 Aufnahme der Wurzelfüllung; 27.04.2009 


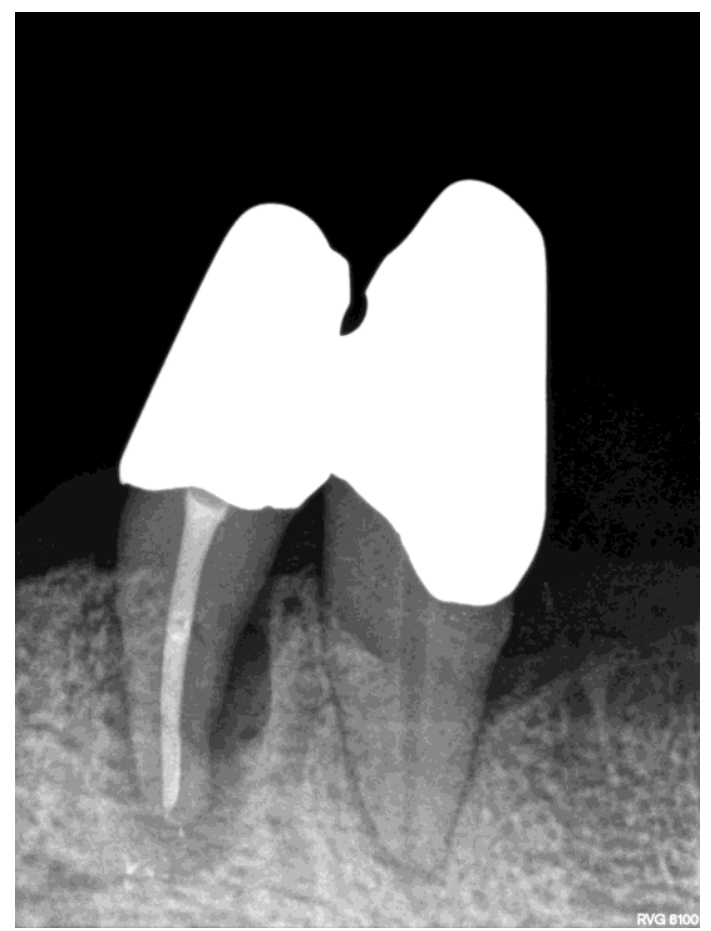

Abbildung 25: Zahn 44 Kontrollaufnahme der Wurzelfüllung; 15.05.2012; Recall nach 3 Jahren; deutliche apikale Aufhellung erkennbar

\subsection{Revisionsbehandlung (Kontrollgruppe 2)}

\subsubsection{Allgemeine Merkmale des Kollektivs}

Im Zeitraum von 2005 bis 2012 wurden in der Zahnarztpraxis Dr. Tulus insgesamt 65 Patienten beziehungsweise 86 Zähne nach nicht erfolgreicher orthograder Wurzelkanalbehandlung endodontisch revidiert. Bis 2013 lagen röntgenologische Kontrollaufnahmen von insgesamt 49 behandelten Zähnen des Gesamtkollektivs zur Nachuntersuchung vor. Dies entspricht einer Recallrate von 57\%. Im Folgenden wird von dieser Recallgruppe ausgegangen. Die Röntgenaufnahmen zur Nachuntersuchung wurden entweder vom jeweiligen Hauszahnarzt oder in der Praxis Dr. Tulus angefertigt.

Die statistische Auswertung der Daten erfolgte mit dem Pearson-ML-Chi2-Test. Eine statistische Signifikanz wird ab einem $p$-Wert $\leq 0,05$ erreicht. 


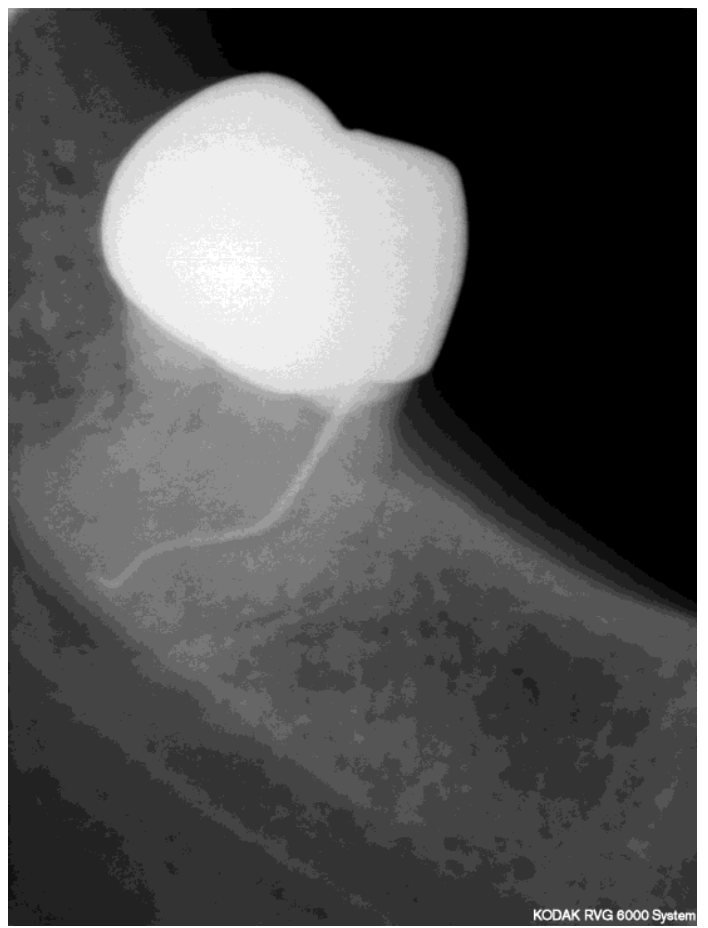

Abbildung 26: Zahn 48 initiale Aufnahme; 08.11.2007; insuffiziente Wurzelfüllung erkennbar

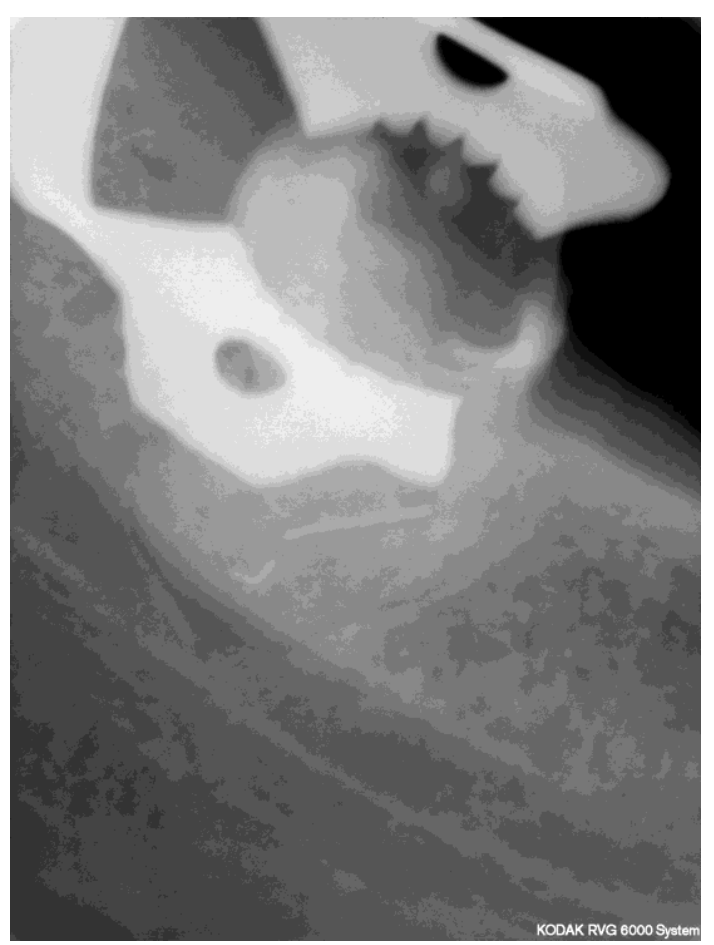

Abbildung 27: Zahn 48 Aufnahme des frakturierten Instruments; 08.11.2007 


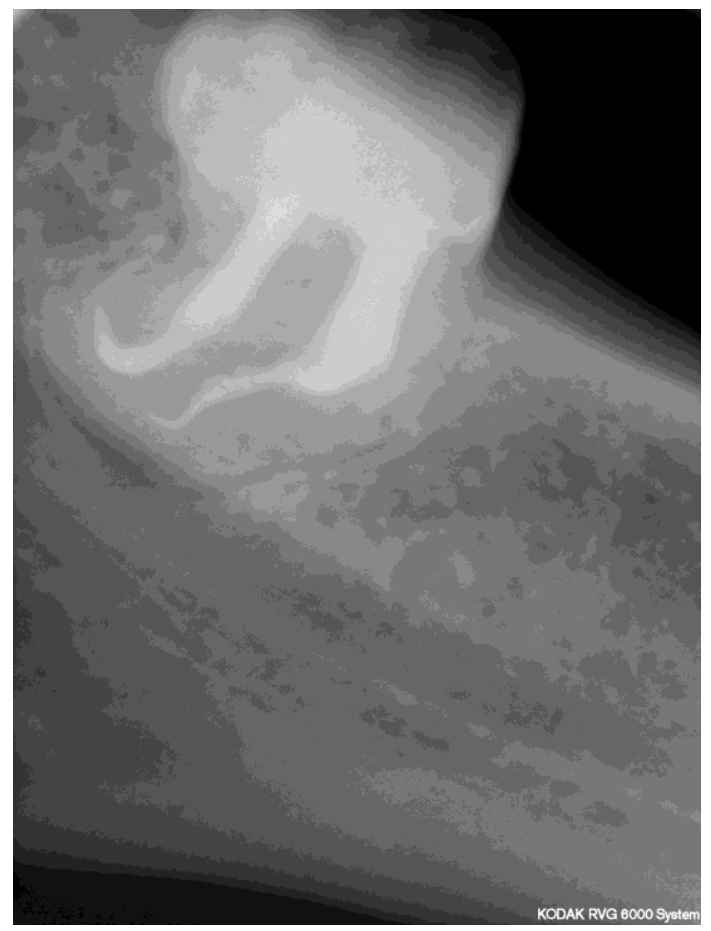

Abbildung 28: Zahn 48 Aufnahme der Wurzelfüllung; 20.11.2007; deutliche Krümmung der Wurzelkanäle erkennbar

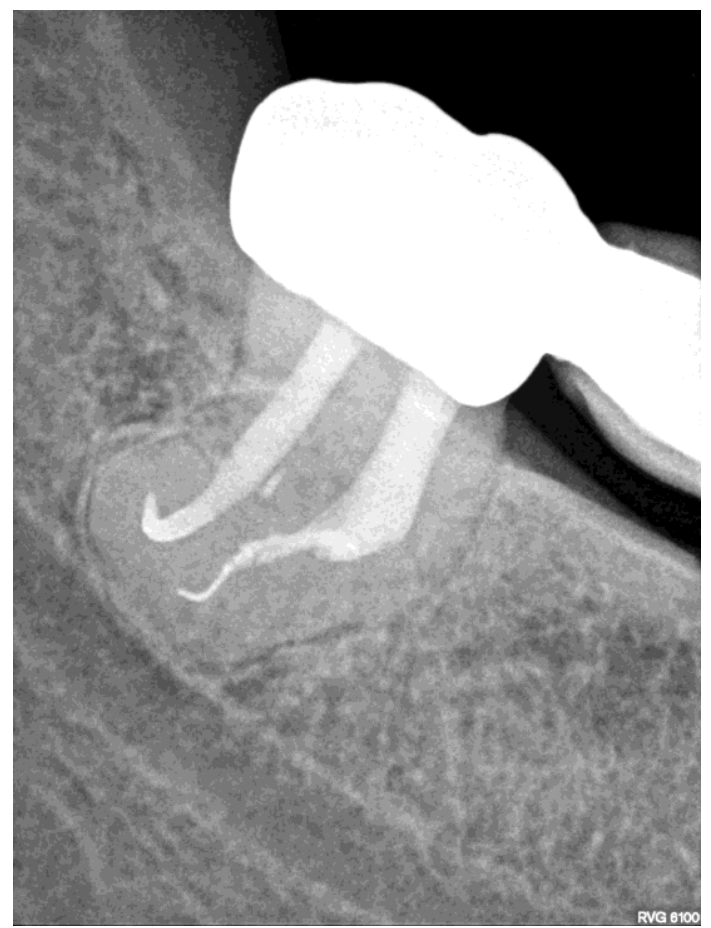

Abbildung 29: Zahn 48 Kontrollaufnahme der Wurzelfüllung; 22.10.2009; Recall nach 23 Monaten 


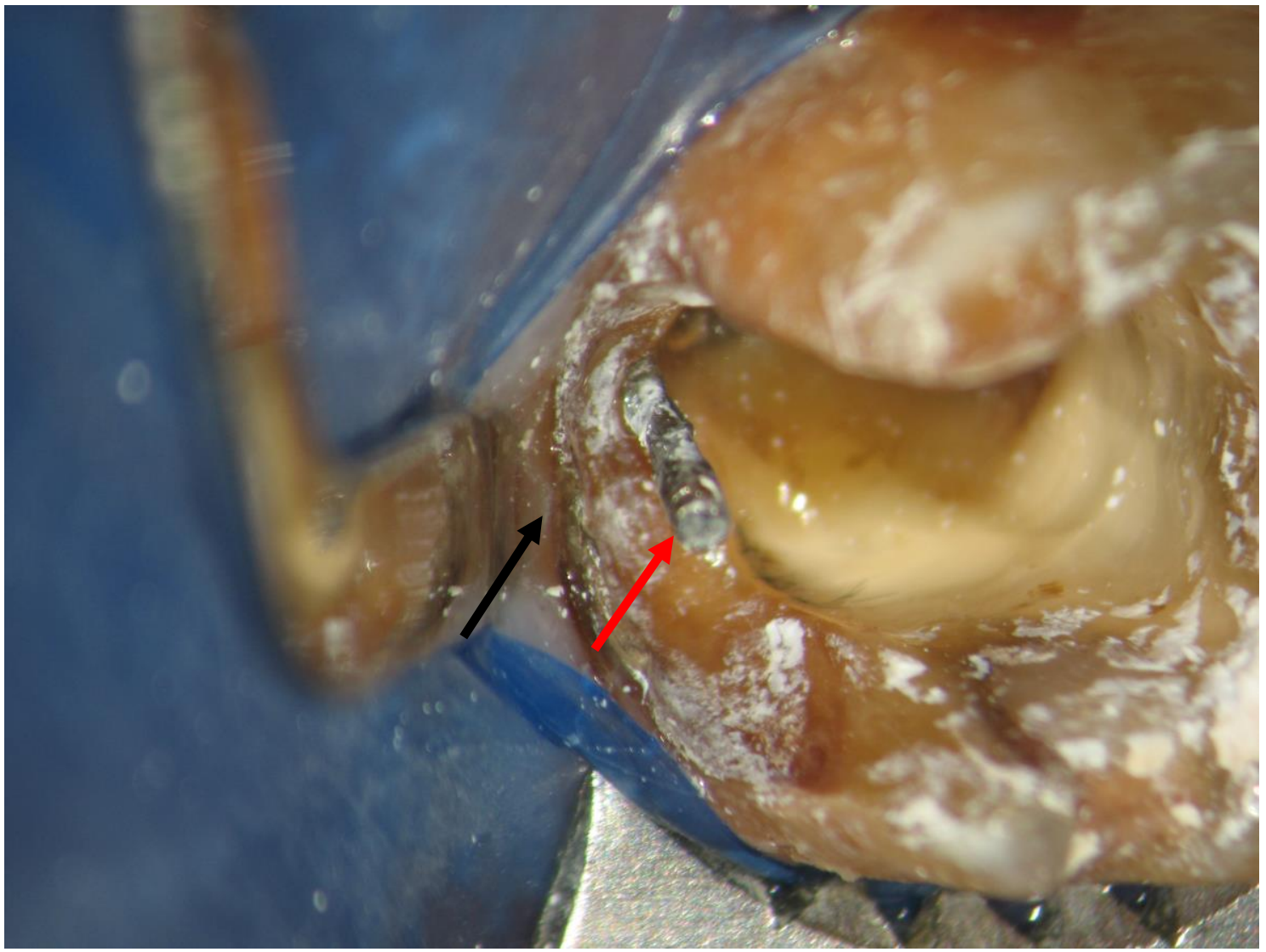

Abbildung 30: Zahn 48 intrakanaläre Aufnahme; Datum; ausgeprägter paragingivaler Defekt (schwarzer Pfeil) und Silberstift erkennbar (roter Pfeil)

\subsubsection{Häufigkeit der Behandlung in den einzelnen Zahngruppen}

In der Kontrollgruppe 2 wurden die Revisionsbehandlungen ebenfalls den jeweiligen Zahngruppen 1 (Front), 2 (Prämolaren), 3 (Molaren) zugeordnet und die Erfolgsquote untersucht. Es wird deutlich, dass eine Revisionsbehandlung an Molaren deutlich häufiger vorgenommen wurde als an Inzisivi oder Prämolaren. Von insgesamt 49 revidierten Zähnen waren 37 Molaren. 78,4\% der Molaren konnten erfolgreich therapiert werden. Von insgesamt 49 Revisionsbehandlungen wurden 2 an Frontzähnen, 10 an Prämolaren und 37 an Molaren vorgenommen. Die Erfolgsquote lag bei den Frontzähnen bei 50\%, bei den Prämolaren bei $80 \%$ und bei den Molaren bei 78,4\%.

Die unterschiedlichen Erfolgsquoten können jedoch aufgrund der verschiedenen Gruppenstärke nicht verglichen werden. In Abbildung 31 wird der Erfolg in Abhängigkeit von der Zugehörigkeit zur Zahngruppe graphisch dargestellt. 


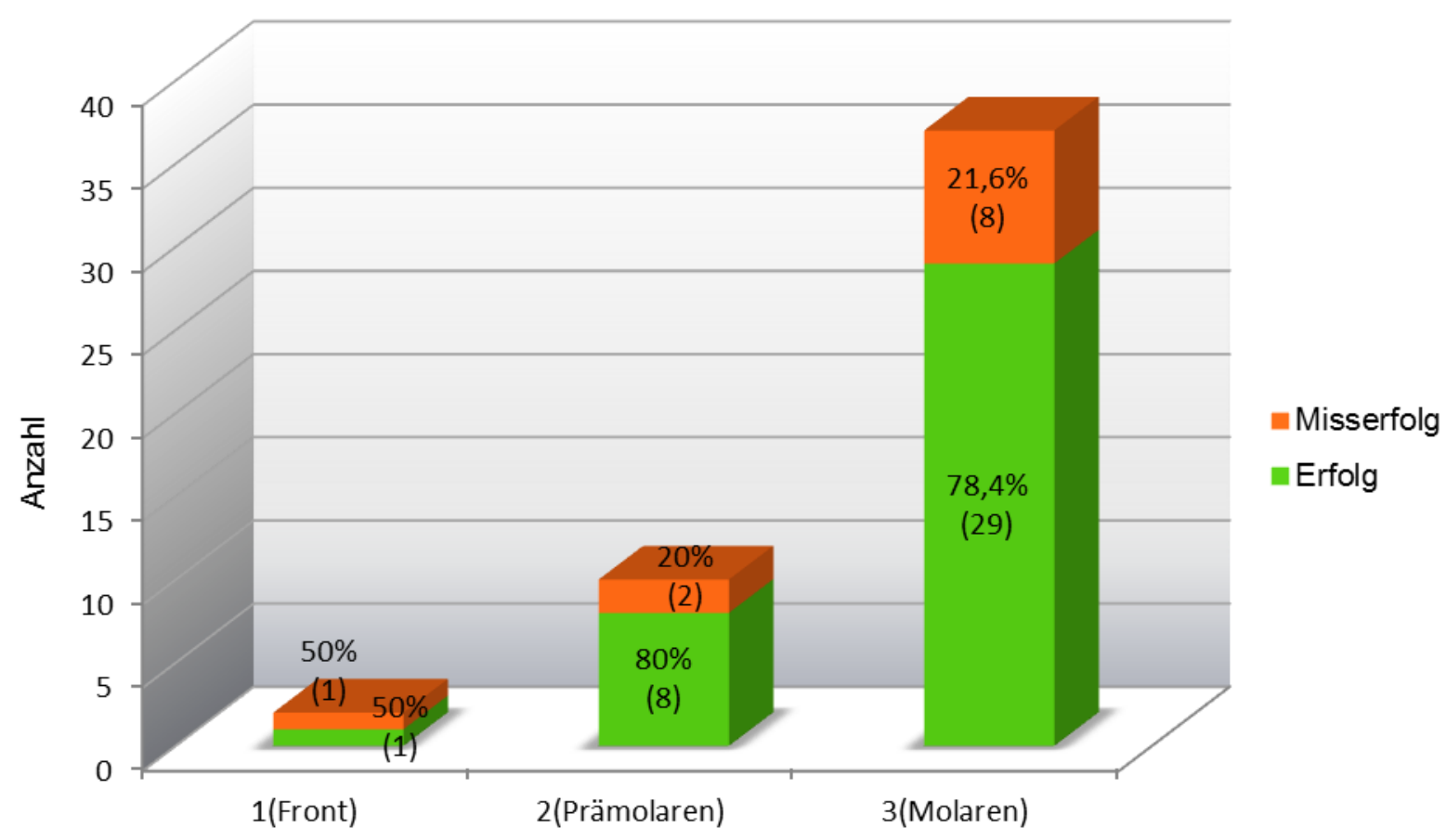

Abbildung 31: Erfolg in Abhängigkeit von der Zugehörigkeit zur Zahngruppe

\subsubsection{Recallzeitraum der Kontrollgruppe 2 (Revisionsbehandlung)}

Der Recallzeitraum lag zwischen 3 und 60 Monaten. Der errechnete Medianwert beträgt 23 Monate. Ausreißer und Extremwerte wurden bei der Errechnung nicht beachtet. 50\% der Fälle hatten einen kürzeren und 50\% der Fälle einen längeren Recallzeitraum als 23 Monate. Abbildung 32 zeigt in einem Boxplot den Recallzeitraum in Monaten. 


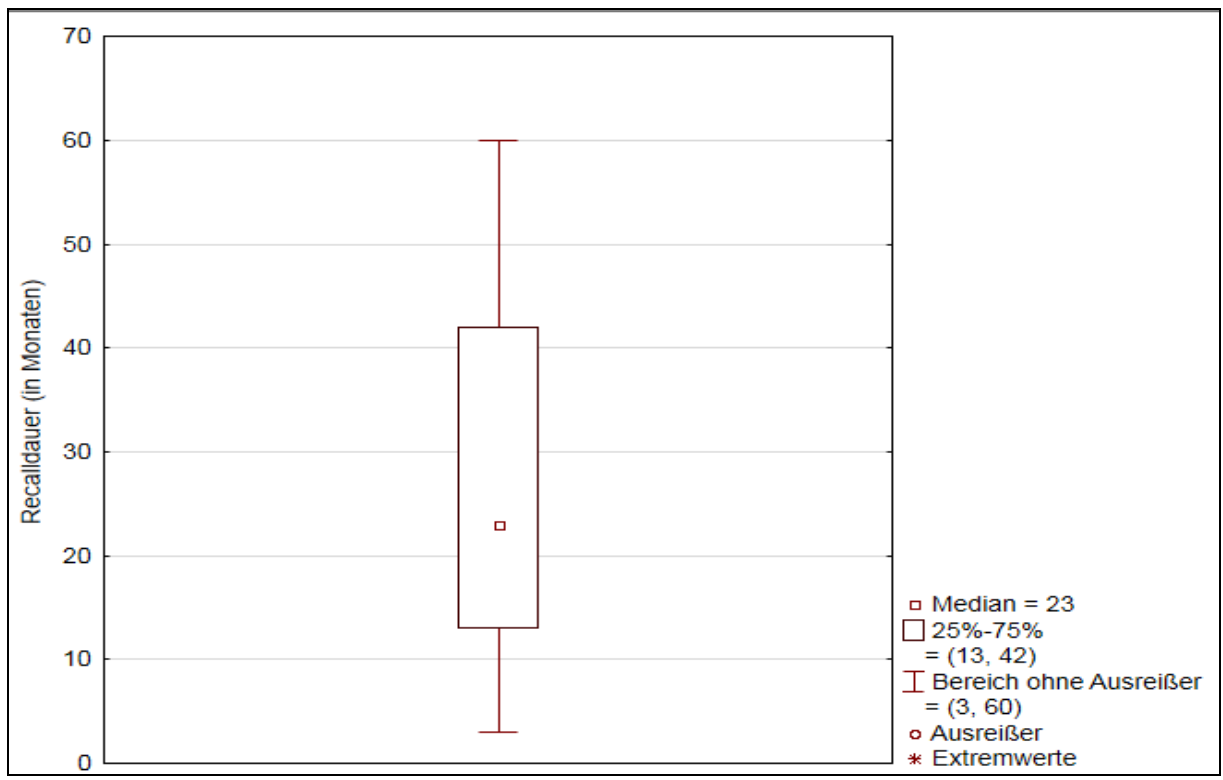

Abbildung 32: Recalldauer der Kontrollgruppe 2 in Monaten

\subsubsection{Präoperativer Befund des Periapex (Parodontitis apicalis)}

Anhand von Röntgenaufnahmen wurde untersucht, ob initial eine Parodontitis apicalis bestand. 30 von 49 Zähnen wiesen röntgenologisch eine apikale Aufhellung auf. Die durchgeführte Revisionsbehandlung führte in 66,7\% der Fälle mit initialer Parodontitis apicalis zum Erfolg $(n=20)$. 33,3\% $(n=10)$ konnten nicht erfolgreich therapiert werden und mussten als Misserfolg gewertet werden.

19 Zähne wiesen hingegen röntgenologisch keine apikale Läsion auf. Es konnte in 94,7\% der Fälle ein Erfolg erzielt werden. Lediglich ein Fall (5,26\%) mussten als Misserfolg gewertet werden.

Nach der statistischen Auswertung mit dem Pearson-ML-Chi²-Test konnte ein signifikanter Unterschied des Erfolgsergebnisses zwischen Zähnen mit und ohne präoperativer Parodontitis apicalis ermittelt werden $(p=0,02)$. Der Erfolg einer Revisionsbehandlung hängt demnach von der apikalen Ausgangssituation ab. Abbildung 33 zeigt die Erfolgsquote in Abhängigkeit von einer initialen Parodontitis apicalis. 


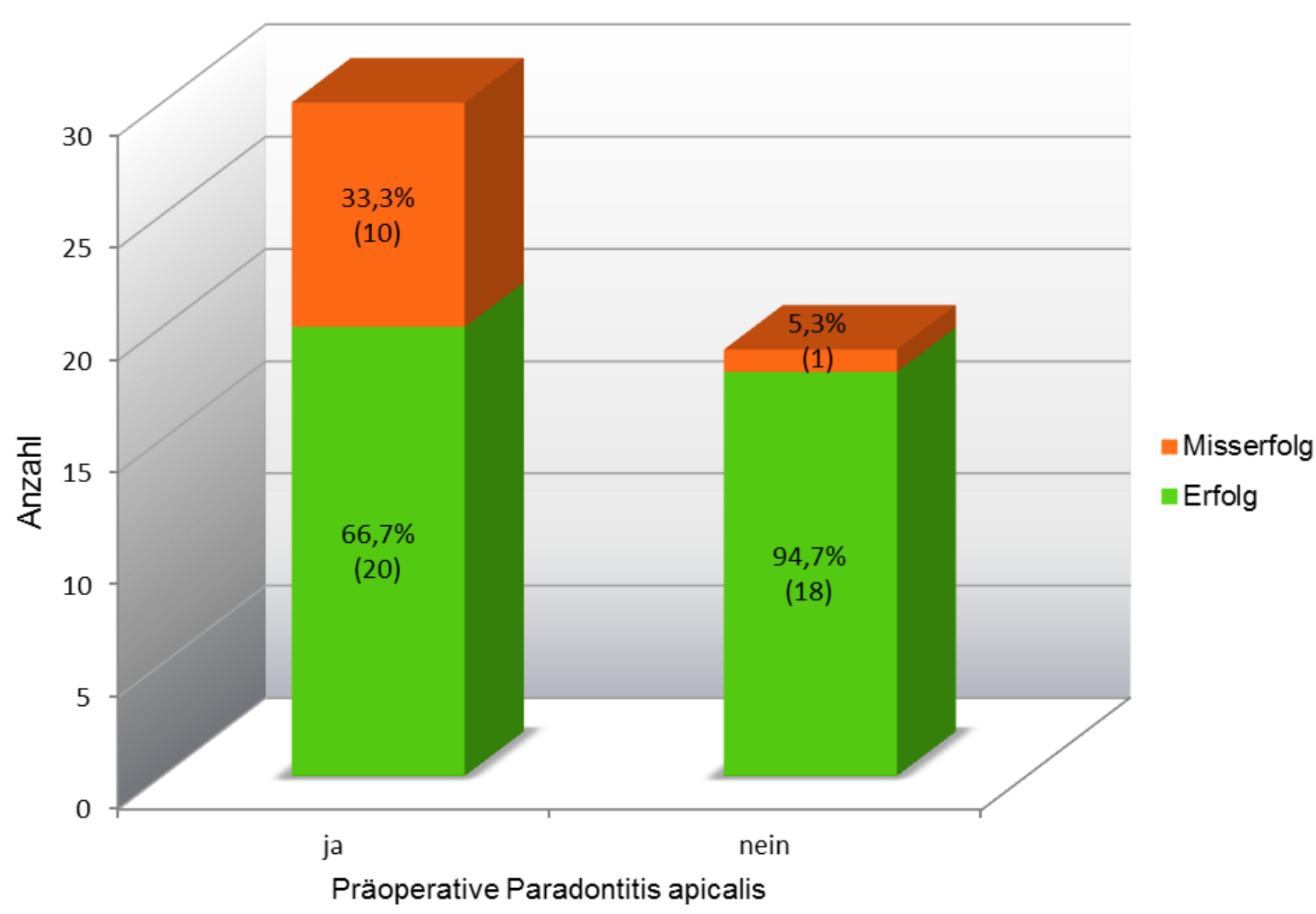

Abbildung 33: Erfolg in Abhängigkeit von der Ausgangsituation des Periapex (Parodontitis apicalis)

\subsubsection{Die medikamentöse Einlage}

In der Gruppe der orthograd revidierten Zähne wurde ebenfalls untersucht, ob eine medikamentöse Einlage eingebracht wurde und ob dieses Vorgehen einen Einfluss auf das Erfolgsergebnis hat. In 20 von 46 Fällen wurde eine Einlage mit Kalziumhydroxid eingebracht und der Zahn in mehreren Sitzungen therapiert. Dieses Vorgehen führte in 80\% $(n=16)$ der Fälle zum Erfolg. 20\% $(n=4)$ der Fälle mussten als Misserfolg gewertet werden.

In 26 von 46 Fällen wurde keine medikamentöse Einlage eingebracht und der Zahn in einer Therapiesitzung behandelt. Dies führte in $73 \%$ der Fälle $(n=19)$ zum Erfolg der Therapie. 27\% der Zähne ( $n=7)$ mussten zum Zeitpunkt der Nachuntersuchung als Misserfolg gewertet werden.

Die statistischen Auswertung mittels Pearson-ML-Chi'-Test ergab $p=0,58$. Die Ergebnisse zeigen, dass eine medikamentöse Einlage mit Kalziumhydroxid keinen wesentlichen Einfluss auf den Therapieausgang einer Revisionsbehandlung hat. Sowohl die einzeitige als auch die zweizeitige Therapie führten zu einem 
ähnlichen Erfolgsergebnis. Abbildung 34 zeigt den Behandlungserfolg in Abhängigkeit von einer medikamentösen Einlage.

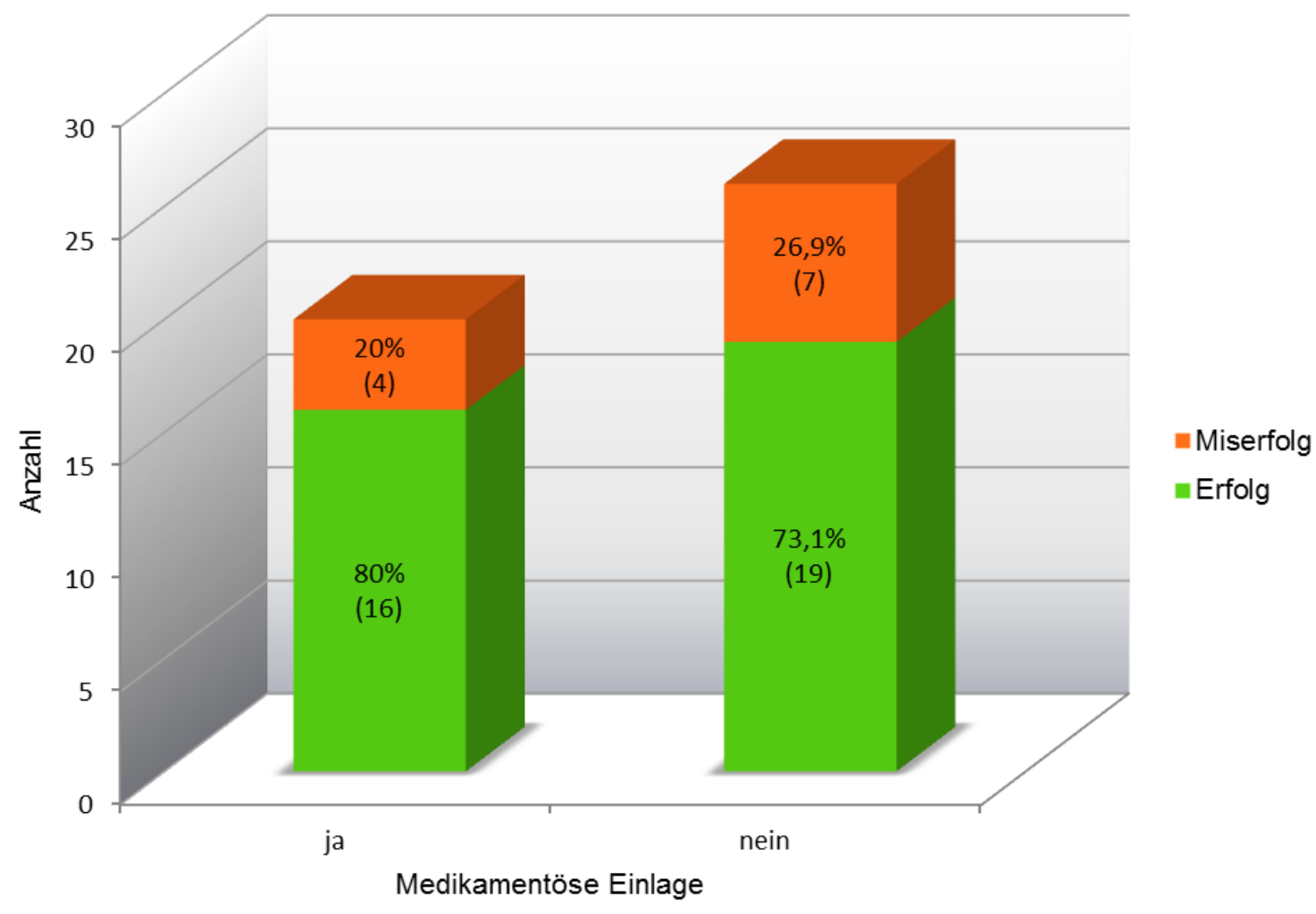

Abbildung 34: Erfolg in Abhängigkeit von der medikamentösen Einlage

\subsubsection{Erfolgsabhängigkeit der Behandlung mit medikamentöser Einlage vom präoperativen Befund des Periapex (Parodontitis apicalis)}

Es wurde untersucht, ob der Behandlungserfolg mit oder ohne medikamentöse Einlage vom präoperativen Befund des Periapex abhängig ist. Da die jeweiligen Gruppen jedoch eine unterschiedliche Fallzahl aufweisen (28 Fälle mit präoperativer Parodontitis apicalis und nur 18 Fälle ohne), ist ein direkter Vergleich nicht möglich. Bei der prozentualen Verteilung der Misserfolgsfälle zeichnet sich eine Tendenz ab. 54,6\% $(n=6)$ der 11 nicht erfolgreich therapierten Fälle hatten präoperativ eine Parodontitis apicalis und wurden einzeitig ohne medikamentöse Einlage behandelt (Tabelle 3). 


\begin{tabular}{|c|c|c|c|c|c|}
\hline & $\begin{array}{c}\text { Parodontitis } \\
\text { apicalis }\end{array}$ & $\begin{array}{c}\text { medikamentöse } \\
\text { Einlage }\end{array}$ & Erfolg & Misserfolg & gesamt \\
\hline Anzahl & ja & ja & 10 & 4 & 14 \\
\hline Anzahl & ja & nein & 8 & 6 & 14 \\
\hline gesamt Gruppe 1 & & & & & 28 \\
\hline Anzahl & nein & ja & 6 & 0 & 6 \\
\hline Anzahl & nein & nein & 11 & 1 & 12 \\
\hline gesamt Gruppe 2 & & & & & 18 \\
\hline Gesamt & & & 35 & 11 & 46 \\
\hline
\end{tabular}

Tabelle 3: Erfolg in Abhängigkeit von einer medikamentösen Einlage und dem präoperativen Befund des Periapex (Parodontitis apicalis)

\subsubsection{Erfolgsquote}

In der Gruppe der orthograden Revisionsbehandlung nach nicht erfolgreicher Primärbehandlung konnte eine Erfolgsquote von $77,6 \%(n=38)$ erzielt werden. Als nicht erfolgreich therapiert mussten $22,5 \%$ der Behandlungen $(n=11)$ eingestuft werden.

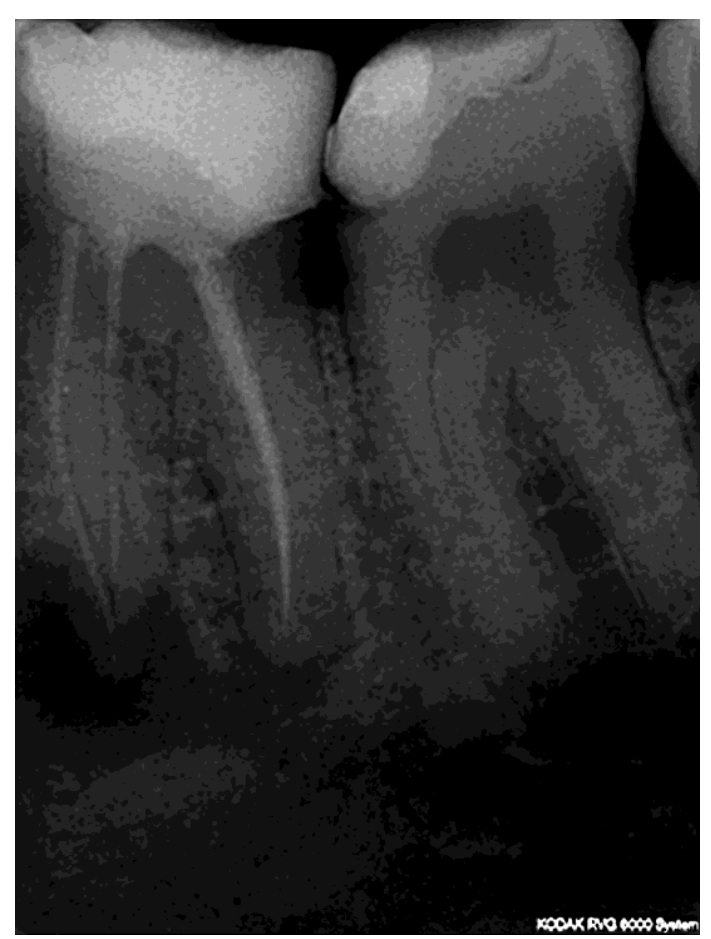

Abbildung 35: Zahn 36 initiale Aufnahme; 08.04.2009; insuffiziente Wurzelfüllung und apikale Aufhellung an der mesialen Wurzelspitze erkennbar 


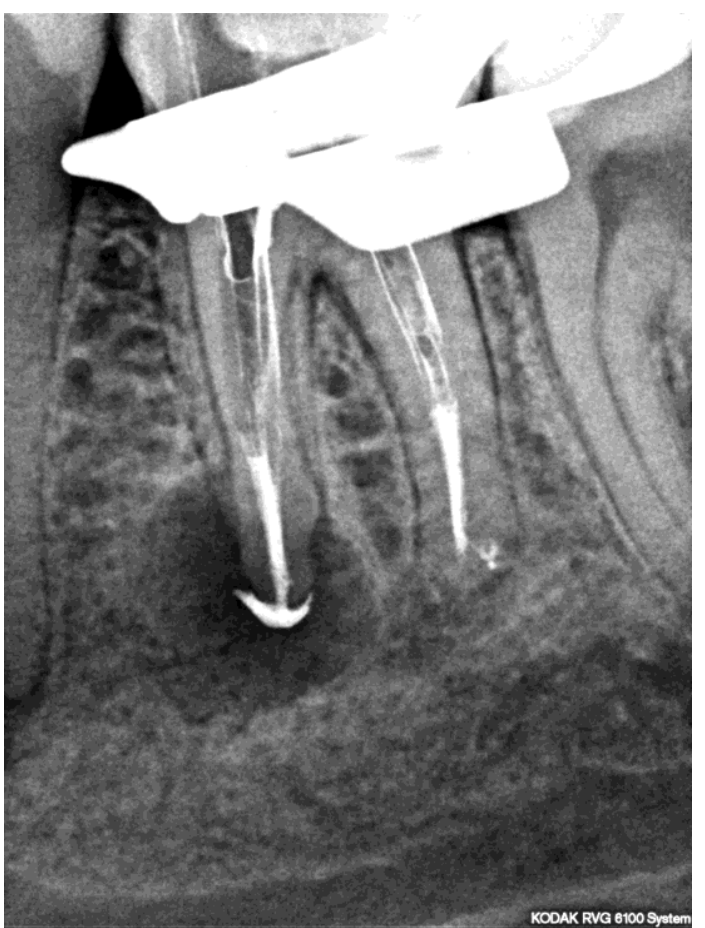

Abbildung 36: Zahn 36 Aufnahme der Wurzelfüllung/Downpack; 13.05.2009; apikaler Puff an der mesialen Wurzelspitze

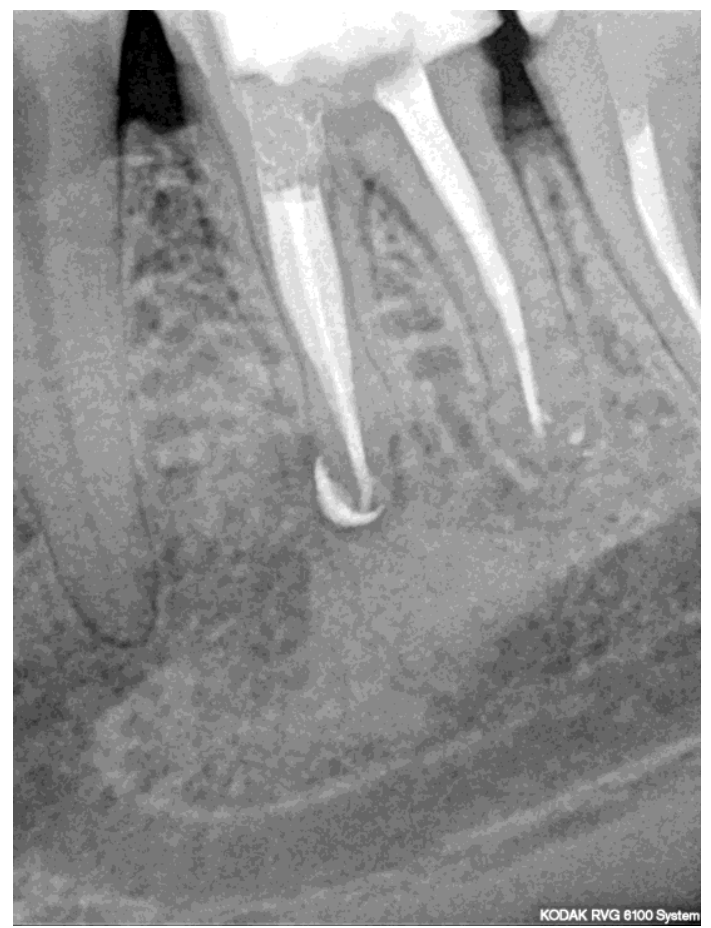

Abbildung 37: Zahn 36 Kontrollaufnahme der Wurzelfüllung; 04.11.2010; Recall nach 18 Monaten; leichte apikale Aufhellung an der mesialen Wurzel noch immer erkennbar 


\subsection{Vergleich der Gruppen}

Um die Erfolgs- und Misserfolgsrate der Hauptgruppe gegen die beiden Kontrollgruppen zu verifizieren, wurden die Gruppen mit dem z-Test gegeneinander verglichen. Dem Test liegt dabei der Stichprobenumfang $n$ der Gruppen und ihre prozentuale Erfolgs- bzw. Misserfolgsrate als Proportion (= Prozentzahl auf die Zahlenwerte 0 bis 1 bezogen) zugrunde. So betrug bei der Hauptgruppe $n=59$ und die Misserfolgsrate 20,3 \%, was einer Proportion von 0,203 entspricht.

Der z-Test zeigte, dass sich alle Gruppen in ihrer Erfolgs- bzw. Misserfolgsrate statistisch nicht signifikant voneinander unterscheiden. Für die klinisch-praktische Vorgehensweise vermitteln diese Ergebnisse, dass eine Revisionsbehandlung nach nicht erfolgreicher orthograder Wurzelkanalbehandlung und Wurzelspitzenresektion genauso erfolgreich sein kann wie eine Primärbehandlung.

\begin{tabular}{|l|c|c|c|}
\hline \multicolumn{1}{|c|}{ Gruppen } & $\mathbf{n}$ & $\begin{array}{c}\text { Proportion } \\
\text { Misserfolg }\end{array}$ & Ergebnisse \\
\hline Hauptgruppe & 59 & 0,203 & $\mathrm{z}=0,287 ;$ \\
\hline Kontrollgruppe 1 & 66 & 0,167 & $\mathrm{P}=0,774$ \\
\hline & & & $\mathrm{z}=0,542 ;$ \\
\hline Kontrollgruppe 1 & 66 & 0,167 & $\mathrm{P}=0,588$ \\
\hline Kontrollgruppe 2 & 49 & 0,225 & $\mathrm{z}=0,0420 ;$ \\
\hline Hauptgruppe & & & $\mathrm{P}=0,967$ \\
\hline Kontrollgruppe 2 & 59 & 0,203 & \\
\hline & 49 & 0,225 & \\
\hline
\end{tabular}

Tabelle 4: Statistischer Vergleich der Misserfolgsrate von Haupt- und Kontrollgruppen (zTest) 


\section{Diskussion}

\subsection{Medikamentöse Einlage}

Das Ziel einer Wurzelkanalbehandlung ist es, die Entstehung einer bakteriell bedingten Parodontitis apicalis zu verhindern oder diese erfolgreich zu therapieren. Die Prävention einer bakteriellen Kontamination bei Vorliegen einer nicht infizierten Pulpa bzw. das Ausmaß der Keimreduktion bei einer infizierten nekrotischen Pulpa sind entscheidend für den Erfolg oder Misserfolg einer Wurzelkanalbehandlung. Die chemomechanische Therapie, das heißt das mechanische Aufbereiten und chemische Desinfizieren des Wurzelkanalsystems mit Spüllösungen, trägt bedeutend zur Keimreduktion bei. Eine absolute Keimfreiheit kann dadurch allerdings nicht erzielt werden (Ørstavik et al. 1991, Yared und Dagher 1994, Dalton et al. 1998, Siqueira et al. 1999), weshalb die Applikation einer antibakteriell wirksamen medikamentösen Einlage empfohlen wird (Ørstavik 2003, Bergenholtz et al. 2003, Bergenholtz und Spångberg 2004). Seit seiner Einführung 1920 wird Kalziumhydroxid $\left(\mathrm{Ca}(\mathrm{OH})_{2}\right)$ als medikamentöse Einlage bei zweizeitigen Wurzelkanalbehandlungen verwendet. Es erfüllt die meisten Anforderungen, die an ein entsprechendes Präparat gestellt werden sollten. Kalziumhydroxid besitzt eine gute antimikrobielle und antiresorptive Wirkung, ist gewebeauflösend, neutralisiert bakterielle Endotoxine und induziert die Hartgewebsneubildung (Drebenstedt 2009).

Die generelle Notwendigkeit einer medikamentösen Einlage mit Kalziumhydroxid zur Desinfektion des Wurzelkanalsystems wird allerdings kontrovers diskutiert. Bei nicht infiziertem Endodont, das heißt bei Vitalexstirpation nach irreversibler Pulpitis ist ein einzeitiges Vorgehen ohne medikamentöse Zwischeneinlage anzustreben (Bergenholtz et al. 2003). Die Gefahr einer Neuinfektion des Wurzelkanalsystems zwischen den Behandlungen soll so reduziert werden.

In den Fällen der vorliegenden Arbeit handelt es sich in der Hauptgruppe und der zweiten Kontrollgruppe um Revisionsbehandlungen. Lediglich die erste Kontrollgruppe beinhaltet endodontische Primärbehandlungen. In allen drei Gruppen wurde sowohl ein- als auch zweizeitig therapiert. Ein statistisch signifikanter Unterschied der Erfolgsquote zwischen den Behandlungen mit und ohne Kalzium- 
hydroxid als medikamentöse Einlage konnte jedoch in diesen Fällen nicht festgestellt werden. Ebenfalls wurde überprüft, ob der Erfolg einer Behandlung mit oder ohne medikamentöse Einlage von dem Vorhandensein einer präoperativen Parodontitis apicalis beeinflusst wird. Da jedoch die Gruppe mit einer präoperativen Parodontitis apicalis eine deutlich höhere Fallzahl $(n=45)$ aufweist als die Gruppe ohne präoperativer Parodontitis apicalis $(n=7)$, ist ein fundierter Vergleich nicht möglich.

Sathorn et al. erstellten eine Übersicht über klinische Studien zur Erfolgsquote einund zweizeitiger Wurzelkanalbehandlungen mit Kalziumhydroxid. Von insgesamt 11 Studien zeigten die drei Studien mit dem höchsten Evidenzniveau keinen signifikanten Unterschied zwischen den beiden Therapievarianten (Trope et al. 1999, Weiger et al. 2000, Peters und Wesselink 2002). Nach deren Auswertung kann keine eindeutige Empfehlung für die ein- oder zweizeitige Therapie ausgesprochen werden (Sathorn et al. 2005).

\subsection{Fallzahl im Vergleich zu anderen Studien}

In der vorliegenden Studie wurde eine orthograde Revision nach nicht erfolgreicher WSR an 86 Zähnen durchgeführt.

Im Vergleich zu weiteren retrospektiven Studien, die sich mit der endodontischen Behandlung beschäftigen, ist dies eine eher geringe Fallzahl. Einige im universitären Betrieb angelegte Studien wie zum Beispiel die Untersuchung von Pekruhn (1986) mit 1140 behandelten Zähnen weisen größere Patientenpools oder auch einen längeren Behandlungszeitraum auf (Meeuwissen und Eschen 1983).

Die Zahl der behandelten Zähne liegt jedoch in den meisten Studien zwischen 100 und 600 (Wang et al. 2004; Barbakow et al. 1980). In der einzigen inhaltlich vergleichbaren Studie von Caliskan liegt die Fallzahl der nach nicht erfolgreicher Wurzelspitzenresektion orthograd revidierter Zähne bei 11 (Caliskan 2005).

Es muss bedacht werden, dass es sich in der vorliegenden Studie um Fälle handelt, die seltener auftreten, da entweder die vorhergehenden Therapieversuche zum Erfolg führten oder der Zahn nach einer langen Therapiehistorie als austherapiert eingestuft und extrahiert wurde. Außerdem wurden alle Fälle vom selben Zahnarzt und nicht von einer größeren Anzahl an Behandlern therapiert. 
Bedenkt man zusätzlich, dass die meisten Studien längere Therapiezeiträume umfassen, weisen Umfang der Untersuchungsgruppe und Untersuchungszeitraum Größen auf, die mindestens erste vorläufige Schlussfolgerungen über das Behandlungskonzept zulassen.

\subsection{Zahngruppen}

Im Gegensatz zu anderen Studien, die sich teilweise nur mit Frontzähnen oder einwurzeligen Zähnen befassen, schließt die vorliegende Untersuchung keine Zahngruppe aus (Harty et al. 1970, Sundqvist et al. 1998). Studien, in denen mehrwurzelige Zähne ausgeschlossen werden, zeigen meist bessere Ergebnisse bezüglich der Erfolgsquote, da mehrwurzelige Zähne ein entsprechend höheres Risiko für Misserfolg aufweisen (Friedman et al. 1995). Der Zugang zum Seitenzahngebiet gestaltet sich schwieriger als zum Frontzahngebiet, die Wurzelmorphologie mehrwurzeliger Zähne ist oftmals komplexer und das Risiko, einen zusätzlichen Kanal zu übersehen, ist höher. Die Verteilung der Behandlungen auf die einzelnen Zahngruppen ist in der vorliegenden Studie nahe zu ausgeglichen. Frontzahnbehandlungen sind leicht überrepräsentativ. Auffällig ist die Verteilung der einzelnen Zahngruppen innerhalb der Kiefer. Ein deutliches Überwiegen der Oberkieferzähne ist hier zu verzeichnen. Von insgesamt 59 Zähnen wurden 41 im Oberkiefer therapiert und nur 18 im Unterkiefer. Zudem fällt der große Unterschied in Hinblick auf die numerische Verteilung auf: Von den 41 im Oberkiefer therapierten Zähnen waren 24 Frontzähne, 11 Prämolaren und nur 6 Molaren. Im Unterkiefer ist ebenfalls ein großer Unterschied in der numerischen Verteilung der Behandlung in den einzelnen Gruppen zu erkennen. Hier überwiegen jedoch die im posterioren Bereich liegende Seitenzähne. Von den insgesamt 18 im Unterkiefer therapierten Zähnen waren 12 Molaren, 5 Prämolaren und lediglich ein Frontzahn.

Die unterschiedliche Verteilung erklärt sich durch die Ätiologie der Wurzelspitzenresektion.

Das chirurgische Vorgehen bei einer Wurzelspitzenresektion an einem mehrwurzeligen Zahn im posterioren Bereich ist wesentlich aufwendiger als an einem einwurzeligen Frontzahn, da der Zugang zum Operationsgebiet deutlich eingeschränkter ist. Die Entscheidung, ob an einem Oberkiefermolar nach 
längerer Therapiehistorie durch einen komplizierten chirurgischen Eingriff mit mittlerer Erfolgsprognose ein Erhaltungsversuch unternommen oder die Problematik durch eine Extraktion behandelt wird, fällt im posterioren Seitenzahnbereich meist für die letztgenannte Therapieoption. Der Zugang zum Operationsgebiet und die Wurzelanatomie des zu resezierenden Zahnes beeinflussen das Ergebnis einer Wurzelspitzenresektion maßgeblicher als die Lokalisation selbst (Friedman 1998). Molaren des Oberkiefers sind zwar im Vergleich zu Molaren des Unterkiefers ähnlich schlecht zugänglich, jedoch weisen sie durch die palatinale Wurzel und Variabilität der Wurzelanatomie einen erhöhten Schwierigkeitsgrad bei der chirurgischen Therapie auf.

Die geringe Fallzahl der Unterkieferfrontzähne lässt sich mit der geringeren Kariesprävalenz erklären.

\subsection{Recallrate}

Die erzielte Recallrate der Hauptgruppe liegt bei $68,6 \%$ bezogen auf die Anzahl der untersuchten Zähne. In der Gruppe der Revisionsbehandlung wurde eine Recallrate von $57 \%$ und in der Gruppe der Primärbehandlung von $72,5 \%$ erzielt. Apt et al. stellten fest, dass die Ergebnisse einer Nachuntersuchung Allgemeingültigkeit besitzen, sobald sie eine Recallrate von über $50 \%$ erreichen (Apt et al. 1975). Daraus folgt, dass die statistisch ermittelten Resultate der vorliegenden Untersuchung zu einem Vergleich mit anderen Studien herangezogen werden können. Die Recallrate ist ein wichtiger Aspekt für die Repräsentativität einer Arbeit und sollte beim Vergleich mit anderen Arbeiten immer beachtet werden. In vielen anderen Studien fehlt die Information über diesen Parameter (Cheung und Lam 1993) oder dessen Wert liegt mit 18\% unter dem von Apt et al. geforderten Wert (August 1996). Friedman fordert für eine evidenzbasierte Studie eine Recallrate von mindestens $80 \%$. Stehen für die Erfolgskontrolle der Patient oder entsprechende Röntgenaufnahmen nicht zur Verfügung, dann ist das Erfolgsergebnis als ungewiss einzustufen. Im besten Fall wären alle fehlenden Fälle erfolgreich therapiert worden und die daraus resultierende Gesamterfolgsrate entsprechend höher. Geht man vom schlechtesten Fall aus, dann wären alle fehlenden Fälle als Misserfolge einzustufen und die daraus resultierende Gesamterfolgsrate entsprechend 
niedriger. Ist die Recallrate einer Studie niedrig, kann das Ergebnis erheblich verzerrt werden und muss gegebenenfalls als ungültig gewertet werden (Friedman 2005).

Die erzielte Recallrate der Hauptgruppe der durchgeführten Studie liegt mit 68,6\% zwar unter den von Friedman geforderten $80 \%$, jedoch auch über den von Apt et al. beschriebenen $50 \%$. Ursache dafür ist die Tatsache, dass es sich um eine reine Überweiserpraxis handelt. Viele Patienten konnten und wollten aufgrund langer Anfahrtswege zu einer Verlaufskontrolle nicht vorstellig werden. Des Weiteren ist die Auswertung des Heilungsverlaufes von der Mitarbeit der Überweiser bei der Erstellung von Kontrollaufnahmen abhängig.

\subsection{Recallzeitraum}

In der vorliegenden Arbeit wurden die behandelten Zähne in einem Zeitraum von elf Monaten bis fünf Jahren nachuntersucht. Nach einer Studie von Ørstavik ist ein Recallzeitraum von ein bis zwei Jahren ausreichend, um eine Aussage über den Erfolg endodontischer Behandlungen treffen zu können (Ørstavik 1996).

Nach einer Stellungnahme der DGZMK kann der Erfolg einer Wurzelkanalbehandlung erst nach einem Beobachtungszeitraum von mindestens vier Jahren endgültig beurteilt werden (DGZMK 2001). Es werden für die klinische und röntgenologische Kontrolle einer Wurzelkanalbehandlung Zeitintervalle von sechs Monaten und einem, zwei und vier Jahren nach Abschluss der Therapie empfohlen (DGZMK 2005). Andere Autoren geben jedoch ebenfalls an, dass die Präsenz einer postendodontischen Erkrankung bereits innerhalb von zwei Jahren nach Therapieabschluss diagnostiziert werden kann. Sie empfehlen die klinische und röntgenologische Kontrolle des behandelten Zahnes nach einem beziehungsweise zwei Jahren (Wu und Wesselink 2005).

$57,6 \%$ aller Nachuntersuchungen der vorliegenden Studie fanden in diesem Schlüsselzeitraum statt und 35,6\% erfolgten nach mehr als 24 Monaten. In nur 6,8\% der Fälle wurden bereits nach 11 Monaten nachuntersucht.

Aufgrund der teilweise kurzen Beobachtungszeit lässt sich für einige Misserfolgsfälle noch eine Heilungsmöglichkeit annehmen. Dafür sind weitere Kontrollen erforderlich. 


\subsection{Die periapikale Ausgangssituation}

In der vorliegenden Studie wurde erfasst, ob der Zahn vor der Behandlung röntgenologisch eine apikale Aufhellung aufwies. Laut Friedman (1998) hat eine Parodontitis apicalis im Ausgangsbefund erheblichen Einfluss auf das Ergebnis einer endodontischen Behandlung. Sowohl kurze Zeit nach der Behandlung durchgeführte Kontrolluntersuchungen als auch Langzeitkontrollen an Zähnen mit apikaler Aufhellung zeigten deutlich schlechtere Resultate als Zähne, die präoperativ röntgenologisch unauffällig waren. In mehreren Veröffentlichungen wird dies bestätigt (Sjögren et al. 1990, Ørstavik und Hörsted-Bindslev 1993). Die Erfolgsquote bei Primärbehandlungen verschlechtert sich demnach im Vergleich zu apikal unauffälligen Fällen um 10-20\%.

Von dieser Tendenz weichen die Ergebnisse der vorliegenden Arbeit jedoch teilweise ab. Nach Auswertung der Daten mit dem Pearson Chi-Test hat das Vorhandensein einer präoperativen Parodontitis apicalis an Zähnen nach nicht erfolgreicher Wurzelspitzenresektion keinen statistisch signifikanten Einfluss auf das Erfolgsergebnis $(p=0,13)$. Die Auswertung der Ergebnisse der Primär- und Revisionsbehandlung bestätigen allerdings die in der Literatur angegebenen Aussagen zur periapikalen Ausgangssituation. In beiden Kontrollgruppen konnte nach der statistischen Auswertung ein signifikanter Unterschied zwischen Zähnen mit und ohne präoperativer Parodontitis apicalis ermittelt werden. Der Erfolg einer Primärbehandlung oder einer Revisionsbehandlung hängt demnach von der periapikalen Ausgangssituation ab.

Laut Gorni und Gagliani muss in Fällen, in denen die ursprüngliche Wurzelkanalanatomie durch vorhergehende endodontische Behandlungen verändert wurde von einer geringeren Erfolgswahrscheinlichkeit der orthograden Revision ausgegangen werden (Gorni und Gagliani 2004). Daher ist die orthograde Revision an nicht erfolgreich wurzelspitzenresezierten Zähnen ein Therapieversuch mit nicht vorhersagbarem Behandlungserfolg (Hermann 2007). Der Therapieerfolg der in der Literatur existierenden Falldarstellungen und der vorliegenden Studie widerlegen diese Aussagen. Die häufigste Ursache für den Misserfolg endodontischer Behandlungen ist die Reinfektion oder Persistenz von Mikroorganismen im apikalen Drittel des Wurzelkanalsystems (Nair et al. 1990). Dieser problematische, schwierig zugängliche Bereich fehlt an Zähnen mit bereits resezierter Wurzelspitze. Das apikale Delta mit komplizierten anatomischen 
Strukturen wie extremen Krümmungen, Isthmen und Seitenkanälen wird durch die Wurzelspitzenresektion entfernt, sodass die mechanische und chemische Aufbereitung und Desinfektion des Wurzelkanalsystems einfacher erreicht werden kann. Das Fehlen der apikalen Konstriktion erfordert jedoch erhöhte Vorsicht bei der Präparation, Längenbestimmung und der chemischen Desinfektion, um ein Überinstrumentieren und Überpressen der Spülflüssigkeiten zu vermeiden.

Mit Hilfe des OP-Mikroskops ist es außerdem unter starker Vergrößerung möglich, alle Wurzelkanäle bzw. auch vorher nicht aufgefundene oder koronal obliterierte Wurzelkanäle, die fortbestehende Symptome verursachen, sicher darzustellen und aufzubereiten.

\subsection{Vergleich der Erfolgsquoten mit Literaturangaben}

Vergleicht man die Erfolgsquote der Hauptgruppe mit denen in der Literatur angegebenen Erfolgsquoten anderer endodontischer Behandlungen, so lässt sich feststellen, dass diese niedriger ist. Auch die Erfolgsquoten der Kontrollgruppen sind mit 75,8\% der Primärbehandlungen und 77,5\% der Revisionsbehandlungen im Vergleich geringer bzw. im niedrigeren Bereich vergleichbarer Untersuchungen. Laut DGZMK kann für Zähne mit irreversibler Pulpitis oder Pulpanekrose ohne assoziierte periapikale Läsion eine Erfolgsrate von $85-95 \%$ und für Zähne mit infiziertem Endodont und assoziierter periapikaler Läsion eine Erfolgsrate von 7085\% angegeben werden. Für Revisionsbehandlungen werden Erfolgsquoten von 89-95\% für Zähne ohne assoziierte Befunde einer periapikalen Parodontitis und $50-70 \%$ für wurzelkanalbehandelte Zähne mit infiziertem Endodont und assoziierter periapikaler Läsion angegeben (DGZMK 2001). Es ist jedoch zu bedenken, dass die Fälle der Hauptgruppe deutlich komplizierter zu therapieren sind als Primär- oder Revisionsbehandlungen. Des Weiteren handelt es sich bei dem Behandler um einen Spezialisten, der größtenteils überwiesene Fälle therapiert, welche oftmals von vornherein einen erhöhten Schwierigkeitsgrad aufweisen.

\subsection{Erfolgskriterien}

Als Kriterium für den Erfolg beziehungsweise Misserfolg der Behandlung wurde das röntgenologische Vorhandensein einer Parodontitis apicalis herangezogen. 
Klinische Beschwerdefreiheit sollte ebenfalls bestehen. Die eindeutigsten Ergebnisse über den Ausgang einer endodontischen Behandlung liefert sicherlich eine histologische Nachuntersuchung. Diese ist jedoch in vivo nicht möglich. In der vorliegenden Untersuchung wurden all jene Fälle als absoluter Erfolg gewertet, bei denen es nach einem Beobachtungszeitraum von mindestens 11 Monaten röntgenologisch zu einer kompletten Ausheilung der Parodontitis apicalis kam und ein durchgehend verfolgbarer Parodontalspalt normaler Breite zu erkennen war. Als Misserfolg wurden alle Zähne eingestuft, bei denen die apikale Aufhellung größenkonstant geblieben war, nach wie vor Schmerzen, Schwellungen oder andere klinische Symptome bestanden oder der Zahn extrahiert werden musste. In Fällen, in denen eine deutlich Heilungstendenz aufgrund der Verkleinerung der apikalen Aufhellung zum Zeitpunkt der Nachuntersuchung zu erkennen war, wurden als "in Heilung“ gewertet. Eine weitere Abstufung wurde nicht vorgenommen.

Laut Ørstavik et al. (1986) kann in Grenzfällen, in denen nur noch eine sehr geringe apikale Aufhellung zu erkennen ist, ein relativer Erfolg im Sinne einer gerade vor sich gehenden Ausheilung angenommen werden. Diese zusätzliche Abstufung der positiven Ergebnisse führt allerdings zu einer Beeinflussung der Erfolgsquote und im Resultat zu einer erschwerten Vergleichbarkeit der unterschiedlichen Studien miteinander.

Teilweise stark differierende Erfolgs- und Misserfolgsergebnisse einzelner Studien können außerdem auf die unterschiedlichen Techniken und angewandten Materialien zurückgeführt werden. Laut Friedman ist es vor allem die unterschiedliche Bewertung von Erfolg und Misserfolg, die zu Fehlinterpretationen führt. Demnach kann eine Behandlung genau dann als Erfolg gewertet werden, wenn es zu einer klinischen und röntgenologischen Ausheilung der apikalen Läsion kommt, oder auch wenn sich die apikale Läsion röntgenologisch bei klinischer Beschwerdefreiheit lediglich verkleinert, oder bei Persistenz der Parodontitis apicalis und klinischer Beschwerdefreiheit (Friedman 2002).

Beim Vergleich der vorliegenden Ergebnisse mit denen anderer Studien muss dies berücksichtigt werden. Erst durch die Gegenüberstellung der jeweiligen Erfolgskriterien kann eine fundierte Einschätzung der Ergebnisse abgegeben werden. In der durchgeführten Studie wurden sowohl die klinische Beschwerdefreiheit als auch die röntgenologisch sichtbare Ausheilung der apikalen Läsion zur Erfolgs- 
bewertung herangezogen. Eine kritische Einschätzung der Ergebnisse scheint somit gegeben.

Weitere Faktoren, die die Ergebnisse von Studien beeinflussen, sind die Lokalisation des Zahnes und die Anzahl der Wurzeln. Ein einwurzeliger Frontzahn mit geradem Wurzelkanalverlauf stellt im Allgemeinen geringere Anforderungen an den behandelnden Zahnarzt und birgt weniger Komplikationen als ein mehrwurzeliger Molar mit gekrümmten Wurzelkanälen. Der Zugang zu mehrwurzeligen Zähnen ist zudem eingeschränkt. Daher ist zu berücksichtigen, ob in der herangezogenen Studie überwiegend einwurzelige Zähne therapiert wurden oder zusätzlich oder überwiegend auch mehrwurzelige Zähne.

In der vorliegenden Studie wurden 25 Frontzähne, 16 Prämolaren und 18 Molaren therapiert.

In den meisten Studien wurde keine spezielle Vorauswahl der zu untersuchenden Fälle getroffen, das heißt es wurden keine Ein- oder Ausschlusskriterien aufgestellt. In manchen Studien wurden allerdings Fälle mit schlechter Prognose von der Bewertung ausgeschlossen (Chong et al. 2003) während in anderen Studien vor allem diese Fälle aufgenommen wurden (Skoglund und Persson 1985). Hieraus wird deutlich, dass die Selektion der Fälle ebenfalls einen signifikanten Einfluss auf das Ergebnis hat.

Für die Fälle in der vorliegenden Studie wurden keine speziellen Aus- oder Einschlusskriterien erstellt. In Fällen, in denen aus Sicht des Behandlers aufgrund der Vorbehandlung keine Aussicht auf Therapieerfolg bestand, wurde kein Erhaltungsversuch unternommen. Diese Fälle wurden nicht in die Studie aufgenommen.

Die Erfolgsquoten der unterschiedlichen Studien und Übersichten variieren stark und zeigen somit auf, dass es offensichtlich verschiedenen Ein- und Ausschlusskriterien gab bzw. generell unterschiedliche Voraussetzungen. Zusätzlich sind einige Studien bereits älter als 10 Jahre.

Nach aktuellem Stand der Literatur ist eine evidenzbasierte Entscheidung für eine orthograde Revision einer Wurzelkanalbehandlung statt einer Wurzelspitzenresektion nicht möglich (Hülsmann 2007). Allerdings ist davon auszugehen, dass in Fällen von nicht erfolgreichen Wurzelspitzenresektionen die orthograde Revision die Ursache für den Misserfolg, die intrakanaläre Infektion behebt und mit hoher Wahrscheinlichkeit zum Erfolg führt (Fristad et al. 2004). 
Die vorliegende Untersuchung bestätigt diese Aussage. In 69,5\% der Fälle, in denen eine orthograde Revision nach nicht erfolgreicher Wurzelspitzenresektion durchgeführt wurde, konnte durch dieses Vorgehen ein Erfolg erzielt werden. Für reguläre Revisionsbehandlungen wird in der Literatur eine Erfolgsquote von 8995\% bei Zähnen mit revisionsbedürttiger Wurzelkanalbehandlung ohne assoziierte Befunde einer periapikalen Parodontitis und $70-85 \%$ bei Zähnen mit infiziertem Endodont und assoziierter periapikaler Läsion nach primärer Wurzelkanalbehandlung angegeben (DGZMK 2001). Mit einer Erfolgsrate von 69,5\% reicht das Ergebnis der vorliegenden Arbeit fast an diese Erfolgsquoten heran. Durch die orthograde, nichtchirurgische Revision können bei insuffizienter Wurzelkanalbehandlung und Wurzelspitzenresektion Zähne, die als austherapiert eingestuft wurden unter Umständen erfolgreich behandelt und erhalten werden. Nach aktuellem Stand der Literatur kann jedoch noch keine evidenzbasierte Erfolgsprognose erstellt werden. 


\section{Zusammenfassung}

Die vorliegende Untersuchung befasst sich mit der orthograden endodontischen Revision als Therapie bei Zähnen nach nicht erfolgreicher Wurzelkanalbehandlung und nicht erfolgreicher Wurzelspitzenresektion.

Ziel dieser Arbeit ist es, durch eine retrospektive Auswertung prä- und postoperativer Röntgenaufnahmen zu klären, ob eine orthograd-endodontische Revisionsbehandlung an wurzelspitzenresezierten Zähnen mit persistierender Parodontitis apicalis oder an Zähnen, an denen aufgrund röntgenologisch insuffizienter Behandlungsqualität das Auftreten einer Parodontitis apicalis zu erwarten ist, eine ausreichende Erfolgsquote aufweist, um für dieses Verfahren eine Empfehlung zur klinischen Anwendung aussprechen zu können.

Die häufigsten Ursachen für das Scheitern einer endodontischen Behandlung sind die Persistenz von Mikroorganismen im Endodont nach unzureichender Aufbereitung und Desinfektion oder die Reinfektion des Endodonts wegen einer insuffizienten restaurativen Versorgung. Diese Ursachen können nur durch eine vollständige Entfernung des infizierten Wurzelkanalfüllmaterials und durch intensives Desinfizieren des Endodonts mithilfe von Spüllösungen und medikamentösen Einlagen behoben werden. Die Extraktion des betroffenen Zahnes ist eine weitere Therapieoption.

In der vorliegenden Arbeit wurden alle Fälle vom selben endodontischspezialisierten Zahnarzt therapiert. Die entsprechenden Röntgenbilder wurden retrospektiv von zwei externen Auswertern beurteilt.

In 59 Fällen wurde eine orthograde Revision nach nicht erfolgreicher Wurzelkanalbehandlung und Wurzelspitzenresektion durchgeführt. Folgende Parameter wurden untersucht:

- Zahn

- Präoperatives Vorliegen einer Parodontitis apicalis

- Versorgung mit einer retrograden Füllung: ja/nein

- Falls Ja: Material, soweit identifizierbar (Amalgam/Zement)

- Intraoperative Entfernung der retrograden Füllung: ja/nein

- Medikamentöse Einlage: ja/nein 
- Falls Ja: welche?

- Technik und Materialien zur Wurzelkanalfüllung

- Dauer der Kontrollzeit

- Ausheilung der Läsion bzw. Neuentwicklung einer Läsion: ja/nein

Nach einem Zeitraum von mindestens 11 Monaten wurden die Zähne nachuntersucht.

In 69,5\% der Fälle führte diese Therapie zum Erfolg.

Es konnte gezeigt werden, dass das Vorliegen einer präoperativen Parodontitis apicalis keinen signifikanten Einfluss auf die Heilung hat. Von insgesamt 51 Fällen, in denen eine solche Läsion röntgenologisch zu erkennen war, konnte in 64,7\% der Fälle eine Heilung erzielt werden.

Das Vorhandensein einer retrograden Füllung konnte das Ergebnis nicht signifikant beeinflussen. Aufgrund der geringen Fallzahl konnte nicht untersucht werden, ob das Entfernen oder das Belassen einer retrograden Wurzelfüllung einen signifikanten Einfluss auf das Behandlungsergebnis hat.

Da noch nicht ausreichend evidenzbasierte Literatur vorliegt, kann die orthograde Revision nach nicht erfolgreicher Wurzelkanalbehandlung und Wurzelspitzenresektion noch nicht als routinemäßig zu empfehlende Therapieoption angesehen werden. Berücksichtigt man allerdings, dass es sich in der Regel nach nicht erfolgreicher Primärbehandlung, evtl. nicht erfolgreicher orthograder Revisionsbehandlung und nicht erfolgreicher Wurzelspitzenresektion um den dritten bis vierten Behandlungsversuch handelt und die Alternative in der Extraktion besteht, erscheint eine Erfolgsquote von $69,5 \%$ deutlich weniger ungünstig. Wenn es tatsächlich gelingt, noch einen beträchtlichen Anteil derart komplexer Fälle langoder auch nur mittelfristig zu erhalten, kann die orthograde Revisonsbehandlung nach nicht erfolgreicher Wurzelspitzenresektion im ausgewählten Einzelfall eine wertvolle Therapieoption darstellen. 


\section{Ausblick}

Durch verbesserte Techniken, Materialien und Instrumente wird die Therapie solcher endodontischen Problemfälle in Zukunft erfolgversprechender. Weitere klinische Studien mit höheren Fallzahlen sind erforderlich, um den klinischen Evidenzgrad zu verbessern. 


\section{Literaturverzeichnis}

Appel C (2011): Orthograde Revision bei persistierender periapikaler Parodontitis nach Wurzelspitzenresektion. Dtsch Zahnärztl Z $\underline{66}, 196-211$

Appel C, Hülsmann M: Probleme der Wurzelkanalfüllung. In: Probleme in der Endodontie. Prävention, Identifikation und Management. Hrsg. v. Hülsmann M, Schäefer E; Quintessenz Verlag, Berlin 2007, 323-363

Apt H, Dyrna G, Nitzsche W, Vokler J (1975): Mathematisch-statistische Aussagekraft klinisch-röntgenologischer Nachuntersuchungen von Wurzelbehandlungen. Zahn Mund Kieferheilkd Zentralbl 63, 19-22

August DS (1996): Long term postsurgical results on teeth with periapical radiolucencies. J Endod 22, 380-383

Balto HA (2004): Attachment and morphological behaviour of human periodontal Ligament fibroblasts to Mineral Trioxide Aggregate: A scanning electron microscope study. J Endod 30, 25-29

Barbakow FH, Cleaton Jones P, Friedman D (1980): An evaluation of 566 cases of root canal therapy in general dental practice. 1. Diagnostic criteria and treatment details. J Endod $\underline{6}, 456-460$

Bargholz C: Revisionen. In: Praxisleitfaden Endodontie. Hrsg. v. Bargholz C, Hör D, Zirkel C; Urban und Fischer, München 2006; 296-321

Bargholz C, Hülsmann M, Schäfer E: Revisionen. In: Probleme in der Endodontie. Hrsg. v. Hülsmann M, Schäfer E; Quintessenz Verlag, Berlin 2007; 471-497 
Bergenholtz G, Spångberg L (2004): Controversies in endodontics. Crit Rev Oral Biol Med 15, 99-114

Bergenholtz G, Hørsted-Bindslev P, Reit C: Textbook of Endodontology (Treatment of the necrotic pulp) Blackwell, Oxford 2003

Bruce GR, McDonald NJ, Sydiskis RJ (1993): Cytotoxicity of retrofill materials. J Endod 19, 288-292

Büttel L (2008): Behandlung obliterierter Frontzähne nach gescheiterter rein retrograder Therapie. Endodontie 17, 269-276

Camilleri J (2007): Hydratation mechanisms of mineral trioxide aggregate. Int Endod J 40, 462-470

Camilleri J (2008): Characterization of hydratation products of mineral trioxide aggregate. Int Endod J $\underline{41}$, 408-417

Caliskan MK (2005): Nonsurgical retreatment of teeth with periapical lesions previously managed by either endodontic or surgical intervention. Oral Surg Oral Med Oral Pathol Oral Radiol Endod 100, 242-248

Callis PD, Santini A (1987): Tissue response to retrograde root fillings in the ferret canine: a comparison of a glass ionomer cement and gutta-percha with sealer. Oral Surg Oral Med Oral Pathol $\underline{64}$, 475-479

Caplan DJ (2004): Epidemiologic issues in studies of association between apical periodontitis and systemic health. Endod Topics $\underline{8}, 15-35$

Chalfin H, Kellert M, Weseley P (1993): Postsurgical endodontics. J Endod 19, 307-311 
Cheung LK, Lam J (1993): Apicectomie of posterior teeth - a clinical study. Aust Dent J $\underline{38}, 17-21$

Chong BS, Pitt Ford TR (2005): Root-end filling materials: rational and tissue response. Endod Topics 11, 114-130

Chong BS, Pitt Ford TR, Hudson MB (2003): A prospective clinical study of mineral trioxide aggregate and IRM when used as root-end filling materials in endodontic surgery. Int Endod J $\underline{36}, 520-526$

Chong BS, Pitt Ford TR, Kariyawasam SP (1997): Short-term tissue response to potential root-end filling materials in infected root canals. Int Endod J 30, 240-249

Dalton BC, Ørstavik D, Phillips C, Petiette M, Trope M (1998): Bacterial reduction with nickel-titanium rotary instrumentation. J Endod 24, 763-737

Daoudi MF, Saunders WP (2002): In vitro evaluation of furcal perforation repair using Mineral Trioxide Aggregate or resin modified glass ionomer cement with and without the use of the operating microscope. J Endod 28, 512-515

Drebenstedt S: Desinfektion des Wurzelkanalsystems; in: Rödig T, Hülsmann M, Nordmeyer S, Drebenstedt S: Grundlagen der modernen Endodontie; Spitta Verlag, Balingen 2009, 176-202

Drebenstedt S, Hülsmann M, Bargholz C (2011): Orthograde Revision nach Wurzelspitzenresektion. Endodontie 20, 251-267

European Society of Endodontology (1994): Quality guidelines for endodontic treatment. Int Endod J 27, 115-14

European Society of Endodontology (2006): Consensus report of the European Society of Endodontology on quality guidelines for endodontic therapy. Int Endod J $\underline{39}, 923$ 
Fava LRG (2001): Calcium hydroxide in endodontic retreatment after two nonsurgical and two surgical failures: report of a case. Int Endod J 34, 72-80

Friedman S: Treatment outcome and prognosis of endodontic therapy. In: Essential Endodontology: Prevention and Treatment of Apical Periodontitis. Hrsg. v. Ørstavik D, Pitt Ford TR. Blackwell Science, Oxford 1998, 367-401

Friedman S (2002): Considerations and concepts of case selection in the management of post-treatment endodontic disease (retreatment failure). Endod Topics 1 , 54-78

Friedman S (2005): The prognosis and expected outcome of apical surgery. Endod Topics 11, 219-262

Friedman S, Löst C, Zarrabian M, Trope M (1995): Evaluation of success and failure after endodontic therapy using a glass ionomer cement sealer. J Endod $\underline{21}$, 384- 390

Fristad I, Molven O, Halse A (2004): Nonsurgically retreated root filled teeth radiographics finding after 20-27 years. Int Endod $\mathrm{J} \underline{37}, 8-12$

Fuss Z, Lustig J, Katz A, Tamse A (2001): An evaluation of endodontically treated vertical root fractured teeth: impact of operative procedures. J Endod $\underline{27}, 46-48$

Gagliani MM, Gorni FGM, Strohmenger L (2005): Periapical resurgery versus periapical surgery: a 5 year longitudinal comparison. Int Endod J $\underline{38}, 320-327$

Gomes BP, Ferraz CC, Vianna ME, Berber VB, Teixeira FB, Souza-Filho FJ (2001): In vitro antimicrobial activity of several concentrations of sodium hypochlorite and chlorhexidine gluconate in the elimination of Enterococcus faecalis. Int Endod J $\underline{34}$, 424-428 
Gorni FGM, Gagliani MM (2004): The outcome of endodontic retreatment: a two years follow up. J Endod $\underline{30}, 1-4$

Hancock HH, Sigurdsson A, Trope M, Moiseiwitsch J (2001): Bacteria isolated after unsuccessful endodontic treatment in a North American population. Oral Surg Oral Med Oral Pathol Oral Radiol Endod 91, 579-586

Harty F, Parkins B, Wengraf A (1970): Success rate in root canal therapy a retrospective study of conventional cases. Br Dent J $\underline{129}, 13-407$

Heppeler J, Hülsmann M (2006): Enterococcus Faecalis - ein Problemkeim. Endodontie 15, 137-144

Herrmann HW (2007): Orthograde Revision an Zähnen mit apikaler Aufhellung und Zustand nach Wurzelspitzenresektion. Endodontie 16, 321-328

Holland R, De Souza V, Nery MJ, Filho JAO, Bernabe PFE, Dezan E (1999): Reaction of Dogs' Teeth to Root Canal Filling with Mineral Trioxide Aggregate or a Glass Ionomer Sealer. J Endod 25, 728-730

Hülsmann M, Schäfer E (2005): Good clinical practice: Die Wurzelkanalbehandlung. Gemeinsame Stellungnahme der DGZ und der DGZMK. Dtsch Zahnärztl Z $\underline{60}$,

Hülsmann M, Schäfer E: Probleme in der Endodontie. Prävention, Identifikation und Managment. Quintessenz Verlag, Berlin 2007

Hülsmann M, Rödig T, Nordmeyer S (2007): Complications during root canal irrigation. Endod Topics 16, 27-63

Hülsmann M, Drebenstedt S, Nordmeyer S, Rödig T (2011): Die orthograde Revision bei persistierender Parodontitis apicalis nach Wurzelspitzenresektion. Endodontie 20, 251-267 
Hülsmann M, Nordmeyer S, Drebenstedt S, Holscher C, Rödig T: Nonsurgical retreatment of apicected teeth with persisting apical periodontitis - a treatment option. Decision making, treatment options, and case presentations. Int Endod J zur Publikation eingereicht

Jesslén P, Zetterqvist L, Heimdahl A (1995): Long-term results of amalgam versus glass ionomer cement as apical sealant after apicectomy. Oral Surg Oral Med Oral Pathol Oral Radiol Endod 79, 101-103

Keiser K, Johnson CC, Tipton DA (2000): Cytotoxicity of mineral trioxide aggregate using human periodontal ligament fibroblasts. J Endod $\underline{26}, 288-291$

Kirkevang LL, Wenzel A (2003): Risk indicators for apical periodontitis. Community Dent Oral Epidemiol $\underline{31}, 59-67$

Kleier DJ (1984): Nonsurgical retreatment of a postsurgical endodontic failure. J Endod 10, 577-579

Krupp C (2011): Orthograde Entfernung retrograde Wurzelkanalfüllung. Endodontie 20, 269-282

Lehtinen R (1986): Tissue reactions to glass ionomer cement and dental amalgam in the rat. Proc Finn Dent Soc 82, 144-147

Mead C, Javidan-Nejad S, Mego ME, Nash B, Torabinejad M (2005): Levels of evidence for the outcome of endodontic surgery. J Endod 31, 19-24

Meeuwissen R, Eschen S (1983): Twenty years of endodontic treatment. J Endod 9, 390-393 
Mente J, Hage N, Pfefferle T, Koch MJ, Dreyhaupt J, Staehle HJ, Friedman S (2009): Mineral Trioxide Aggregate apical plugs in teeth with open apical foramina: A retrospective analysis of treatment outcome. J Endod 35, 1354-1358

Mitchell PJC, Pitt Ford TR, Torabinejad M, McDonald F (1999): Osteoblast biocompatibility of mineral trioxide aggregate. Biomaterials $\underline{20}, 167-173$

Moiseiwitsch JR, Trope M (1998): Nonsurgical root canal therapy treatment with apparent indications for root-end surgery. Oral Surg Oral Med Oral Pathol Oral Radiol Endod 86, 335-340

Molander A, Reit C, Dahlen G, Kvist T (1998): Microbiological status of root-filled teeth with apical periodontitis. Int Endod J $\underline{31}, 1-7$

Nair PNR, Sjögren U, Krey G, Sundqvist G (1990): Therapy resistant foreign body giant cell granuloma at the periapex of a root-filled human tooth. J Endod 16, 589595

Nakata TT, Bea KS, Baumgartner JC (1998): Perforation repair comparing Mineral Trioxide Aggregate and amalgam using an anaerobic bacterial leakage model. J Endod 24, 184-186

Ng Y-L, Mann V, Gulabivala K (2010): Tooth survival following non-surgical root canal treatment: a systematic review of the literature. Int Endod J $\underline{43}, 171-189$

Ørstavik D (1996): Time-course and risk analyses of the development and healing of chronic apical periodontitis in man. Int Endod J 29, 150- 155

Ørstavik D (2003): Wurzelkanaldesinfektion - Eine Übersicht über Auffassung und jüngste Entwicklungen. Endodontie 12, 343-352

Ørstavik D, Hörsted-Bindslev P (1993): A comparison of endodontic treatment results at two dental schools. Int Endod J 26, 348-354 
Ørstavik D, Kerekes K, Eriksen HM (1986): The periapikal index: A scoring system for radiographic assessment of apical periodontitis. Endod Dent Traumatol 2, 2034

Ørstavik D, Kerekes K, Molven O (1991): Effects of extensive apical reaming and calcium hydroxide dressing on bacterial during treatment of apical periodontitis. Int Endod J 24, 1-7

Pannkuk TF (2011): A new technique for nonsurgical retreatment of teeth with amalgam root end fillings: Case series. J Endod 37, 414-418

Persson G (1973): Prognosis of reoperation after apiectomy. Swed Dent J $\underline{66}$, 4967

Peters LB, Wesselink PR (2002): Periapical healing of endodontically treated teeth in one and two visits obturated in the presentce or absence of defectable microorganisms. Int Endod J 35, 660-707

Peterson J, Gutmann JL (2001): The outcome of endodontic resurgery: a systematic review. Int Endod J $\underline{34}, 169-175$

Pinheiro ET, Gomes BP, Ferraz CC, Sousa EL, Teixeira FB, Souza-Filho FJ (2003): Microorganisms from canals of root-filled teeth with periapical lesions. Int Endod J $\underline{36}, 1-11$

Pirani C, lacono F, Chersoni S, Sword J, Pashley DH, Tay FR, Looney S, Gandolfi $M G$, Prati C (2009): The effect of ultrasonic removal of various root-end filling materials. Int Endod J 42, 1015-1025

Portenier I, Waltimo TMT, Haapasalo M (2003): Enterococcus faecalis - the root canal survivor and 'star' in posttreatment disease. Endod Topics $\underline{6}$, 135-159 
Rubinstein R, Kim S (1999): Short-term observation of the results of endodontic surgery with the use of a surgical operation microscope and Super EBA as a root end filling material. J Endod 25, 43-48

Rud J, Andreasen JO, Moller Jensen JE (1972): A multivariate analysis of the influence of various factors upon healing after endodontic surgery. Int J Oral Surg $1,258-271$

Rud J, Munksgaard EC, Andreasen JO, Rud V, Asmussen E (1991a): Retrograde root filling with composite and a dentin-bonding agent. 1. Endod Dent Traumatol $\underline{7}$, 118-125

Rud J, Munksgaard EC, Andreasen JO, Rud V (1991b): Retrograde root filling with composite and a dentin-bonding agent. 2. Endod Dent Traumatol $\underline{7}, 126-131$

Sathorn C, Parashos P, Messer HH (2005): Effectiveness of single- versus multiple-visit endodontic treatment of teeth with apical periodontitis: a systematic review and metaanalysis. Int Endod J $\underline{38}, 347-355$

Saunders WP (2005): Considerations in the revision of previous surgical procedures. Endod Topics 11, 206-218

Schwartz RS, Mauger M, Clement DJ, Walker WA (1999): Mineral Ttrioxide Aggregate: a new material for endodontics. JADA 130, 967-975

Schwartz-Arad D, Yarom N, Lustig JP, Kaffe I (2003): A retrospective radiographic study of root-end surgery with amalgam and intermediate restorative material. Oral Surg Oral Med Oral Pathol Oral Radiol Endod 96, 472-477

Sedgley C, Buck G, Appelbe O (2006): Prevalence of Enterococcus faecalis at multiple oral sites in endodontic patients using culture and PCR. J Endod $\underline{32}$, 104109 
Setzer FC, Shah SB, Kohli MR (2010): Outcome of endodontic surgery: A metaanalysis of the literature - Part 1: Comparison of traditional root-end surgery and endodontic microsurgery. J Endod 36, 1757-1765

Siqueira JF (2001): Aetiology of root canal failure: why well-treated teeth can fail. Int Endod J $\underline{34}, 1-10$

Siqueira JF jr, Lima KC, Magalhaes FA, Lopes HP, de Uzeda M (1999): Mechanical reduction of the bacterial population in the root canal by three instrumentation techniques. $\underline{25}, 332-335$

Siren EK, Haapasalo Mp, Ranta K, Salmi P, Kerosuo EN (1997): Microbiological findings and clinical treatment procedures in endodontic cases selected for microbiological investigation Int Endod J $\underline{30}$, 91-95

Sjögren U, Hagglund B, Sundqvist G, Wing K (1990): Factors affecting the longterm results of endodontic treatment. J Endod $\underline{16}, 498-504$

Skoglund A, Persson G (1985): A follow-up study of apicoectomized teeth with total loss of the buccal bone plate. Oral Surg Oral Med Oral Pathol $\underline{59}, 78-81$

Soares JA, Nunes E, Silveira FF, Santos SMC, Oliveira MTF (2009): Endodontic re-treatment associated with the elimination of amalgam root-end filling through sinus tracts: A report of two cases. Aust Endod J $\underline{35}$; 59-64

Soluti A, Lee SJ, Torabinejad M (1993): Sealing ability of a mineral trioxide aggregate in lateral root perforations. (Abstract 59) J Endod 19, 199

Song M, Shin SJ, Kim E (2011): Outcomes of endodontic microresurgery: a prospective clinical study. J Endod $\underline{37}, 316-320$

Stewart GG (1975): Calcium hydroxide-induced root healing. J Am Dent Assoc $\underline{90}$, $793-800$ 
Stöckl G (2008): Orthograde und chirurgische Revision nach Misserfolg einer alleinigen Wurzelspitzenresektion. Endodontie 17, 277-283

Stuart CH, Schwartz SA, Beeson TJ, Owatz CB (2006): Enterococcus faecalis: Its role in root canal treatment failure and current concepts in retreatment. $\mathrm{J}$ Endod 32, 93-98

Sunde PT, Olsen I, Debelian GJ, Tronstad L (2002): Microbiota of periapical lesions refractory to endodontic therapy. J Endod 28; 304-310

Sundqvist G, Figdor D, Persson S, Sjögren U (1998): Microbiologic analysis of teeth with failed endodontic treatment and the outcome of conservative retreatment. Oral Surg Oral Med Oral Pathol Oral Radiol Endod 85, 86-93

Svensäter G, Bergenholtz G (2004): Biofilms in endodontic infections. Endod Topics $\underline{9}, 27-36$

Tahan E, Celik D, Er K, Tasdemir T (2010): Effect of unintentionally extruded Mineral Trioxide Aggregate in treatment of tooth with periradicular lesion: A case report. J Endod $\underline{36}, 760-763$

Tassery H, Remusat M, Koubi G, Pertot WJ (1997): Comparison of the intraosseous biocompatibility of Vitremer and super EBA by implantation into the mandible of rabbits. Oral Surg Oral Med Oral Pathol Oral Radiol Endod 83, 602608

Theodosopoulou JN, Niederman R (2005): A systematic review of in vitro retrograde obturation materials. J Endod $\underline{31}, 341-349$

Torabinejad M, Kettering JD (1995): Cytotoxicity of four root end filling materials. J Endod 21, 489-492 
Torabinejad M, Chivian N (1999): Clinical applications of Mineral Trioxide Aggregate. J Endod 25, 197-205

Torabinejad M, Watson TF, Pitt Ford TR (1993): Sealing ability of a Mineral Trioxide Aggregate when used as a root end filling material. J Endod 19, 591-595 Torabinejad M, Smith PW, Kettering JD, Pitt Ford TR (1995): Comparative investigation of marginal adaptation of Mineral Trioxide Aggregate and other commonly used root-end filling materials. J Endod 21 , 295-299

Torabinejad M, Pitt Ford TR, McKendry DJ, Abedi HR, Miller DA, Kariyawasam SP (1997): Histologic assessment of Mineral Trioxide Aggregate as a root-end filling in monkeys. J Endod $\underline{23}$, 225-228

Torabinejad M, Corr R, Handyside R (2009): Outcome of nonsurgical retreatment and endodontic surgery: a systematic review. J Endod 35, 930-937

Trope M, Löst C, Schmitz HJ, Friedman S (1996): Healing of apical periodontitis in dogs after apicoectomy and retro-filling with various filling materials. Oral Surg Oral Med Oral Pathol Oral Radiol Endod 81, 221-228

Trope M, Delano EO, Ørstavik D (1999): Endodontic treatment of teeth with apical periodontitis: single vs. multivisit treatment. J Endod 25, 345-350

Tsesis I, Faivishevsky V, Kfir A, Rosen E (2009): Outcome of surgical endodontic treatment performed by a modern technique: A meta-analysis of literature. $\mathrm{J}$ Endod $\underline{35}, 1505-1511$

Tulus G (2007): Wie würden Sie entscheiden? Kasuistik. Endodontie 16, 331, 361364

Tulus G (2008): Wie würden Sie entscheiden? Endodontie 17, 267-268, 285-289 
Von Arx T (2005): Die Retroplast-Technik, Retrograde Obturation mit Komposit und Adhäsivtechnik in der endodontischen Chirurgie. Schweiz Monatsschr Zahnmed 115, 1191-1199

Von Arx T, Gerber C, Hardt N (2001): Periradicular surgery of molars: a prospective clinical study with a one-year follow up. Int Endod J $\underline{34}, 520-525$

Wang Q, Cheung GSP, Ng RPY (2004): Survival of surgical endodontic treatment performed in a dental teaching hospital: a cohort study Int Endod J $\underline{37}$, 764-775

Weiger R (1992): Konservative endodontische Revision nach erfolgloser Wurzelspitzenamputation - ein Fallbericht. Endodontie 3; 239-243

Weiger R, Rosendahl R, Löst C (2000): Influence of calcium hydroxide intracanal dressings on the prognosis of teeth with endodontically induced periapical lesions. Int Endod J $\underline{33}$, 219-226

Weiger R, Geurtsen W, Heidemann D, Löst C, Petschelt A, Raab W, Schäfer E, Hickel R (2001): Zur Prognose von Wurzelkanalbehandlungen Wissenschaftliche Stellungnahme der DGZMK. Dtsch Zahnärztl Z $\underline{56}$

Weldon JK, Pashley DH, Loushine RJ, Weller RN, Kimbrough WF (2002): Sealing ability of Mineral Trioxide Aggregate and Super-EBA when used as furcation repair materials: A longitudinal study. J Endod 28, 467-470

West NM, Lieb RJ (1985): Biologic root-end closure on a traumatized and surgically resected maxillary central incisor. Endod Dent Traumatol 1, 146-149

Wu MK, Wesselink PR (2005): Timeliness and effectiveness in the surgical management of persistent post-treatment periapical pathosis. Endod Topics 11, 25-31 
Yared GM, Dagher FE (1994): Influence of apical enlargement on bacterial infection during treatment of apical periodontitis. J Endod 20, 535-537

Zahnärztliche Zentralstelle Qualitätssicherung (2007): Leitlinie Wurzelspitzenresektion (2007) Endodontie 16, 304.

Zetterqvist I, Anneroth G, Nordenram A (1987): Glass-ionomer cement as retrograde filling material. An experimental investigation in monkeys. Int $\mathrm{J}$ Oral Maxillofac Surg 16, 459-464

Zetterqvist I, Hall G, Holmlund A (1991): Apicectomy: a comparative clinical study of amalgam and glass ionomer cement as apical sealants. Oral Surg Oral Med Oral Pathol $\underline{71}, 489-491$ 


\section{Anhang}

\section{Abbildungsverzeichnis}

Abbildung 1: Zahn 36 initiale Aufnahme; 15.06.2010; mesiale Wurzel reseziert, deutliche apikale Aufhellung an beiden Wurzelspitzen erkennbar....................... 37 Abbildung 2: Zahn 36 Aufnahme der Wurzelfüllung; 02.07.2010 …................... 38 Abbildung 3: Zahn 36 Kontrollaufnahme der Wurzelfüllung; 08.12.2011; vollständige Ausheilung der apikalen Aufhellung 38 Abbildung 4: Zahn 36 intrakanaläre Aufnahme nach Wurzelfüllung; die Pfeile kennzeichnen die mit Guttapercha abgefüllten Kanaleingänge .......................... 39 Abbildung 5: Erfolg in Abhängigkeit von der Zugehörigkeit zur Zahngruppe ........ 40 Abbildung 6: Anteile der behandelten Zähne in Ober- und Unterkiefer sowie Front, Prämolaren und Molaren ............................................................................ 40

Abbildung 7: Recalldauer der Hauptgruppe in Monaten .................................... 41 Abbildung 8: Erfolg in Abhängigkeit vom präoperativen Befund des Periapex (Parodontitis apicalis) 42

Abbildung 9: Erfolg in Abhängigkeit einer medikamentösen Einlage mit Kalziumhydroxid 43

Abbildung 10: Erfolg in Abhängigkeit vom retrograden Füllmaterial 45 Abbildung 11: Zahn 46 initiale Aufnahme; 28.06.2010; insuffiziente Wurzelfüllung und apikale Aufhellung erkennbar..... 46

Abbildung 12: Zahn 46 Aufnahme der Wurzelfüllung; 22.12.2010 46 Abbildung 13: Zahn 46 Kontrollaufnahme der Wurzelfüllung; 18.12.2012; analoge Aufnahme des überweisenden Zahnarztes digitalisiert; an mesialer Wurzelspitze deutliche apikale Aufhellung erkennbar. Abbildung 14: Zahn 46 intrakanaläre Aufnahme; altes Wurzelfüllmaterial (gelb) und infiziertes Gewebe erkennbar

Abbildung 15: Zahn 46 initiale Aufnahme; 03.06.2009; apikale Aufhellung an beiden Wurzelspitzen erkennbar 
Abbildung 16: Zahn 46 Aufnahme der Wurzelfüllung; 06.09.2009; apikaler Puff an beiden Wurzelspitzen erkennbar

Abbildung 17: Zahn 46 Kontrollaufnahme der Wurzelfüllung; 20.04.2012; vollständige Ausheilung der apikalen Aufhellung 49

Abbildung 18: Zahn 46 intrakanaläre Aufnahme; primäre Zugangskavität; Zahnnerv devital; Kanaleingänge noch nicht dargestellt 50

Abbildung 19: Erfolg in Abhängigkeit von der Zugehörigkeit zur Zahngruppe ...... 51

Abbildung 20: Recalldauer der Kontrollgruppe 1 in Monaten 52 Abbildung 21: Erfolg in Abhängigkeit von der Ausgangssituation des Periapex (Parodontitis apicalis) 53

Abbildung 22: Erfolg in Abhängigkeit von der medikamentösen Einlage 54 Abbildung 23: Zahn 44 initiale Aufnahme; 23.03.2009, keine apikale Aufhellung erkennbar 56

Abbildung 24: Zahn 44 Aufnahme der Wurzelfüllung; 27.04.2009 56 Abbildung 25: Zahn 44 Kontrollaufnahme der Wurzelfüllung; 15.05.2012; Recall nach 3 Jahren; deutliche apikale Aufhellung erkennbar 57 Abbildung 26: Zahn 48 initiale Aufnahme; 08.11.2007; insuffiziente Wurzelfüllung erkennbar 58

Abbildung 27: Zahn 48 Aufnahme des frakturierten Instruments; 08.11.2007 ..... 58 Abbildung 28: Zahn 48 Aufnahme der Wurzelfüllung; 20.11.2007; deutliche Krümmung der Wurzelkanäle erkennbar.

Abbildung 29: Zahn 48 Kontrollaufnahme der Wurzelfüllung; 22.10.2009; Recall nach 23 Monaten.

Abbildung 30: Zahn 48 intrakanaläre Aufnahme; Datum; ausgeprägter paragingivaler Defekt (schwarzer Pfeil) und Silberstift erkennbar (roter Pfeil) ..... 60 Abbildung 31: Erfolg in Abhängigkeit von der Zugehörigkeit zur Zahngruppe ...... 61 Abbildung 32: Recalldauer der Kontrollgruppe 2 in Monaten 62 Abbildung 33: Erfolg in Abhängigkeit von der Ausgangsituation des Periapex (Parodontitis apicalis) 63 Abbildung 34: Erfolg in Abhängigkeit von der medikamentösen Einlage. 64 Abbildung 35: Zahn 36 initiale Aufnahme; 08.04.2009; insuffiziente Wurzelfüllung und apikale Aufhellung an der mesialen Wurzelspitze erkennbar 65 
Abbildung 36: Zahn 36 Aufnahme der Wurzelfüllung/Downpack; 13.05.2009; apikaler Puff an der mesialen Wurzelspitze. 66 Abbildung 37: Zahn 36 Kontrollaufnahme der Wurzelfüllung; 04.11.2010; Recall nach 18 Monaten; leichte apikale Aufhellung an der mesialen Wurzel noch immer erkennbar 66

\section{Tabellenverzeichnis}

Tabelle 1: Erfolg in Abhängigkeit von einer medikamentösen Einlage und vom präoperativen Befund des Periapex (Parodontitis apicalis) 44 Tabelle 2: Erfolg in Abhängigkeit von einer medikamentösen Einlage und vom präoperativen Befund des Periapex (Parodontitis apicalis) 55 Tabelle 3: Erfolg in Abhängigkeit von einer medikamentösen Einlage und dem präoperativen Befund des Periapex (Parodontitis apicalis) 65 Tabelle 4: Statistischer Vergleich der Misserfolgsrate von Haupt- und Kontrollgruppen (z-Test) 67 


\section{Datengrundlagen}




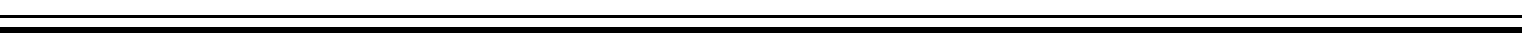




\section{Abkürzungsverzeichnis}

bzw. beziehungsweise

$\mathrm{CHX} \quad$ Chlorhexidingluconat

DGZMK Deutsche Gesellschaft für Zahn-, Mund- und Kieferheilkunde

EDTA Ethylendiamintetraacetat

ESE European Society of Endodontology

IDZ Institut der Deutschen Zahnärzte

ISO International Organization for Standardization - Internationale

Organisation für Normierung

MTA Mineral Trioxid Aggregat

$\mathrm{NiTi} \quad$ Nickel- Titan- Instrument

OP-Mikroskop Operationsmikroskop mit bis zu 33-facher Vergrößerung

PUI

passive ultrasonic irrigation - passive ultraschallaktivierte Spülung

WSR Wurzelspitzenresektion

z.B. zum Beispiel

ZZQ Zahnärztliche Zentralstelle Qualitätssicherung

ISO 30: $\quad$ Das verwendete Instrument hat an der Arbeitsspitze einen Durchmesser von $0,3 \mathrm{~mm}$ 


\section{Danksagung}

Mein besonderer Dank gilt Prof. Dr. Michael Hülsmann für das Überlassen des Dissertationsthemas und die zu jeder Zeit hervorragende Betreuung. Desweiteren möchte ich mich bei Dr. Gabriel Tulus für die Unterstützung und die Bereitstellung der Behandlungsunterlagen, welche die Grundlage dieser Arbeit bilden, bedanken. 


\section{Lebenslauf}

Als Jüngste von drei Kindern der Zahnärztin Elke Ziegerahn, geborene Jantz, und des Zahnarztes Frank-Michael Ziegerahn wurde ich am 20. September 1986 in Berlin geboren.

Vom August 1993 bis Juli 1998 besuchte ich die Grundschule Groß-Behnitz. Es folgte ein weiteres Jahr auf der Grundschule Roskow. Ab August 1999 besuchte ich das Goethe-Gymnasium Nauen und erlangte im Juli 2006 mit Abschluss des Abiturs die Allgemeine Hochschulreife. Die elfte Klasse absolvierte ich von September 2003 bis Juli 2004 an der Hazelwood Central High in St. Louis, Missouri (USA).

Im Wintersemester 2006/2007 begann ich das Studium der Zahnheilkunde an der Georg-August-Universität Göttingen und legte im Sommersemester 2009 die Zahnärztliche Vorprüfung ab. Nachdem ich am 28.Juni 2012 die Zahnärztliche Prüfung bestanden hatte, erhielt ich am 12.Juli 2012 die Approbation als Zahnärztin.

Seit Oktober 2012 arbeite ich in einer allgemeinzahnärztlichen Praxis als Assistenzzahnärztin. 